\title{
Guía para el manejo de colitis ulcerativa en población adulta (actualización)
}

\section{Guidelines for the management of ulcerative colitis in the adult population (update)}

\author{
Fabián Juliao-Baños, ${ }^{1}$ Marcela Torres-Amaya, ${ }^{2}$ William Otero-Regino, ${ }^{3}$ María Teresa Vallejo, ${ }^{4}$ María Teresa Galiano, ${ }^{5}$ Jhon Feliciano, ${ }^{6}$ Juan
}

Ricardo Márquez, ${ }^{7}$ Alejandro Concha-Mejía, ${ }^{8}$ Fabio Gil-Parada. ${ }^{9}$

\author{
Gacceso abierto \\ Citación: \\ Juliao-Baños F, Torres-Amaya M, Otero-Regino \\ W, Vallejo MT, Galiano MT, Feliciano J, Márquez \\ JR, Concha-Mejía A, Fabio Gil-Parada F. \\ Guía para el manejo de colitis ulcerativa en \\ población adulta (actualización). Rev Colomb \\ Gastroenterol. 2020;35(Supl 2):2-62. https://doi. \\ org/10.22516/25007440.636 \\ 1 Médico internista, especialista en \\ Gastroenterología y Endoscopia Digestiva. \\ Coordinador, Clínica de Enfermedad \\ Inflamatoria Intestinal, Hospital Pablo Tobón \\ Uribe. Profesor, Universidad de Antioquia, \\ Medellín. Investigador principal, líder de la Guía. \\ Medellín, Colombia. \\ Química farmaceuta, magister en Epidemiología \\ Clínica, doctorado en Salud Pública, Instituto de \\ Investigaciones Clínicas, Universidad Nacional \\ de Colombia. Bogotá, Colombia. \\ 3 Médico especialista en Gastroenterología y \\ Endoscopista Gastrointestinal. Profesor titular, \\ Facultad de Medicina, Universidad Nacional de \\ Colombia. Bogotá, Colombia. \\ ${ }^{4}$ Médica cirujana, magíster en Epidemiología \\ Clínica. Instituto de Investigaciones Clínicas, \\ Universidad Nacional de Colombia. Bogotá, \\ Colombia. \\ 5 Médica cirujana, especialista en \\ Gastroenterología y Endoscopista \\ Gastrointestinal. Unidad de Gastroenterología \\ SERVIMED S.A.S y Clínica de Marly. Bogotá, \\ Colombia. \\ ${ }^{6}$ Médico. Especialidad de Farmacología Clínica. \\ Maestría en Epidemiología. Instituto de \\ Investigaciones Clínicas, Universidad Nacional \\ de Colombia. Bogotá, Colombia. \\ Médico cirujano. Coloproctólogo. Director \\ científico, Instituto de Coloproctología ICO, \\ Clínica de las Américas. Medellín, Colombia. \\ ${ }^{8}$ Médico internista, gastroenterólogo y \\ epidemiólogo. Clínica Colsanitas y Fundación \\ Clínica Shaio. Profesor de Gastroenterología, \\ Universidad de la Sabana Bogotá, Colombia. \\ 9 Médico internista, especialista en \\ Gastroenterología y Endoscopia Digestiva. \\ Magíster en Epidemiología. Gastroenterólogo, \\ Clínica Universitaria Colombia. Profesor de \\ postgrado en Gastroenterología, Fundación \\ Universitaria Sanitas. Bogotá, Colombia. \\ Fecha recibido: $11 / 08 / 20$ \\ Fecha aceptado: 16/10/20 \\ (c) (i) $\Theta$
}

\section{Resumen}

Objetivo: desde 2015, la Asociación Colombiana de Gastroenterología, con el apoyo del Instituto de Investigaciones Clínicas de la Universidad Nacional de Colombia, realizó la guía de práctica clínica para el diagnóstico y tratamiento de colitis ulcerativa. Desde la publicación de esta guía, han aparecido nuevas alternativas terapéuticas y nuevos conceptos sobre los objetivos del tratamiento, por lo cual se consideró necesaria su actualización. Materiales y métodos: esta actualización fue realizada por un equipo multidisciplinario con apoyo de la Asociación Colombiana de Gastroenterología y el Instituto de Investigaciones Clínicas de la Universidad Nacional de Colombia. Se desarrollaron preguntas relevantes a nuevos tratamientos y vigilancia endoscópica de los pacientes adultos con colitis ulcerativa y se realizó la búsqueda de guías nacionales e internacionales en bases de datos especializadas. Las guías fueron evaluadas en términos de calidad y aplicabilidad. El Grupo Cochrane llevó a cabo la búsqueda sistemática de la literatura. Las tablas de evidencia y recomendaciones fueron realizadas usando la metodología GRADE. Resultados: se realizó una actualización de la guía para el tratamiento de la colitis ulcerativa en adultos en Colombia y se diseñaron nuevos algoritmos de tratamiento, teniendo en cuenta la extensión y la actividad de la enfermedad y los diferentes niveles de atención. Conclusiones: se estableció la importancia para el tratamiento de la evaluación clínica y endoscópica y se especificaron las indicaciones para el adecuado tratamiento de los pacientes con colitis ulcerativa. Adicionalmente, se dieron recomendaciones de vigilancia endoscópica de cáncer colorrectal y la importancia de la cromoendoscopia.

\section{Palabras clave}

Colitis ulcerativa, actividad, cicatrización mucosa, terapia biológica, vigilancia endoscópica, cromoendoscopia.

\section{Abstract}

Objective: In 2015, the Asociación Colombiana de Gastroenterología (Colombian Association of Gastroenterology), with the support of the Institute of Clinical Research of the Universidad Nacional de Colombia, created the Clinical Practice Guideline for the diagnosis and treatment of ulcerative colitis. Since then, new therapeutic alternatives and concepts about treatment goals have emerged, making it necessary to update its contents. Materials and methods: The present update was carried out by a multidisciplinary team with support from the Asociación Colombiana de Gastroenterología and the Clinical Research Institute of the Universidad Nacional de Colombia. Questions regarding new treatments and endoscopic surveillance of adult patients with ulcerative colitis were developed, and national and international guidelines were searched in specialized databases. The guidelines were evaluated in terms of quality and applicability. The Cochrane Group conducted a systematic search of the existing literature, and evidence tables and recommendations were made using the GRADE methodology. Results: The guideline for the treatment of ulcerative colitis in adults in Colombia was updated, and new treatment algorithms were designed, taking into account the extent and activity of the disease and the different levels of care. Conclusions: The relevance of clinical and endoscopic assessment for treatment was established, and the indications for the proper management of patients with ulcerative colitis were specified. Furthermore, recommendations were made for endoscopic surveillance of colorectal cancer, and the importance of chromoendoscopy was established.

\section{Keywords}

Ulcerative colitis, activity, mucosal healing, biological therapy, endoscopic surveillance, chromoendoscopy. 


\section{JUSTIFICACIÓN}

La colitis ulcerativa (CU) es una enfermedad crónica multifactorial de etiología desconocida, incurable, caracterizada por la presencia de inflamación difusa en la mucosa colónica en ausencia de granulomas. La CU afecta al recto y se extiende en sentido proximal con forma variable, simétrica y circunferencial a lo largo del colón. El 75\% de los pacientes con colitis distal puede tener inflamación localizada periapendicular, conocida como parche cecal, y el $20 \%$ de los que padecen colitis extensa hasta el ciego puede tener inflamación del íleon distal o "backwash" ileítis. Su curso clínico es intermitente, caracterizado por períodos de remisión y recaídas, y sus síntomas característicos son diarrea sanguinolenta asociada frecuentemente a urgencia $y$ tenesmo rectal (1); cuando la enfermedad es extensa, se presentan síntomas sistémicos $(1,2)$.

Desde su descripción inicial a finales del siglo XIX, su prevalencia e incidencia han cambiado de la misma forma que otras enfermedades inmunológicas (3). Históricamente, los estudios con mayor incidencia y prevalencia para CU provienen de los países escandinavos, Reino Unido y Norteamérica (4). Su incidencia oscila entre 1,2 y 20,3 casos por cada 100.000 personas/año y la prevalencia varía de 156 a 291 casos por cada 100.000 habitantes. Una revisión sistemática de 147 estudios encontró que los países con mayor prevalencia de CU se encuentran en Europa (hasta 505 por 100.000 en Noruega) y en Norteamérica (286 por 100.000 ) (5). Recientes datos de Colombia muestran una prevalencia de CU de 67,07 por cada 100.000 y una incidencia anual de 15,22 por cada 100.000 personas para el año de 2017 (6).

En relación con la edad, la CU exhibe un patrón bimodal con un primer pico de aparición entre los 15 y los 30 años, $y$ un segundo pico entre los 50 y los 70 años. El antecedente familiar de enfermedad inflamatoria intestinal es el factor de riesgo independiente más importante. El 5,7\%-15,5\% de los pacientes con CU tienen un familiar de primer grado afectado con esta enfermedad (7). Consistentemente se ha encontrado que el tabaquismo tiene una asociación negativa a la enfermedad ("protector"), con una razón de momios (OR) de 0,58 (intervalo de confianza [IC] del 95\%: 0,45-0,75), como se demostró en un metaanálisis (8). Los pacientes que fuman tienen un curso más leve de la enfermedad, comparado con no fumadores. La apendicectomía también es protectora para el desarrollo de CU. Un metaanálisis encontró una reducción del riesgo del 69\% (OR: 0,31; IC 95\%: 0,25-0,38) (9). Se ha encontrado que el Helicobacter pylori (H. pylori) también se asocia negativamente a esta entidad, con un OR de 0,59 (IC 95\%: 0,39$0,84)$ y, por el contrario, la ausencia de $H$. pylori tiene un riesgo de 11,06 (IC 95\%: 7,98-15,02) para la enfermedad. Se desconoce la causa de esta relación negativa, pero el mayor número de linfocitos $\mathrm{T}$ reguladores en los pacientes con H. pylori podría ser importante (10).

En todos los estudios se ha encontrado que la CU impacta negativamente la calidad de vida de los pacientes que la padecen, afectando seriamente el desempeño laboral y las condiciones de salud. Gran parte de los pacientes que la presentan son diagnosticados tardíamente y hasta en la mitad de los casos el diagnóstico se realiza después de 1 año del inicio de los síntomas (11). En un estudio observacional realizado en la ciudad de Medellín (Colombia), se documentó que, en promedio, el diagnóstico de $\mathrm{CU}$ se estableció a los 9,2 meses desde el inicio de los síntomas (12).

El diagnóstico de CU se hace con base en la historia clínica, los hallazgos al examen físico, las alteraciones endoscópicas o radiológicas, los exámenes de laboratorio y las alteraciones histopatológicas características. La biopsia es confirmatoria cuando las demás manifestaciones están presentes $y$, dependiendo del caso, se ha descartado la presencia de causas infecciosas (bacterias, virus, parásitos y hongos) y no infecciosas de diarrea (colitis microscópica, malabsorción de ácidos biliares, sobrecrecimiento bacteriano, neoplásicas o inducidas por drogas, entre otras). La biopsia aislada, en ausencia de otras manifestaciones, no permite diagnosticar la enfermedad $(1,13)$.

En el año 2005 y definida por consenso de expertos, se creó la clasificación de Montreal, que permite clasificar la CU según su extensión y gravedad (14). Recientemente, el Colegio Americano de Gastroenterología propuso una nueva clasificación de actividad de CU, modificando la clasificación tradicional de Truelove y Witts (15), adicionando biomarcadores como la proteína C-reactiva, la calprotectina y la gravedad endoscópica (16).

Se ha encontrado que el $40 \%$ de los pacientes con diagnóstico de novo en CU presentan solo proctitis, el 30\%-40\% tiene compromiso limitado al colon izquierdo y el $20 \%$ $30 \%$ presenta pancolitis, los cuales tienen peor pronóstico. Cerca del $80 \%$ de los pacientes tienen actividad de leve a moderada al inicio de la enfermedad (17). Una reciente revisión sistemática de 30 estudios elegibles demostró extensión colónica de CU en el 17,8\% a 5 años y en el $31 \%$ a 10 años de seguimiento (18). Una reciente revisión sistemática y metaanálisis encontró que el riesgo de cirugía en CU es del 4,9\%, 11,6\% y 15,6\%, a 1, 5 y 10 años, respectivamente. Los autores concluyeron que hubo una disminución en el riesgo de cirugía en CU en los últimos años (19).

El tratamiento se hace con intervenciones farmacológicas y, en casos específicos, con cirugía. Sin embargo, y pese a la existencia de múltiples estudios aleatorizados, algunas de las situaciones clínicas relacionadas con la entidad continúan siendo respondidas mediante el juicio clínico y la opinión de expertos, lo que se ha visto reflejado en las diferencias conceptuales para el tratamiento de estos pacientes $(1,2,15,20,21)$. 
En el año 2015, la Asociación Colombiana de Gastroenterología, con el apoyo del Instituto de Investigaciones Clínicas de la Universidad Nacional de Colombia, desarrolló la Guía de práctica clínica basada en la evidencia para el diagnóstico y tratamiento de colitis ulcerativa de pacientes adultos. Desde la publicación de esa guía, han aparecido nuevas alternativas terapéuticas y nuevos conceptos sobre los objetivos del tratamiento, por lo cual se consideró necesaria su actualización, presentando nuevas recomendaciones para el enfoque terapéutico y la vigilancia colonoscópica de los pacientes adultos con $\mathrm{CU}$, en el contexto colombiano.

\section{OBJETIVOS}

Esta guía de práctica clínica basada en la evidencia se desarrolló con los siguientes objetivos:

- Disminuir la variabilidad injustificada en el tratamiento, contribuyendo al uso racional y pertinente de los recursos destinados al cuidado de los pacientes con CU.

- Orientar el manejo de los pacientes con CU en las diferentes etapas de la enfermedad y los diferentes niveles de atención.

- Establecer las recomendaciones para la vigilancia con colonoscopia del cáncer colorrectal en pacientes adultos con CU.

\section{POBLACIÓN}

Grupo de pacientes considerados en la guía:

- Pacientes mayores de 16 años con diagnóstico de CU independiente del tiempo de evolución y del estado clínico de la enfermedad.

Pacientes que no serán considerados en esta guía:

- Pacientes con enfermedad de Crohn.

- Pacientes con enfermedad inflamatoria intestinal, no clasificable.

- Pacientes con complicaciones extraintestinales de CU.

- Pacientes con efectos secundarios y/o adversos del tratamiento para CU.

- Pacientes con CU en gestación o lactancia.

- Pacientes con colitis infecciosa.

- Paciente sin diagnóstico definitivo o dudoso de CU.

- Pacientes pediátricos menores de 16 años. Estos pacientes deben ser incluidos en un programa de transición de pediatría a adultos, un año antes de cumplir los 16 años.

\section{ÁMBITO ASISTENCIAL}

La presente guía pretende apoyar al personal clínico asistencial que brinda cuidado a los pacientes mayores de 16 años con diagnóstico de $\mathrm{CU}$ en los diferentes niveles de atención en salud. El manejo de condiciones muy específicas por parte de los profesionales de la salud involucrados en la atención de los pacientes con CU amerita recomendaciones también específicas, que exceden el alcance de la presente guía.

\section{USUARIOS DE LA GUÍA}

Los usuarios de la guía son gastroenterólogos, coloproctólogos, patólogos, cirujanos gastrointestinales, médicos internistas, médicos familiares, médicos generales, pacientes y otros profesionales de la salud interesados en el manejo de la CU. También puede ser usada por tomadores de decisiones tanto en el medio asistencial como en las aseguradoras, los pagadores del gasto en salud y por quienes generan políticas en salud.

\section{FINANCIACIÓN DE LA GUÍA DE PRÁCTICA CLÍNICA}

El desarrollo de la presente guía fue financiado por la Asociación Colombiana de Gastroenterología.

\section{ASPECTOS CLÍNICOS CENTRALES}

La guía hará referencia al tratamiento médico y a la vigilancia endoscópica de la CU. No se abordarán los aspectos relacionados con el pronóstico o la rehabilitación de los pacientes con CU.

\section{METODOLOGÍA}

La presente guía siguió los métodos de desarrollo rápido de guías GRADE propuestos por la Organización Panamericana de la Salud: Directriz para el fortalecimiento de los programas nacionales de guías informadas por la evidencia. Una herramienta para la adaptación e implementación de guías en las Américas (22).

\section{COMPOSICIÓN DEL GRUPO DESARROLLADOR DE LA GUÍA}

El grupo desarrollador de la guía (GDG) contó con la participación de expertos gastroenterólogos, coloproctólogos, cirujanos gastrointestinales, médicos internistas, médicos generales y pacientes.

\section{DECLARACIÓN DE CONFLICTOS DE INTERÉS}

Todos los miembros del GDG, del panel de expertos, así como las personas que participaron en la revisión externa, firmaron un formato de conflicto de interés. Se realizó un análisis de los conflictos y se tomó una decisión de partici- 
pación completa, parcial o exclusión en el desarrollo de la guía. El análisis se encuentra en el Anexo 1.

\section{DECLARACIÓN DE INDEPENDENCIA EDITORIAL}

Se declara que la Fundación Hospital Pediátrico La Misericordia (HOMI) no influenció el contenido de la guía.

\section{DECISIÓN SOBRE LA ACTUALIZACIÓN}

La Asociación Colombiana de Gastroenterología, Cochrane STI y la Universidad Nacional de Colombia desarrollaron en el año 2015 la Guía basada en la evidencia para el manejo de colitis ulcerativa en pacientes adultos. El GDG decidió mediante consenso que las recomendaciones de diagnóstico y abordaje quirúrgico de la guía de colitis de 2015 se encuentran vigentes y no necesitan ser actualizadas. Por lo tanto, se actualizaron 3 preguntas:

- ¿Cuál es la eficacia y seguridad de las intervenciones terapéuticas para inducir y mantener la remisión en pacientes adultos con $\mathrm{CU}$ ?

- ¿Cuál es la efectividad y la seguridad de la terapia biológica para el tratamiento de los pacientes con CU moderada a grave?

- ¿Cuál es la eficacia de la tamización y la vigilancia endoscópica de cáncer colorrectal en pacientes adultos con CU?

\section{ACTUALIZACIÓN DE PREGUNTAS CLÍNICAS DE LA GUÍA DE PRÁCTICA CLÍNICA}

El GDG formuló las preguntas que debían actualizarse en formato PICO (población, intervención, comparación y desenlaces). Las preguntas PICO se encuentran en el Anexo 2. El GDG realizó un ejercicio de priorización de desenlaces con el ánimo de identificar aquellos que resultan claves y que deben ser incluidos. Se identificaron y priorizaron aquellos desenlaces clínicos de seguridad, efectividad, calidad de vida y todo aquel importante para los pacientes. Cada desenlace fue clasificado como crítico, importante no crítico y no importante para los pacientes, con base en una escala de 9 unidades propuesta por el grupo GRADE (23). Posteriormente, se procedió a buscar la evidencia de bases de datos y a diligenciar esta plantilla.

\section{BÚSQUEDA DE LA LITERATURA}

El primer paso desarrollado fue la búsqueda de revisiones sistemáticas de las siguientes bases de datos: Pubmed, Econlit, EMBASE, LILACS, Google Scholar, Cochrane Database of Systematic Reviews (CDRS), Center for Reviews and Dissemination (CRD), que incluye las bases de datos de Health Technology Assessment (HTA) database, Database of Abstracts of Reviews of Effects (DARE) y NHS Economic Evaluation Database (NHS EED).

El especialista de la información del Grupo Cochrane STI, con apoyo del GDG, desarrolló y corrió las estrategias de búsqueda. Las estrategias fueron elaboradas para cada pregunta por medio de la utilización de formatos de identificación de palabras relacionadas con las preguntas clínicas, que funcionaron como sustrato para la selección de los términos Mesh y las palabras clave. Se restringió la búsqueda a estudios en inglés y español. Las estrategias de búsqueda se encuentran disponibles en el Anexo 3 del presente documento, junto con el diagrama PRISMA de selección de la evidencia. La búsqueda se desarrolló hasta julio de 2020.

\section{CALIFICACIÓN DE LA EVIDENCIA}

Las revisiones sistemáticas (RS) identificadas para los diferentes aspectos clínicos fueron evaluadas utilizando la lista de chequeo AMSTAR 2 (24). Cada revisión sistemática fue evaluada con respecto a su contenido, calidad y relevancia clínica para identificar aquellas de mayor calidad metodológica que deberían ser incluidas al interior de la guía. En caso de no identificar revisiones sistemáticas de alta calidad, se procedió a la evaluación de estudios primarios utilizando la herramienta de riesgo de sesgos sugerida por Cochrane (25). Si no se encontraba evidencia, se procedió a la identificación de guías de consenso. La síntesis de los estudios seleccionados se realizó a través de la construcción de los perfiles de evidencia, con ayuda del portal https: / /gradepro.org y los niveles de evidencia fueron graduados según la clasificación GRADE. Los perfiles de evidencia GRADE se encuentran en el Anexo 4.

Para alcanzar la transparencia y simplicidad, el sistema GRADE califica la calidad de evidencia en uno de cuatro niveles: alta, moderada, baja y muy baja. Véase la sección Cómo usar esta guía para más información.

\section{FORMULACIÓN DE LAS RECOMENDACIONES}

Las recomendaciones fueron formuladas en dos pasos. Primero, el GDG elaboró las recomendaciones preliminares considerando el balance riesgo-beneficio, las preferencias de los pacientes y el contexto de implementación. Segundo, las recomendaciones se discutieron y ajustaron en un panel de expertos con representantes de sociedades científicas, entes gubernamentales y pacientes, quienes contribuyeron a definir la fuerza de las recomendaciones.

La metodología GRADE ofrece dos grados de fuerza de recomendación: fuerte y condicional. Una vez se contempló el balance riesgo-beneficio, la calidad de la evidencia, los valores y preferencias y el contexto, se determinó la fuerza de cada recomendación utilizando la siguiente estructura: 


\begin{tabular}{ll}
\hline $\begin{array}{l}\text { Fuerza de la } \\
\text { recomendación }\end{array}$ & \multicolumn{1}{c}{ Significado } \\
\hline Fuerte a favor & $\begin{array}{l}\text { Las consecuencias deseables claramente } \\
\text { sobrepasan las consecuencias indeseables. } \\
\text { Se recomienda hacerlo }\end{array}$ \\
\hline $\begin{array}{ll}\text { Condicional a } \\
\text { favor }\end{array}$ & $\begin{array}{l}\text { Las consecuencias deseables probablemente } \\
\text { sobrepasan las consecuencias indeseables. } \\
\text { Se sugiere hacerlo }\end{array}$ \\
\hline $\begin{array}{l}\text { Condicional en } \\
\text { contra }\end{array}$ & $\begin{array}{l}\text { Las consecuencias indeseables probablemente } \\
\text { sobrepasan las consecuencias deseables. }\end{array}$ \\
\hline $\begin{array}{l}\text { Fuerte en } \\
\text { contra }\end{array}$ & $\begin{array}{l}\text { Las consecuencias indeseables claramente } \\
\text { sobrepasan las consecuencias deseables. }\end{array}$ \\
\hline
\end{tabular}

Finalmente, se verificó que el panel de expertos estuviera de acuerdo con las recomendaciones sugeridas y que estas incorporaran la perspectiva de los participantes. El grado de recomendación y cada recomendación fueron votadas a través de una votación electrónica. Si en la primera ronda no se logró obtener la mayoría de los votos (mayor del $70 \%)$, se procedió a otra ronda. En la reunión del panel de expertos, se obtuvo mayoría en todas las votaciones en la primera ronda.

\section{CONTEXTUALIZACIÓN DE LA EVIDENCIA}

A partir de la síntesis de evidencia, de las reuniones del GDG y del panel de expertos, se identificaron aspectos relevantes del contexto de implementación de las recomendaciones, los cuales ayudaron al proceso de generación de las recomendaciones considerando su aplicabilidad. Adicionalmente, se crearon las matrices de juicio de valor para cada grupo de recomendaciones, que contienen las apreciaciones sobre el impacto del problema, los efectos deseables, los efectos no deseados, la confianza en la evidencia, la consistencia de la evidencia, el balance de los efectos, los recursos requeridos, la calidad global de la evidencia y la equidad, aceptabilidad y factibilidad de la implementación.

\section{INCORPORACIÓN DE LAS PREFERENCIAS DE LOS PACIENTES}

La presente guía incluyó valores y preferencias de los pacientes provenientes de la literatura y de los aportes de un representante de pacientes al panel de expertos.

\section{INCORPORACIÓN DE COSTOS Y ACCESO}

En la presente guía se consideraron aspectos globales de costos y acceso en áreas remotas a los servicios de salud, con el fin de formular recomendaciones implementables en el contexto colombiano.

\section{ACTUALIZACIÓN DE LA GUÍA}

Esta guía se actualizará en 3 años siguiendo la metodología utilizada en esta actualización.

\section{PREGUNTAS CLÍNICAS}

\section{¿CUÁL ES LA ESCALA MÁS ÚTIL PARA ESTABLECER LA ACTIVIDAD DE COLITIS ULCERATIVA EN PACIENTES DIAGNOSTICADOS?}

Se identificó una guía de práctica clínica para el manejo de CU (AGREE II 12/23), desarrollada por el Colegio Americano de Gastroenterología en el año 2019, la cual recomienda una escala de actividad con nuevas definiciones de CU activa, moderada/grave, en remisión y fulminante. Adicionalmente, incorpora desenlaces reportados por los pacientes y resultados endoscópicos y de laboratorio. Esto se determinó mediante el índice de actividad de CU (16).

\begin{tabular}{|c|c|}
\hline $\begin{array}{l}\text { Factores que } \\
\text { pueden fortalecer } \\
\text { una recomendación }\end{array}$ & Comentario \\
\hline $\begin{array}{l}\text { Calidad de la } \\
\text { evidencia }\end{array}$ & $\begin{array}{l}\text { La calidad de la evidencia es muy baja con } \\
\text { limitaciones por alto riesgo de sesgos y que } \\
\text { proviene de consenso de expertos. }\end{array}$ \\
\hline $\begin{array}{l}\text { Balance entre los } \\
\text { efectos deseables } \\
\text { e indeseables }\end{array}$ & $\begin{array}{l}\text { El panel de expertos considera que la escala } \\
\text { es útil, dado que incluye pruebas de laboratorio } \\
\text { que se realizan de rutina para el diagnóstico } \\
\text { de CU y permite establecer la gravedad de una } \\
\text { manera más eficaz, lo cual permite proveer el } \\
\text { tratamiento adecuado. }\end{array}$ \\
\hline $\begin{array}{l}\text { Valores y } \\
\text { preferencias }\end{array}$ & $\begin{array}{l}\text { La evidencia proveniente de revisiones } \\
\text { sistemáticas reporta que los pacientes } \\
\text { consideran que deben tener una interacción } \\
\text { constante con el médico tratante y recibir } \\
\text { explicación de cómo se realiza el diagnóstico } \\
\text { (26). }\end{array}$ \\
\hline $\begin{array}{l}\text { Costos (asignación } \\
\text { de recursos) }\end{array}$ & $\begin{array}{l}\text { Las pruebas incluidas en la escala se } \\
\text { encuentran cubiertas por el sistema de salud y } \\
\text { el plan de beneficios. }\end{array}$ \\
\hline $\begin{array}{l}\text { Aceptabilidad y } \\
\text { viabilidad }\end{array}$ & $\begin{array}{l}\text { La medición de la cicatrización de la mucosa } \\
\text { como mejoría clínica de la CU, al ser medida } \\
\text { con la nueva escala, requiere endoscopias } \\
\text { adicionales al manejo usual, lo que puede } \\
\text { dificultarse para algunos pacientes. }\end{array}$ \\
\hline
\end{tabular}




\begin{tabular}{|c|c|c|}
\hline Dirección & n. ${ }^{\circ}$ & Resumen \\
\hline $\begin{array}{l}\text { Fuerte a } \\
\text { favor }\end{array}$ & 1 & $\begin{array}{l}\text { Se recomienda que la actividad de colitis ulcerativa } \\
\text { se determine mediante la utilización del índice de } \\
\text { actividad de colitis ulcerativa desarrollado por el } \\
\text { Colegio Americano de Gastroenterología. } \\
\text { Calidad de evidencia muy baja Ciii (opinión de } \\
\text { expertos) }\end{array}$ \\
\hline
\end{tabular}

\section{¿CUÁL ES EL TRATAMIENTO MÁS EFECTIVO Y SEGURO PARA INDUCIR Y MANTENER LA REMISIÓN DE LOS PACIENTES MAYORES DE 16 AÑOS CON COLITIS ULCERATIVA, DE ACUERDO CON SU EXTENSIÓN Y GRAVEDAD?}

\section{Aspectos generales del tratamiento}

Una revisión sistemática de la literatura (AMSTAR 2: críticamente baja calidad) evaluó los desenlaces clínicos a largo plazo asociados a la curación de la mucosa en pacientes con CU activa. Los autores incluyeron los estudios de pacientes con CU activa sin colectomía previa sin remisión clínica o endoscópica al inicio del tratamiento. Para la calificación del estado de curación de la mucosa, se incluyeron estudios que hubieran realizado al menos una evaluación endoscópica luego del inicio del tratamiento, entre 1 y 6 meses. Como desenlaces clínicos a largo plazo, los autores consideraron la remisión clínica a largo plazo, definida como la presencia de remisión clínica mayor o igual a 52 semanas y al menos 6 meses de remisión a partir de la primera evaluación endoscópica realizada en el seguimiento. La revisión estableció como desenlaces secundarios la tasa libre de colectomía, la frecuencia de curación de la mucosa y el tiempo libre de corticosteroides por al menos 52 semanas y al menos 6 meses posterior al primer seguimiento endoscópico. El rango de seguimiento estuvo entre 12 y 56,4 meses.

La revisión recuperó 11 estudios de cohorte prospectiva y dos ensayos clínicos con análisis post hoc para un total de 2073 pacientes con CU moderada a grave, quienes recibieron tratamientos no biológicos (prednisolona, inmunosupresores, antibióticos y leucocitoféresis) y tratamiento biológico (infliximab: seis estudios; adalimumab: un estudio). Se encontró que la obtención de la curación mucosa se asoció a una mayor remisión clínica a largo plazo (OR: 4,5; IC 95\%: 2,12-9,52; 11 estudios, 1381 pacientes) una mejor tasa libre de colectomía (OR: 4,15; IC 95\%: 2,53-6,81; ocho estudios, 1480 pacientes), una mejor persistencia de curación de la mucosa (OR: 8,4; IC 95\%: 3,13-22,53; seis estudios, 823 pacientes), sin presentar diferencias en la frecuencia en el tiempo libre de corticosteroides (OR: 9,7; IC 95\%: 0,94-99,67; tres estudios, 576 pacientes) (27).

\begin{tabular}{|c|c|}
\hline $\begin{array}{l}\text { Factores que } \\
\text { pueden fortalecer } \\
\text { una recomendación }\end{array}$ & Comentario \\
\hline $\begin{array}{l}\text { Calidad de la } \\
\text { evidencia }\end{array}$ & $\begin{array}{l}\text { La calidad de la evidencia es muy baja, con } \\
\text { limitaciones por inconsistencia y alta sospecha } \\
\text { de sesgo de publicación. }\end{array}$ \\
\hline $\begin{array}{l}\text { Balance entre los } \\
\text { efectos deseables e } \\
\text { indeseables }\end{array}$ & $\begin{array}{l}\text { El panel de expertos considera que la } \\
\text { remisión clínica y la cicatrización mucosa } \\
\text { son los objetivos terapéuticos buscados en } \\
\text { los pacientes colombianos con CU, dado que } \\
\text { permiten con mayor certeza conocer la eficacia } \\
\text { del tratamiento. }\end{array}$ \\
\hline $\begin{array}{l}\text { Valores y } \\
\text { preferencias }\end{array}$ & $\begin{array}{l}\text { La evidencia proveniente de las revisiones } \\
\text { sistemáticas reporta que los pacientes } \\
\text { consideran que deben tener una interacción } \\
\text { constante con el médico tratante y recibir } \\
\text { explicación de cómo se realiza el tratamiento, así } \\
\text { como considerar los efectos a largo plazo (26). }\end{array}$ \\
\hline $\begin{array}{l}\text { Costos (asignación } \\
\text { de recursos) }\end{array}$ & $\begin{array}{l}\text { La medición de la cicatrización de la mucosa } \\
\text { como desenlace requiere endoscopias } \\
\text { adicionales al manejo usual, lo cual puede } \\
\text { aumentar los costos. }\end{array}$ \\
\hline $\begin{array}{l}\text { Aceptabilidad y } \\
\text { viabilidad }\end{array}$ & $\begin{array}{l}\text { El panel expresó que considera que la } \\
\text { mayoría de los clínicos están de acuerdo } \\
\text { con los desenlaces que deben buscarse en } \\
\text { los pacientes y que están en línea con los } \\
\text { organismos internacionales. }\end{array}$ \\
\hline
\end{tabular}

\section{Dirección $\quad n .^{\circ} \quad$ Resumen}

Objetivos del tratamiento

\begin{tabular}{|c|c|c|}
\hline $\begin{array}{l}\text { Fuerte a } \\
\text { favor }\end{array}$ & 2 & $\begin{array}{l}\text { Se recomienda que el objetivo del tratamiento } \\
\text { sea la remisión clínica y la cicatrización mucosa } \\
\text { (remisión profunda y sostenida); esta última se } \\
\text { asocia a una menor tasa de colectomía y menor } \\
\text { riesgo de displasia y cáncer colorrectal. } \\
\text { Calidad de evidencia muy baja } \oplus \text { } ๑ \text { }\end{array}$ \\
\hline $\begin{array}{l}\text { Punto de } \\
\text { buena } \\
\text { práctica }\end{array}$ & $\sqrt{ }$ & $\begin{array}{l}\text { La selección del tratamiento de colitis ulcerativa } \\
\text { debe estar basada en la extensión, la gravedad } \\
\text { y de acuerdo con el pronóstico individual de } \\
\text { cada paciente. }\end{array}$ \\
\hline $\begin{array}{l}\text { Punto de } \\
\text { buena } \\
\text { práctica }\end{array}$ & $\sqrt{ }$ & $\begin{array}{l}\text { Se consideran factores de mal pronóstico en } \\
\text { colitis ulcerativa, para ayudar a orientar el } \\
\text { tratamiento, los pacientes que presenten los } \\
\text { siguientes factores de riesgo: } \\
\text { - edad <30 años; } \\
\text { - compromiso endoscópico grave; } \\
\text { - colitis extensa; } \\
\text { - hospitalización por actividad de colitis; } \\
\text { - PCR elevada; } \\
\text { - albúmina baja; } \\
\text { - uso de esteroides al inicio de la enfermedad; } \\
\text { - colangitis esclerosante asociada; } \\
\text { - infección por Clostridium/citomegalovirus }\end{array}$ \\
\hline
\end{tabular}




\section{Terapias en pacientes con colitis ulcerativa activa}

\section{Terapias para inducción de la remisión (actualizado de la guía de CU 2015)}

\section{Aminosalicilatos tópicos vs. placebo}

Una revisión sistemática de la literatura identificada por el grupo desarrollador de la guía NICE, puntaje AMSTAR 2 de baja calidad, evaluó la seguridad y la efectividad de los aminosalicilatos tópicos versus placebo para la inducción de la remisión en los pacientes con proctitis y CU de leve a moderada, actividad con extensión al recto hasta los 20 $\mathrm{cm}$ del reborde anal y en colon hasta el ángulo esplénico. Los desenlaces evaluados fueron la frecuencia de mejoría sintomática, la proporción de pacientes con mejoría endoscópica (con criterio Baron), la frecuencia de mejoría endoscópica y clínica y la aparición de eventos adversos serios y no serios derivados de la terapia (eritema facial o fiebre leve, entre otros). Se recuperaron 7 ensayos clínicos controlados para un total de 476 participantes, en donde se evaluó la intervención de interés con un seguimiento de 0 a 6 semanas. Comparado con el grupo placebo, los pacientes asignados al grupo de aminosalicilatos tópicos alcanzaron una mayor frecuencia de inducción de la remisión clínica de 0 a 2 semanas (razón de riesgo [RR]: 3,84; IC 95\%: 2,05-7,19), remisión endoscópica de 0 a 2 semanas (RR: 7,54; IC 95\%: 2,08-27,36), remisión clínica y endoscópica de 2 a 4 semanas (RR: 10,27: IC 95\%: 0,62-169,16) y remisión clínica y endoscópica de 4 semanas a 6 semanas (RR: 10,21; IC 95: 1,52-68,49). El uso de esta intervención tampoco incrementó la frecuencia de eventos adversos (RR: 0,29; IC 95\%: 0,04-2,14) o de eventos adversos serios durante la terapia (RR: 0,26; IC 95\%: 0,03-2,29), ni redujo la frecuencia de cuidado intrahospitalario durante el tratamiento por deterioro clínico (RR: 0,26; IC 95\%: 0,03-2,29). La calidad de la evidencia fue moderada por limitaciones en la precisión y el riesgo de sesgo (28).

\section{Aminosalicilatos supositorios vs. enema líquido}

Una revisión sistemática de la literatura identificada por el grupo desarrollador de la guía NICE, puntaje AMSTAR 2 de baja calidad, evaluó la seguridad y la efectividad del uso de aminosalicilatos en supositorios versus enema líquido para la inducción de remisión en pacientes con proctitis ulcerativa de actividad leve a moderada, con extensión hasta los $20 \mathrm{~cm}$ del reborde anal. Los desenlaces evaluados fueron la frecuencia de remisión clínica y endoscópica de 0 a 2 y de 2 a 4 semanas. Se recuperó 1 ensayo clínico controlado para un total de 39 participantes, en donde se evaluó la intervención de interés con un seguimiento de 0 a 4 semanas. Comparado con el enema líquido, el tratamiento con supositorios de aminosali- cilatos no se asoció a una mayor o menor frecuencia de remisión clínica de 0 a 2 semanas (RR: 1,18; IC 95\%: 0,58-2,42) o de 2 a 4 semanas (RR: 0,99; IC 95\%: 0,72-1,36). El uso de enemas tampoco incrementó la frecuencia de remisión endoscópica de 0 a 2 semanas (RR: 1,58; IC 95\%: 0,7-3,59) ni de 2 a 4 semanas (RR: 1,13; IC 95\%: 0,75-1,72) cuando se comparó con la presentación en supositorios. La calidad de la evidencia fue muy baja por limitaciones en la precisión y el riesgo de sesgos (28).

\section{Aminosalicilatos tópicos una vez vs. dos veces al día}

Una revisión sistemática de la literatura identificada por el grupo desarrollador de la guía NICE, puntaje AMSTAR 2 de baja calidad, evaluó la seguridad y la efectividad del uso de aminosalicilatos tópicos una vez versus dos veces al día para el tratamiento de los pacientes con $\mathrm{CU}$ de leve a moderada, con extensión desde los $20 \mathrm{~cm}$ del reborde anal hasta el ángulo esplénico del colon. Los desenlaces evaluados fueron la frecuencia de remisión clínica (definida como DAI <3) y la proporción de eventos adversos durante el seguimiento. Se recuperaron 12 ensayos clínicos controlados para un total de 2143 pacientes, en donde se evaluó la intervención de interés con un rango de seguimiento de 2 a 8 semanas. La administración de aminosalicilatos tópicos dos veces al día no incrementó la frecuencia de pacientes que experimentaron remisión clínica de 2 a 4 semanas (RR: 0,94; IC 95\%: 0,62-1,41), ni de 4 a 6 semanas (RR: 1,08; IC 95\%: 0,85-1,36), pero tampoco se asoció a una mayor o menor frecuencia de eventos adversos derivados de la terapia (RR: 0,96; IC 95\%: 0,67-1,38). La calidad de la evidencia fue muy baja por limitaciones en la precisión y el riesgo de sesgos (28).

\section{Aminosalicilatos tópicos vs. orales}

Una revisión sistemática de la literatura puntaje AMSTAR 2, de moderada calidad, comparó la seguridad y la efectividad de los aminosalicilatos tópicos y orales para el tratamiento de los pacientes con proctitis y CU de leve a moderada con extensión desde el recto hasta los $15 \mathrm{~cm}$ del reborde anal y en colon sigmoides hasta $50 \mathrm{~cm}$ del reborde anal. Los desenlaces evaluados fueron remisión, prevención de recaídas y eventos adversos relacionados con la terapia. Se recuperaron 12 ensayos clínicos controlados para un total de 322 pacientes, en donde se evaluó la intervención de interés con un rango de seguimiento de 3 semanas a 24 meses. Cuando se comparó la administración de aminosalicilatos tópicos con la terapia oral, los pacientes asignados al brazo de tratamiento tópico no experimentaron una mayor o menor frecuencia de remisión clínica de 4 a 8 semanas (RR: 0,82; IC 95\%: 0,52-1,28), pero sí una menor frecuencia de recaídas con la terapia tópica sobre la oral de 6 a 24 meses (RR: 0,64; IC 95\%: 0,43-0,95). No hubo diferencias 
estadísticamente significativas en cuanto la a frecuencia de eventos adversos (RR: 0,61; IC 95\%: 0,24-1,52) entre los grupos. La calidad de la evidencia fue muy baja por algunas limitaciones en el riesgo de sesgo, la aplicabilidad, la precisión y la consistencia de los resultados (29).

\section{Aminosalicilatos orales vs. aminosalicilatos orales más tópicos}

Una revisión sistemática con puntaje AMSTAR 2, de moderada calidad, comparó la seguridad y la efectividad de la administración de aminosalicilatos orales frente al uso de aminosalicilatos orales y tópicos para el tratamiento de los pacientes con CU de leve a moderada, con extensión desde proctitis hasta pancolitis. Los desenlaces evaluados fueron la frecuencia de remisión clínica (definido por la resolución de la rectorragia, EAI [endoscopic activity index] menor de 4) y la frecuencia de recaídas. Se recuperaron 12 ensayos clínicos controlados para un total de 322 pacientes, en donde se evaluó la intervención de interés con un rango de seguimiento de 3 semanas a 24 meses. Comparado con la monoterapia, el tratamiento con aminosalicilatos en terapia combinada se asoció a un aumento en la frecuencia de remisión clínica (RR: 0,65; IC 95\%: 0,47-0,91), sin que esto se viera reflejado en una menor frecuencia de recaídas (RR: 0,48; IC 95\%: $0,17-1,38)$ o de eventos adversos derivados de la intervención (RR: 0,77; IC 95\%: 0,55-1,19). La calidad de la evidencia fue muy baja por algunas limitaciones en la precisión, la consistencia y el riesgo de sesgos (30).

\section{Efectividad y seguridad de 5-ASA oral para la inducción de la remisión en pacientes con colitis ulcerativa}

Una revisión sistemática con puntaje AMSTAR 2, de moderada calidad, evaluó la efectividad y la seguridad del uso de 5-ASA para la inducción de la remisión en pacientes con CU. Los pacientes incluidos fueron pacientes adultos con diagnóstico de CU leve a moderada, definida bajo los criterios de Truelove de 1955. Como comparaciones, los autores incluyeron el uso de 5-ASA versus placebo, sulfasalazina $u$ otras formulaciones de 5-ASA, dentro de las cuales se incluyeron los esquemas de dosis (una dosis diaria versus dos o tres dosis al día) y los productos comerciales Asacol, Claversal, Salofak y Pentasa. Como desenlaces de efectividad, la revisión incluyó el porcentaje de pacientes que no obtuvieron remisión clínica o global de acuerdo con los criterios definidos por los autores de los estudios primarios, la mejoría clínica, la remisión o mejoría endoscópica y la falla a la adherencia al tratamiento; los desenlaces de seguridad evaluados fueron la ocurrencia de al menos un evento adverso, el porcentaje de abandono del tratamiento por eventos adversos y las pérdidas al seguimiento.

La revisión recuperó 53 estudios. Para la comparación de 5-ASA contra placebo, los autores encontraron que el uso de 5-ASA tuvo una menor frecuencia de fallos en la inducción de la remisión clínica o global (11 estudios, 2387 pacientes; RR: 0,86\%; IC 95\%: 0,82-0,89), menor frecuencia de fallos en la inducción de la mejoría clínica (3 estudios, 231 pacientes; RR: 0,79; IC 95\%: 0,64-0,97), menor frecuencia de fallos en la inducción de la remisión endoscópica (4 estudios, 1154 pacientes; RR: 0,77; IC 95\%: 0,77; 0,67-0,89), menor frecuencia de fallos en la inducción de mejoría endoscópica (4 estudios, 416 pacientes; RR: 0,71; IC 95\%: 0,59-0,86) y una menor frecuencia de abandono del tratamiento por eventos adversos (13 estudios, 2372 pacientes; RR: 0,72; IC 95\%: 0,54-0,97), sin encontrar diferencias entre las comparaciones en frecuencias de eventos adversos.

Por otro lado, para la comparación de 5-ASA versus sulfasalazina, la revisión reportó diferencias a favor del uso de 5-ASA en el porcentaje de abandono de tratamiento por eventos adversos (RR: 0,40; IC 95\%: 0,24-0,68; 10 estudios, 640 pacientes) y la frecuencia de eventos adversos (RR: 0,48; IC 95\%: 0,36-0,63; 12 estudios, 909 pacientes), sin encontrar diferencias entre las intervenciones en la reducción del fallo en la inducción de la remisión o mejoría clínica, la inducción de la remisión o mejoría endoscópica y la inducción de la remisión general.

Finalmente, al comparar entre el uso de mesalazina en dosis única mediante los productos MMX (liberación prolongada por más tiempo), Salofalk (liberación dependiente de $\mathrm{pH}$ ) y Pentasa (liberación controlada) contra la administración de dos o tres veces por semana, los autores de la revisión no encontraron diferencias estadísticamente significativas en la reducción del fallo a la inducción de la remisión o mejoría clínica o endoscópica, ni en la frecuencia de eventos adversos o el porcentaje de abandono del tratamiento por eventos adversos. De la misma manera, al comparar las diferentes presentaciones del medicamento, la revisión no encontró diferencias ni en la inducción de la respuesta o la remisión clínica o endoscópica ni en el porcentaje de eventos adversos (31).

La calidad de la evidencia fue moderada por limitaciones en la precisión.

\section{Evidencia clínica: corticoides orales vs.}

placebo (tomada de la Guía de CU 2015)

Una revisión sistemática de la literatura puntaje AMSTAR 2, de moderada calidad, evaluó la efectividad del uso de glucocorticoides administrados por vía oral o parenteral (hidrocortisona, cortisona, prednisolona, metilprednisolona, prednisona, betametasona, beclometasona o fluticasona) para la inducción de la remisión en los pacientes con CU activa con diferentes rangos de extensión de la enfermedad. Los desenlaces evaluados fueron la frecuencia de no remisión clínica y endoscópica, definida como la 
presencia de dos o menos deposiciones al día sin sangre, la ausencia de fiebre o taquicardia, el reporte de valores de hemoglobina y velocidad de sedimentación globular normal (o en mejoría) y la ganancia de peso. Se recuperaron 5 ensayos clínicos controlados para un total de 445 pacientes, en donde se evaluó la intervención de interés con un rango de seguimiento de 3 a 8 semanas. Cuando se comparó con placebo, la administración de glucocorticoides disminuyó la proporción de pacientes que no alcanzaron la remisión clínica (RR: 0,65; IC 95\%: 0,45-0,93) (32). La calidad de la evidencia fue muy baja por limitaciones en la inconsistencia y en la precisión.

\section{Efectividad y seguridad de la budesonida para la inducción de la remisión en pacientes con colitis ulcerativa}

Una revisión sistemática de la literatura puntaje AMSTAR 2 , de moderada calidad, evaluó la efectividad y seguridad del uso de budesonida para la inducción de la remisión de pacientes con CU. La revisión incluyó pacientes con diagnóstico de CU cuya actividad hubiera sido medida con cualquier escala y usando la definición empleada por los autores de los estudios primarios. La comparación de interés consistió en el uso de budesonida en presentación estándar o en presentación de liberación prolongada (MMX) contra placebo, y los desenlaces de efectividad considerados fueron la remisión clínica según la definición empleada por los estudios primarios, la mejoría clínica, endoscópica o histológica, la curación endoscópica de la mucosa, los cambios en el puntaje de actividad usado por los estudios primarios, la calidad de vida, la necesidad de uso de corticoides intravenosos y la necesidad de cirugía. Como desenlace de seguridad, se consideró la frecuencia de eventos adversos. El rango de medición de los desenlaces estuvo entre 2 y 9 semanas.

Los autores encontraron 6 ensayos clínicos. Al comparar con placebo, se encontró que el uso de budesonida en $9 \mathrm{mg}$ de liberación prolongada tuvo una mayor probabilidad de remisión clínica y endoscópica (RR: 2,25; IC 95\%: 1,50-3,39, 3 estudios, 900 pacientes), mayor resolución de los síntomas (RR: 1,86; IC 95\%: 1,25-2,77, 2 estudios, 442 pacientes), mayor mejoría (RR: 1,29; IC 95\%: 1,01-1,66) y remisión endoscópica (RR: 1,56; IC 95\%: 1,13-2,16), sin presentar diferencias en la frecuencia de eventos adversos o la probabilidad de mejoría clínica. Para la comparación de la dosis de budesonida de $6 \mathrm{mg}$ versus placebo, la revisión encontró diferencias a favor de la budesonida en la mejoría de los síntomas (RR: 1,56; IC 95\%: 1,04-2,35, 2 estudios, 440 pacientes), sin encontrar diferencias en la remisión o mejoría endoscópica, la frecuencia de eventos adversos o eventos adversos serios y el abandono del tratamiento por eventos adversos.

De manera complementaria, la revisión realizó análisis adicionales incluyendo las comparaciones de budesonida estándar contra prednisolona, en donde no encontró diferencias en la mejoría clínica o remisión endoscópica, la remisión histológica, la frecuencia de eventos adversos o la frecuencia de abandono del tratamiento por eventos adversos. También comparó budesonida convencional versus mesalazina, en donde se encontró una mayor frecuencia de remisión en el grupo que recibió mesalazina (RR: 0,72; IC 95\%: 0,57-0,91), sin encontrar diferencias en la remisión o mejoría endoscópica, la remisión histológica, la frecuencia de eventos adversos o el abandono del tratamiento por eventos adversos. Finalmente, para la comparación de budesonida de liberación prolongada frente a Entocort EC, los autores no encontraron diferencias entre los medicamentos en la obtención de la remisión o mejoría clínica o endoscópica, la remisión histológica, la mejoría de los síntomas o la frecuencia de eventos adversos serios (33). La calidad de la evidencia fue muy baja por limitaciones en la consistencia y la precisión.

\section{Evidencia clínica: azatioprina vs. placebo (tomada de la guía de CU 2015)}

Una revisión sistemática de la literatura identificada por el grupo desarrollador de la guía NICE puntaje AMSTAR 9/11 evaluó la seguridad y la efectividad de la azatioprina para inducir la remisión en los pacientes con CU de actividad leve a moderada. Los desenlaces evaluados fueron la frecuencia de remisión clínica, definida con la escala de Truelove y Witts, y la proporción de pacientes que alcanzaron la remisión endoscópica. Se recuperó un ensayo clínico controlado para un total de 80 pacientes, en donde se evaluó la intervención de interés con un seguimiento de 2 a 4 semanas. Cuando se comparó frente al grupo asignado a recibir placebo, el tratamiento con azatioprina no incrementó la frecuencia de remisión clínica (RR: 1,15; IC 95\%: 0,87-1,51) o endoscópica (RR: 1,67; IC 95\%: 0,83-3,36), ambos evaluados de 2 a 4 semanas (28). La calidad de la evidencia fue muy baja por algunas limitaciones en la precisión, la consistencia y el riesgo de sesgo.
Factores que pueden fortalecer

una recomendación

Calidad de la evidencia

Balance entre los efectos deseables e indeseables

\section{Comentario}

La calidad de la evidencia de forma global es muy baja, con limitaciones en la consistencia, la precisión y el riesgo de sesgo.

El panel de expertos consideró para cada una de las alternativas terapéutica disponibles para inducir la remisión en los pacientes la evidencia de eficacia y de eventos adversos, con el fin de recomendar las opciones más seguras. 


\begin{tabular}{ll}
$\begin{array}{l}\text { Valores y } \\
\text { preferencias }\end{array}$ & $\begin{array}{l}\text { La evidencia proveniente de revisiones } \\
\text { sistemáticas reporta que los pacientes } \\
\text { consideran que deben ser consultados para la } \\
\text { selección de la terapia, la frecuencia y la ruta } \\
\text { de administración (26). El paciente invitado } \\
\text { al panel de expertos mencionó la importancia } \\
\text { de seleccionar una alternativa que sea rápida } \\
\text { en lograr el alivio de los síntomas y mejorar la } \\
\text { calidad de vida. }\end{array}$ \\
\hline $\begin{array}{l}\text { Costos (asignación } \\
\text { de recursos) }\end{array}$ & $\begin{array}{l}\text { Todas las alternativas propuestas se } \\
\text { encuentran en el plan de beneficios del país. }\end{array}$ \\
\hline $\begin{array}{l}\text { Aceptabilidad y } \\
\text { viabilidad }\end{array}$ & $\begin{array}{l}\text { El panel considera que las alternativas } \\
\text { propuestas para reducir la admisión serán } \\
\text { aceptadas por los diferentes actores del } \\
\text { sistema de salud. }\end{array}$ \\
\hline
\end{tabular}

Dirección

Resumen

Inducción de remisión

Fuerte a favor 3 Se recomienda el uso de mesalazina como primera elección para la inducción de la remisión en pacientes con colitis ulcerativa leve a moderada en dosis estándar (2 a $3 \mathrm{~g} / \mathrm{d}$ ). Calidad de evidencia moderada $\oplus \oplus \oplus \mathrm{O}$

Fuerte a favor 4 En pacientes con colitis ulcerativa leve a moderada izquierda o extensa se recomienda la combinación de mesalazina tópica y oral para la inducción de la remisión. Calidad de evidencia muy baja $\oplus$ O००

Fuerte a favor 5 En pacientes con proctitis ulcerativa se recomienda el manejo con ASA tópico rectal. Calidad de evidencia muy baja $\oplus$ O००

Fuerte a favor 6 Se recomienda el uso de glucocorticoides como terapia de primera línea para inducir la remisión en pacientes con colitis ulcerativa activa moderada a grave de cualquier extensión. Calidad de evidencia muy baja $\oplus$ O००

Fuerte a favor 7 Se recomienda el uso de budesonida MMX o prednisona oral para la inducción de la remisión en pacientes con colitis ulcerativa con actividad leve a moderada, que no respondan a las dosis apropiadas de 5-ASA oral más 5-ASA tópico.

Calidad de evidencia muy baja $\oplus$ O००

Punto de $\quad \sqrt{ }$ La dosis sugerida de inducción de budesonida buena práctica MMX es de $9 \mathrm{mg} / \mathrm{d}$ por 8 semanas.

Fuerte en $\quad 8$ No se recomienda el uso de azatioprina para contra inducir la remisión en pacientes con colitis ulcerativa leve a moderada. Calidad de evidencia muy baja $\oplus$ O००

\section{Terapias para el mantenimiento de la remisión}

\section{Efectividad y seguridad de azatioprina y 6-mercaptopurina para el mantenimiento de la remisión en pacientes con colitis ulcerativa}

Una revisión sistemática de la literatura puntaje AMSTAR 2 , de calidad moderada, evaluó la efectividad y la seguridad del uso de azatioprina o 6-mercaptopurina vía oral en pacientes con CU en remisión. La población incluida fue pacientes con CU en remisión, la cual fue definida por los autores de la revisión como la presencia de síntomas leves o ausentes con suspensión completa del tratamiento con corticosteroides y con evidencia endoscópica de inflamación de la mucosa ausente o grado 1 . Como intervenciones, la revisión incluyó los estudios que hayan evaluado el uso de azatioprina o 6-mercaptopurina oral, y las comparaciones halladas fueron azatioprina versus placebo, 6-mercaptopurina versus 5-ASA, azatioprina versus sulfasalazina, 6-mercaptopurina versus metotrexato y azatioprina versus ciclosporina. Los desenlaces de efectividad considerados por la revisión fueron el fallo en el mantenimiento de la remisión clínica o endoscópica a los 12 meses, definida como la presencia de recaída del cuadro o del abandono del estudio. Como desenlaces de seguridad, la revisión evaluó la frecuencia de eventos adversos y el abandono del tratamiento por eventos adversos.

La revisión incluyó siete ensayos clínicos. En cuanto a los estudios que evaluaron la azatioprina, se encontró que, frente a la sulfasalazina, no hubo diferencias en la frecuencia de los pacientes que no lograron mantener la remisión ni en la frecuencia de eventos adversos ( 1 estudio, 25 pacientes). Igualmente, en la comparación contra ciclosporina, no se encontraron diferencias ni en el mantenimiento de la remisión, el abandono del tratamiento por eventos adversos o la ocurrencia de cualquier evento adverso (1 estudio, 16 pacientes). En la comparación de azatioprina frente a placebo, la revisión reportó diferencias a favor de la azatioprina para mantener la remisión ( $R R$ de fallo en el mantenimiento de la remisión: 0,68; IC 95\%: 0,54-0,86; 4 estudios, 232 pacientes), sin encontrar diferencias en la frecuencia de eventos adversos o el abandono del tratamiento por eventos adversos. En lo que respecta a las comparaciones que incluyeron 6-mercaptopurina, se encontró que, al compararla con 5-ASA, esta presentó una menor frecuencia de fallos en el mantenimiento de la remisión (RR: 0,53; IC 95\%: 0,31-0,9; 1 estudio, 22 pacientes), sin encontrar diferencias en la frecuencia de eventos adversos o el abandono del tratamiento por eventos adversos. De manera similar, al compararse contra metotrexato, 6-mercaptopurina tuvo un 
mejor mantenimiento de la remisión ( $R R$ de fallo en el mantenimiento de la remisión: 0,55; IC 95\%: 0,31-0,95; 1 estudio, 26 pacientes) sin encontrar diferencias en la frecuencia de abandono del tratamiento por eventos adversos (34). La calidad de la evidencia fue muy baja por limitaciones en la consistencia y la precisión de los resultados.

\section{Efectividad y seguridad del uso de probióticos en pacientes con colitis ulcerativa}

Una revisión sistemática puntaje AMSTAR 2, de calidad críticamente baja, evaluó la eficacia y la seguridad del uso de probióticos, fructanos, prebióticos tipo inulina y simbióticos para la inducción o la remisión de la actividad en pacientes con CU. La población incluida fue adultos y niños con CU activa o inactiva, sin realizar otra especificación. Como intervenciones, se consideró el uso de probióticos, prebióticos (definidos como un sustrato que se usa de formas selectiva por los microorganismos huéspedes para obtener un beneficio en salud) y simbióticos, los cuales fueron definidos como compuestos que contienen la combinación de probióticos y prebióticos. El desenlace de eficacia de interés considerado fue la remisión de la enfermedad, sin otra especificación. Los comparadores no fueron reportados de forma explícita por los autores.

La revisión incluyó 18 estudios con un total de 1491 pacientes, de los cuales, 16 evaluaron la efectividad del uso de probióticos, 1 evaluó la efectividad del uso de prebiótico y 1 evaluó la efectividad del uso de simbióticos. Para el uso de probióticos versus control no especificado en pacientes con CU activa no se encontraron diferencias en la frecuencia de remisión al evaluarse con las escalas propuestas por los estudios primarios (RR: 1,46; IC 95\%: 0,94-2,27), ni en el mantenimiento de la remisión en los pacientes con CU inactiva (RR: 1,38; IC 95\%: 0,86-2,21). De manera complementaria, los autores realizaron un análisis de subgrupos para evaluar la frecuencia de remisión de acuerdo con el microorganismo incluido en el producto y encontraron que el uso de la cepa VSL\#3 presentó una mayor frecuencia de remisión (IC 95\%: 1,99; 1,25-3,15), como terapia adjunta a otros tratamientos en CU activa leve a moderada. No se encontraron diferencias en la remisión en los probióticos que incluían bifidobacterias, otras no bifidobacterias y mutaflor. La revisión no brindó información sobre la eficacia de prebióticos o simbióticos, ni consideró la evaluación de eventos adversos (35).

La calidad de la evidencia fue muy baja por limitaciones en el riesgo de sesgos, la consistencia y la precisión.

\begin{tabular}{ll}
\multicolumn{1}{c}{$\begin{array}{c}\text { Factores que } \\
\text { pueden fortalecer } \\
\text { una recomendación }\end{array}$} & \multicolumn{1}{c}{ Comentario } \\
\hline $\begin{array}{l}\text { Calidad de la } \\
\text { evidencia }\end{array}$ & $\begin{array}{l}\text { La calidad de la evidencia de forma global } \\
\text { es muy baja por el riesgo de sesgos, la } \\
\text { consistencia y la precisión. }\end{array}$ \\
$\begin{array}{ll}\text { Balance entre los } \\
\text { efectos deseables e } \\
\text { indeseables }\end{array}$ & $\begin{array}{l}\text { El panel de expertos consideró para cada una } \\
\text { de las alternativas terapéuticas disponibles } \\
\text { para mantener la remisión en los pacientes la } \\
\text { evidencia de eficacia y de eventos adversos. }\end{array}$ \\
$\begin{array}{ll}\text { Se recomienda vigilar a los pacientes por } \\
\text { eventos adversos como azoospermia y linfoma. }\end{array}$ \\
preferencias & $\begin{array}{l}\text { La evidencia proveniente de las revisiones } \\
\text { sistemáticas reporta que los pacientes } \\
\text { consideran que deben ser consultados para la } \\
\text { selección de la terapia, la frecuencia y la ruta } \\
\text { de administración (26). El paciente invitado } \\
\text { al panel de expertos mencionó la importancia } \\
\text { de seleccionar una alternativa que sea rápida } \\
\text { en lograr el alivio de los síntomas y mejorar la } \\
\text { calidad de vida. }\end{array}$ \\
\hline $\begin{array}{l}\text { Costos (asignación } \\
\text { de recursos) }\end{array}$ & $\begin{array}{l}\text { Todas las alternativas propuestas se } \\
\text { encuentran en el plan de beneficios del país. }\end{array}$ \\
$\begin{array}{ll}\text { El panel considera que se presentarán algunas } \\
\text { dificultades en el acceso a 6-mercaptopurina } \\
\text { por su costo elevado y baja disponibilidad } \\
\text { en ciertas áreas. Los probióticos no fueron } \\
\text { recomendados dada su evidencia de no efecto } \\
\text { en el mantenimiento de la remisión. }\end{array}$ \\
\hline
\end{tabular}

Dirección $\mathrm{n}^{\circ} \quad$ Resumen

Mantenimiento de la remisión

Fuerte a 9 Se recomienda el uso de inmunosupresores tiopurínicos favor para mantener en remisión a los pacientes con colitis ulcerativa dependiente de esteroides. Calidad de evidencia muy baja $\oplus$ O००

Fuerte a $\quad 10$ Se recomienda el uso de 6-mercaptopurina favor para mantener en remisión a los pacientes con colitis ulcerativa que presentan intolerancia a la administración de azatioprina. Calidad de evidencia muy baja $\oplus$ O००

Condicional 11 Se sugiere el uso de VSL\#3 (probiótico) para a favor inducir la remisión en los pacientes con colitis ulcerativa activa leve a moderada, como terapia adjunta al tratamiento con 5-ASA y esteroides. Calidad de evidencia muy baja $\oplus$ O००

Fuerte en 12 No se recomienda el uso de probióticos como contra terapia de mantenimiento de la remisión en pacientes con colitis ulcerativa. Calidad de evidencia muy baja $\oplus$ O०० 


\section{Efectividad y seguridad del uso de tofacitinib vs. biológicos para el tratamiento de pacientes con colitis ulcerativa moderada a grave. Resultados de un metaanálisis en red}

Una revisión sistemática con metaanálisis en red y puntaje AMSTAR 2, de calidad críticamente baja, evaluó la efectividad y la seguridad del uso de tofacitinib versus placebo o medicamentos biológicos en pacientes con $\mathrm{CU}$ y actividad moderada a grave. Los pacientes incluidos fueron pacientes con diagnóstico de CU moderada a grave, definida como la presencia de un puntaje de 6 a 12 puntos medido con la escala de la Clínica Mayo y un puntaje del dominio endoscópico de 2 o 3, sin otra especificación clínica realizada por los autores. Las intervenciones consideradas fueron tofacitinib, adalimumab, golimumab, infliximab y vedolizumab. Los desenlaces de efectividad considerados fueron respuesta clínica, remisión clínica y estado de curación de la mucosa al final de la inducción y al finalizar la fase de mantenimiento; la respuesta clínica fue definida como: a) un descenso de 3 puntos en la escala usada (Clínica Mayo) $y$ un descenso de al menos 1 punto en el dominio de sangrado rectal o un puntaje absoluto en este dominio de $0 \mathrm{o}$ 1; la remisión clínica fue definida como la obtención de un puntaje de 2 puntos o menos evaluados con la escala de la Clínica Mayo y que ningún dominio excediera la calificación de 1 punto; la curación de la mucosa fue medida con el dominio endoscópico de la escala, y se definió curación si el puntaje fue 0 o 1 . Como desenlaces de seguridad, la revisión consideró la frecuencia de cualquier evento adverso y la frecuencia de eventos adversos serios. El rango de seguimiento de los desenlaces fue entre 6 y 54 semanas.

La revisión recuperó 19 ensayos clínicos. En las comparaciones directas se encontró que todas las intervenciones consideradas presentaron una mayor respuesta clínica y remisión clínica en comparación contra placebo. Para tofacitinib, los autores reportaron una frecuencia de respuesta clínica 2,42 veces mayor que placebo (IC 95\%: 1,61-3,63; 2 estudios, 577 pacientes), una remisión clínica 2,47 veces mayor que placebo (IC 95\%: 1,41-4,34; 3 estudios, 577 pacientes) y una mayor frecuencia de curación de la mucosa (RR: 2,06; IC 95\%: 1,25-3,39; 2 estudios, 521 pacientes). En el análisis de comparaciones indirectas entre las intervenciones, no se encontraron diferencias en la frecuencia de respuesta clínica o remisión clínica entre tofacitinib y alguno de los medicamentos biológicos incluidos.

En cuanto a la frecuencia de eventos adversos, en las comparaciones directas no se encontraron diferencias estadísticamente significativas en la frecuencia de eventos adversos serios entre Tofacitinib y placebo (RR: 0,69; IC 95\%: 0,43-1,09; 4 estudios, 1812 pacientes) y tampoco se encontraron diferencias significativas en la frecuencia de cualquier evento adverso y eventos adversos serios en el análisis de las comparaciones indirectas.

Finalmente, en la evaluación de la probabilidad de ser el mejor tratamiento, infliximab tuvo la mayor probabilidad de serlo en los desenlaces de respuesta clínica (60\%) y curación de la mucosa $(51,4 \%)$, mientras que tofacitinib tuvo una probabilidad de ser el mejor del 3,7\% en curación de la mucosa (tercer lugar), $3 \%$ en remisión clínica (cuarto lugar) y 5,2\% en curación de la mucosa (tercer lugar). En relación con los eventos adversos, vedolizumab presentó menor probabilidad de eventos adversos $(40,2 \%)$ y eventos adversos serios $(87,7 \%)$ comparado con los otros medicamentos. Tofacitinib tuvo una probabilidad del $35,6 \%$ de ser el más seguro para eventos adversos (segundo lugar) y del 6,5\% de ser el más seguro para eventos adversos serios (segundo lugar) (36). La calidad de la evidencia fue muy baja por limitaciones en la evidencia directa, la precisión y la sospecha de sesgo de publicación.

Por otro lado, una revisión sistemática y puntaje AMSTAR 2, de calidad críticamente baja, evaluó la eficacia y la seguridad del uso de tofacitinib para la inducción de remisión en pacientes con $\mathrm{CU}$ moderada a grave definida de acuerdo con los criterios establecidos en los estudios primarios. Como comparaciones, la revisión consideró el uso de tofacitinib versus placebo. Como desenlaces de eficacia, la revisión consideró la remisión o respuesta clínica, la cicatrización de la mucosa, la remisión endoscópica o de los síntomas y la calidad de vida, las cuales fueron definidas de la misma manera que la establecida por los autores de los estudios primarios. Como desenlaces de seguridad, la revisión evaluó la frecuencia de eventos adversos, eventos adversos serios e infecciones serias.

La revisión incluyó tres estudios con un total de 1220 pacientes. Los autores encontraron diferencias estadísticamente significativas a favor del uso de tofacitinib en los desenlaces de remisión clínica (OR: 3,84; IC 95\%: 2,29-6,44), respuesta clínica (OR: 2,95; IC 95\%: 2,21-3,95), remisión endoscópica (OR: 5,65; IC 95\%: 2,25-14,17), remisión de los síntomas (OR: 2,85; IC 95\%: 1,46-5,54), curación de la mucosa (OR: 2,7; IC 95\%: 1,81-4,03) y cambios en el puntaje de calidad de vida tanto con la escala IBDQ (Inflammatory Bowel Disease Questionnaire) (diferencia de medias [DM]: 13,3; IC 95\%: 9,7-16,91) como con la escala SF-36 en el dominio físico (DM: 3,45; IC 95\%: 2,44-4,45) $y$ el dominio mental (DM: 3,94; IC 95\%: 2,69-5,19), aunque los pacientes que recibieron tofacitinib presentaron una mayor frecuencia de infecciones (OR: 1,51; IC 95\%: 1,05-2,19). La revisión no encontró diferencias entre las comparaciones para la frecuencia de eventos adversos (OR: 0,93; IC 95\%: 0,68-1,28) eventos adversos serios (OR: 0,63; IC 95\%: 0,34-1,15), la frecuencia de abandono 
del tratamiento por eventos adversos (OR: 0,94; IC 95\%: $0,34-2,6)$ o la frecuencia de infecciones serias (OR: 3,17 ; IC 95\%: 0,56-17,94) (37).

\begin{tabular}{|c|c|}
\hline $\begin{array}{c}\text { Factores que } \\
\text { pueden fortalecer } \\
\text { una recomendación }\end{array}$ & Comentario \\
\hline $\begin{array}{l}\text { Calidad de la } \\
\text { evidencia }\end{array}$ & $\begin{array}{l}\text { La calidad de la evidencia de forma global } \\
\text { es muy baja por el riesgo de sesgos, la } \\
\text { consistencia y la precisión. }\end{array}$ \\
\hline $\begin{array}{l}\text { Balance entre los } \\
\text { efectos deseables e } \\
\text { indeseables }\end{array}$ & $\begin{array}{l}\text { El panel de expertos consideró la eficacia de } \\
\text { tofacitinib y los eventos adversos reportados. } \\
\text { Dado que es un medicamento reciente, aún } \\
\text { no se conocen los eventos adversos a largo } \\
\text { plazo, por lo que los pacientes requieren } \\
\text { monitorización. Adicionalmente, se consideró } \\
\text { una alternativa para pacientes que no } \\
\text { responden o son intolerantes a antifactor de } \\
\text { necrosis tumoral (anti-FNT). }\end{array}$ \\
\hline $\begin{array}{l}\text { Valores y } \\
\text { preferencias }\end{array}$ & $\begin{array}{l}\text { La evidencia proveniente de revisiones } \\
\text { sistemáticas reporta que los pacientes } \\
\text { consideran que deben ser consultados para } \\
\text { la selección de la terapia, la frecuencia y la } \\
\text { ruta de administración (Bewer, 2013). El panel } \\
\text { considera que los pacientes lo preferirían } \\
\text { porque se administran por vía oral. }\end{array}$ \\
\hline $\begin{array}{l}\text { Costos (asignación } \\
\text { de recursos) }\end{array}$ & $\begin{array}{l}\text { El panel considera que los costos pueden ser } \\
\text { los mismos que con terapia biológica. }\end{array}$ \\
\hline $\begin{array}{l}\text { Aceptabilidad y } \\
\text { viabilidad }\end{array}$ & $\begin{array}{l}\text { El panel considera que, al ser un medicamento } \\
\text { por vía oral, puede ser más fácil su } \\
\text { administración en pacientes que se encuentran } \\
\text { fuera de las ciudades principales, debido a que } \\
\text { no requiere aplicación en centros de infusión. }\end{array}$ \\
\hline Dirección & Resumen \\
\hline \multicolumn{2}{|c|}{ Colitis ulcerativa moderada a grave } \\
\hline $\begin{array}{l}\text { Condicional a } \\
\text { favor }\end{array}$ & $\begin{array}{l}\text { Se sugiere el uso de tofacitinib para inducir } \\
\text { y mantener la remisión en pacientes con } \\
\text { colitis ulcerativa moderada a grave, no } \\
\text { respondedores o intolerantes a anti-FNT. } \\
\text { Calidad de evidencia muy baja } \oplus \text { ○০০ }\end{array}$ \\
\hline $\begin{array}{l}\text { Punto de buena } \sqrt{ } \\
\text { práctica }\end{array}$ & $\begin{array}{l}\text { Los pacientes con colitis ulcerativa que usan } \\
\text { tofacitinib deben tener monitorización del perfil } \\
\text { lipídico y recibir vacunación previa contra } \\
\text { herpes zóster. }\end{array}$ \\
\hline $\begin{array}{l}\text { Punto de buena } \sqrt{ } \\
\text { práctica }\end{array}$ & $\begin{array}{l}\text { Los pacientes refractarios al tratamiento o } \\
\text { en quienes no sea posible obtener remisión } \\
\text { deben ser remitidos a centros especializados } \\
\text { en el manejo de pacientes con colitis } \\
\text { ulcerativa. }\end{array}$ \\
\hline
\end{tabular}

Punto de buena $\sqrt{ }$ En julio de 2019, la FDA recomendó utilizar práctica tofacitinib con precaución en pacientes con factores de riesgo de tromboembolismo venoso (mayores de 65 años, antecedente previo de trombosis, inmovilizados, trastornos de la coagulación, malignidad, infarto de miocardio, tabaquismo, hipertensión arterial, diabetes mellitus, $\mathrm{HDL}<40 \mathrm{mg} / \mathrm{dL}$, enfermedad coronaria, falla cardíaca, uso de anticonceptivos o terapia de remplazo hormonal), debido a que se encontró un riesgo incrementado de trombosis en un estudio en artritis reumatoide con la dosis de $10 \mathrm{mg}$ cada $12 \mathrm{~h}$. Por lo anterior, en pacientes con $\mathrm{CU}$, el tratamiento de inducción con la dosis de $10 \mathrm{mg}$ cada $12 \mathrm{~h}$ no debe darse por más de 16 semanas, y en caso de respuesta, continuar la dosis de mantenimiento de $5 \mathrm{mg}$ cada 12 h. En caso de sospecha clínica de tromboembolismo venoso, debe suspenderse inmediatamente el tofacitinib.

\section{Efectividad y seguridad del uso de cúrcuma en pacientes con colitis ulcerativa activa leve a moderada} Una revisión sistemática y puntaje AMSTAR 2, de calidad críticamente baja, evaluó la efectividad y la seguridad de la terapia con cúrcuma en pacientes con CU activa. Los pacientes incluidos fueron pacientes adultos con CU detectada por clínica y endoscopia, cuya actividad fuera definida como leve a moderada de acuerdo con la escala usada por los estudios primarios. La intervención de interés consistió en la terapia con cúrcuma por vía oral en adyuvancia y como comparadores consistieron en la administración de placebo o ningún tratamiento en adyuvancia. Los desenlaces de efectividad fueron la proporción de pacientes que hubieran alcanzado la remisión medida con las escalas CAI (Colitis Activity Index) SCCAI (Simple Clinical Colitis Activity Index) y UCDAI (Colitis Disease Activity Index), el mantenimiento de la remisión, los cambios en los puntajes de actividad de la enfermedad, la remisión endoscópica (curación de la mucosa) y la respuesta clínica. Como desenlaces de seguridad, los autores consideraron la frecuencia de eventos adversos. El rango de seguimiento de los desenlaces fue entre 4 semanas y 12 meses.

La revisión recuperó cuatro ensayos clínicos con un total de 241 participantes. Los autores no encontraron diferencias entre las comparaciones en la remisión clínica (OR: 4,33; IC 95\%: 0,78-24) ni en la frecuencia de pacientes que presentaron cambios en el puntaje de actividad (cúrcuma, rango del $20 \%$ al $61 \%$; placebo, rango del $12,5 \%$ al $36 \%$ ) o curación mucosa (cúrcuma, rango del $22 \%$ al $34 \%$; placebo, rango del $0 \%$ al $30 \%$ ). En cuanto a los des- 
enlaces de seguridad, no se encontraron diferencias en la interrupción del tratamiento (OR calculado con los datos reportados: 1,15; IC 95\%: 0,41-3,21) o en la frecuencia de eventos adversos (38).

La calidad de la evidencia fue muy baja por limitaciones en el riesgo de sesgos, la consistencia, la precisión y el sesgo de publicación.

\section{Efectividad y seguridad del cannabis en pacientes con colitis ulcerativa}

Una revisión sistemática y puntaje AMSTAR 2, de calidad moderada, evaluó la efectividad y la seguridad del uso de cannabis en pacientes con CU. Los pacientes incluidos fueron pacientes mayores de 18 años con diagnóstico de $\mathrm{CU}$ activa o quiescente, definida por escala de la Clínica Mayo o DAI (Disease Activity Index). La intervención de interés fue el uso de cannabis o compuestos derivados de este en cualquier presentación y administración; como comparadores, los autores consideraron al placebo o cualquier terapia activa para el tratamiento de la CU. Los desenlaces de efectividad evaluados por la revisión fue la remisión clínica definida tal como fue catalogada por los estudios primarios, el mantenimiento de la remisión, la respuesta clínica, la remisión endoscópica, la respuesta histológica, la calidad de vida y la mejoría de los síntomas. Como desenlaces de seguridad, la revisión evaluó la frecuencia de eventos adversos, la frecuencia de eventos adversos serios y el abandono del tratamiento por eventos adversos.

La revisión incluyó dos ensayos clínicos (92 pacientes), con un período de seguimiento de 10 semanas. La revisión detectó que los pacientes que usaron cannabinoides tuvieron una mayor frecuencia de eventos adversos (RR: 1,28; IC 95\%: 1,05-1,56; 1 estudio, 60 pacientes), sin encontrar diferencias significativas en la remisión clínica (RR: 0,94; IC 95\%: 0,39-2,25: 1 estudio, 60 pacientes), la respuesta clínica (RR: 1,37; IC 95\%: 0,59-3,21; 1 estudio, 60 participantes), el control de los síntomas (DM en escala de dolor: 0,32; IC 95\%: -0,51-1,15; DM sangrado rectal: $-0,09$; IC 95\%: $-0,47-0,29)$, la frecuencia de deposiciones (DM: 0; IC 95\%: $-0,35-0,35)$, la frecuencia de eventos adversos serios (RR: 0,12; IC 95\%: 0,01-2,11) o el abandono del tratamiento por eventos adversos (RR: 2,14; IC 95\%: 0,83-5,51) (39).

La calidad de la evidencia fue baja por limitaciones en la precisión de los resultados.

\section{Dirección $n .^{\circ}$}

Resumen

\section{Colitis ulcerativa activa}

No existe suficiente evidencia que permita recomendar o no el uso de la cúrcuma o del cannabis en pacientes con colitis ulcerativa activa.

Efectividad y seguridad del trasplante de microbiota de materia fecal en pacientes con colitis ulcerativa activa Una revisión sistemática y puntaje AMSTAR 2, de calidad críticamente baja, evaluó la efectividad y la seguridad del trasplante de microbiota de materia fecal en pacientes con CU activa. Los pacientes incluidos fueron pacientes adultos con CU activa tanto clínica como endoscópica medida con la escala de la Clínica Mayo y la escala SCCAI (Simple Clinical Colitis Activity Index). La intervención de interés fue el trasplante de microbiota de materia fecal en cualquier modalidad y los comparadores fueron el uso de placebo, definido como el excipiente del trasplante de materia fecal sin microbiota, o el trasplante autólogo de material fecal. Los desenlaces de efectividad considerados fueron la remisión clínica con remisión o respuesta endoscópica, la remisión clínica sola y la remisión endoscópica sola. Como desenlaces de seguridad, los autores consideraron la frecuencia de eventos adversos serios. El rango de seguimiento de los desenlaces fue entre 7 y 12 semanas. La revisión recuperó cuatro ensayos clínicos con un total de 277 pacientes. Los autores encontraron que el trasplante de microbiota de materia fecal tiene una mejor remisión clínica sola (RR: 0,76; IC 95\%: 0,62-0,93) y remisión clínica con respuesta o remisión endoscópica (RR: 0,8; IC 95: 0,71-0,89), al compararse contra placebo. La revisión no encontró diferencias en la remisión endoscópica sola (RR: 0,85; IC 95\%: 0,96$1,05)$ o en la frecuencia de eventos adversos serios (RR: 1,4; IC 95\%: 0,55-3,58) (40).

La calidad de la evidencia fue baja por limitaciones en la precisión y el sesgo de publicación.

Factores que

pueden fortalecer

una recomendación

Calidad de la

evidencia

Balance entre los

efectos deseables e

indeseables

Valores y

preferencias

\section{Costos (asignación de recursos)}

Aceptabilidad y viabilidad
Comentario

La calidad de la evidencia fue baja por las limitaciones en la precisión y el sesgo de publicación.

El balance riesgo-beneficio del trasplante de microbiota de material fecal es adecuado para ser recomendado.

La evidencia proveniente de las revisiones sistemáticas reporta que los pacientes consideran que deben ser consultados para la selección de la terapia (Bewer, 2013).

El panel considera que es una tecnología costosa para nuestro medio y no se encuentra en el plan de beneficios.

Muy pocos centros en Colombia saben cómo realizar el trasplante de microbiota de material fecal, por lo que su implementación presenta desafíos. 
Dirección

n.

Resumen

Colitis ulcerativa activa

Condicional a 14 Se sugiere el trasplante de microbiota de favor materia fecal para el tratamiento de la colitis ulcerativa moderada a grave refractaria a tratamiento médico. Calidad de evidencia baja $\oplus \oplus 00$

Punto de buena $\sqrt{ }$ El trasplante de materia fecal debe hacerse en práctica centros especializados con experiencia en este procedimiento.

\section{¿CUÁL ES LA EFECTIVIDAD Y LA SEGURIDAD DE LA TERAPIA BIOLÓGICA PARA EL TRATAMIENTO DE LOS PACIENTES CON COLITIS ULCERATIVA MODERADA A GRAVE?}

\section{Evidencia clínica: eficacia/efectividad de agentes antagonistas del FNT- $\alpha$ e inhibidor de integrina $\alpha 4 \beta 7$ para el tratamiento de colitis ulcerativa moderada a grave}

Se encontró una revisión sistemática y puntaje AMSTAR 2, de calidad moderada (41), la cual evaluó la eficacia de las terapias biológicas (adalimumab, infliximab, golimumab y vedolizumab) en adultos con CU activa moderada a grave. Los desenlaces clínicos evaluados fueron respuesta clínica, remisión clínica y curación de la mucosa, tanto en inducción como en mantenimiento.

En tres estudios que involucraron a 741 pacientes, adalimumab en inducción demostró beneficios respecto a placebo para la respuesta clínica (OR: 1,89; IC 95\%: 1,41-2,5), remisión clínica (OR: 1,82; IC 95\%: 1,19-2,83) y curación de la mucosa (OR: 1,53; IC 95\%: 1,14-2,07). La calidad de la evidencia fue moderada por algunas limitaciones en la presencia de riesgo de sesgos. Para terapia de mantenimiento proveniente de dos estudios con 260 pacientes, no se encontraron diferencias significativas para los desenlaces de respuesta clínica (OR: 1,33; IC 95\%: 0,77-2,22) o curación de la mucosa (OR: 1,49; IC 95\%: 0,95-2,39). Para la remisión clínica, el OR fue de 1,97 con un IC 95\% de 1,133,5. La calidad de la evidencia fue de baja a muy baja por la presencia de riesgo de sesgos e imprecisión.

Para golimumab en inducción, se encontró un estudio comparado con placebo que incluyó a 309 pacientes. Este estudio demostró resultados favorables para golimumab para respuesta clínica (OR: 2,54; IC 95\%: 1,79-3,70), remisión clínica (OR: 3,54; IC 95\%: 2,00-6,56) y curación de la mucosa (OR: 1,91; IC 95\%: 1,33-2,73). Para terapia de mantenimiento, golimumab fue superior a placebo en los desenlaces de respuesta clínica (OR: 2,27; IC 95\%: 1,39-
3,60) y remisión clínica (OR: 1,79; IC 95\%: 1,09-3,04). La

calidad de la evidencia fue alta.

En relación con infliximab versus placebo en inducción, se encontraron dos estudios con 486 pacientes, que demostraron resultados favorables para la intervención con el FNT- $\alpha$ en los desenlaces de respuesta clínica (OR: 4,11; IC 95\%: 2,84-6,1), remisión clínica (OR: 5,12; IC 95\%: 3,18-8,58) y curación de la mucosa (OR: 3,42 ; IC 95\%: 2,00-5,94). La calidad de la evidencia fue moderada por algunas limitaciones en la presencia de riesgo de sesgos. Para terapia de mantenimiento proveniente de un estudio con 129 pacientes, no se encontraron diferencias significativas con infliximab frente a placebo en la respuesta clínica (OR: 1,66; IC 95\%: 0,79-3,50), remisión clínica (OR: 1,24; IC 95\%: 0,61-2,67) y curación de la mucosa (OR: 1,98; IC 95\%: 0,96-4,04). La calidad de la evidencia fue baja por presencia de riesgo de sesgos, evidencia indirecta e imprecisión.

Para el inhibidor de integrina $\alpha 4 \beta 7$, vedolizumab, se encontró un estudio con 206 pacientes bajo terapia de inducción. Vedolizumab fue superior a placebo en respuesta clínica (OR: 3,17; IC 95\%: 1,72-6,16), remisión clínica (OR: 4,42; IC 95\%: 1,72-14,00) y curación de la mucosa (OR: 2,97; IC 95\%: 1,59-5,37). La calidad de la evidencia fue alta. En terapia de mantenimiento, se encontró un estudio con 151 pacientes que comparó vedolizumab frente a placebo, siendo favorable el primero para respuesta clínica (OR: 5,27; IC 95\%: 2,68-11,6), remisión clínica (OR: 3,63; IC 95\%: 1,75-7,72) y curación de la mucosa (OR: 4,79; IC 95\%: 2,33-9,93) (41). La calidad de la evidencia fue alta.

Otra revisión sistemática más actualizada realizó comparaciones indirectas, con puntaje AMSTAR 8/11 (41), entre los diferentes medicamentos biológicos para la CU moderada a grave: adalimumab, golimumab, infliximab y vedolizumab. Solo infliximab $5 \mathrm{mg} / \mathrm{kg}$ fue superior a adalimumab en la remisión clínica a las 6-8 semanas (OR: 2,35; IC 95\%: 1,35-4,14) y respuesta clínica a las 6-8 semanas (OR: 2,10; IC 95\%: 1,33-3,27). Infliximab también fue superior a golimumab en la respuesta clínica a las 6-8 semanas (OR: 1,60; IC 95\%: 1,01-2,56). Para curación de la mucosa, infliximab fue superior a adalimumab y golimumab (OR: 2,01; IC 95\%: $1,28-3,16$; y OR: 1,67 ; IC 95\%: 1,04-2,67, respectivamente). No hubo diferencias entre las diferentes comparaciones para remisión clínica a las 48-54 semanas (42). La calidad de la evidencia fue baja por la presencia de riesgo de sesgos y evidencia indirecta.

Un estudio de 769 pacientes comparó vedolizumab con adalimumab en adultos con CU moderada a grave. En la semana 52, el grupo con vedolizumab, comparado con el grupo de adalimumab, logró una mayor tasa de remisión clínica $(31,3 \%$ vs. 22,5\%; IC 95\%: 2,5-15,0; $p=0,006)$ y de 
respuesta endoscópica (39,7\% vs. 27,7\%; IC 95\%: 5,3-18,5; $p<0,001)$, aunque no hubo diferencia en la remisión clínica libre de esteroides (43).

\section{Evidencia clínica: eficacia/efectividad y seguridad de CT-P13, un biosimilar del agente antagonista del FNT- $\alpha$ infliximab para el tratamiento de colitis ulcerativa}

Se encontró una revisión sistemática puntaje AMSTAR, de calidad moderada (44), donde se evaluó la efectividad y la seguridad de biosimilares de agentes anti-FNT- $\alpha$ en pacientes con enfermedad inflamatoria intestinal. Los desenlaces clínicos evaluados fueron respuesta clínica (a las 8-14 semanas), remisión clínica (a las 8-14 semanas), efectos adversos globales, infecciones, reacciones a la infusión, respuesta clínica sostenida (a las 30-32 semanas) y remisión clínica sostenida (a las 51 semanas). No se encontraron ensayos clínicos controlados, ni estudios de otros biosimilares diferentes a CT-P13.

Para la CU y el desenlace de respuesta clínica, se identificaron cinco estudios observacionales con un total de 180 pacientes, con una tasa conjunta de respuesta clínica de 0,74 (IC 95\%: 0,65-0,82). La tasa conjunta de remisión clínica fue de 0,50 (IC 95\%: 0,41-0,59). Por su parte, la tasa conjunta de respuesta clínica sostenida y de remisión clínica sostenida fue de 0,96 (IC 95\%: 0,58-1) y de 0,83 (IC 95\%: 0,19-0,99), respectivamente. En cuanto a la seguridad, tres estudios observacionales que incluyeron a 78 pacientes tuvieron una tasa conjunta de eventos adversos globales de 0,08 (IC 95\%: 0,03-0,17). De la misma forma, se encontró una tasa conjunta de infecciones de 0,03 (IC 95\%: 0,01-0,08; 4 estudios, 140 pacientes) y una tasa conjunta de reacciones a la infusión de 0,03 (IC 95\%: 0,01-0,08; 4 estudios, 140 pacientes) (44). La calidad de la evidencia fue muy baja por la presencia de riesgo de sesgos.

\section{Evidencia clínica: eficacia/efectividad de ustekinumab para el tratamiento de colitis ulcerativa moderada a grave}

Un estudio reciente con ustekinumab, un antagonista de la subunidad p40, que comparten la IL-12 e IL-23, en pacientes con CU moderada a grave, encontró una tasa de remisión clínica a la semana 8 de $15,6 \%$ con una dosis intravenosa de $130 \mathrm{mg}$ y de $15,5 \%$ con una dosis intravenosa de $6 \mathrm{mg} / \mathrm{kg}$ comparada con una tasa de 5,3\% con placebo $(p<0,001$, para ambas comparaciones). El grupo de pacientes con respuesta clínica fue aleatorizado y el tratamiento se continuó con $90 \mathrm{mg}$ subcutáneos cada 12 semanas, cada 8 semanas o placebo, con lo que se logró una tasa de remisión clínica de $38,4 \%, 43,8 \%$ y $24,0 \%$, respectivamente
( $p=0,002$ y $p<0,001)$; de igual manera, se logró respuesta endoscópica en el $43,6 \%, 51,1 \%$ y $28,6 \%$, respectivamente $(p=0,002$ y $p<0,001)(45)$.

\section{Evidencia clínica: seguridad de agentes antagonistas del FNT- $\alpha$ e inhibidores de integrinas $\alpha 4 \beta 7$ para el tratamiento de colitis ulcerativa moderada a grave}

Se encontró una revisión sistemática puntaje AMSTAR 2, de calidad moderada (46), donde se evaluó el perfil de seguridad de medicamentos biológicos en pacientes con CU activa moderada a grave. Los desenlaces clínicos evaluados fueron cualquier evento adverso, eventos adversos serios, infección y reacción en el lugar de la infección, tanto en inducción como en mantenimiento.

En dos ensayos clínicos que involucraron a 849 pacientes, adalimumab en inducción no tuvo diferencias significativas comparado con placebo para cualquier efecto adverso (OR: 1,18; IC 95\%: 0,87-1,61) e infección (OR: 1,04; IC $95 \%: 0,71-1,53)$. Tuvo mayor posibilidad de reacción en el sitio de inyección respecto a placebo (OR: 2,16; IC 95\%: 1,01-4,62). Para el desenlace de eventos adversos serios, se obtuvo un OR de 0,48 (IC 95\%: 0,26-0,89). Para la terapia de mantenimiento proveniente de dos estudios con 790 pacientes, no tuvo diferencias significativas comparado con placebo para cualquier efecto adverso (OR: 1,33; IC 95\%: 0,65-2,71), evento adverso serio (OR: 1,10; IC 95\%: 0,731,67) e infección (OR: 1,23; IC 95\%: 0,31-1,65). Tuvo mayor posibilidad de reacción en el sitio de la inyección con respecto a placebo (OR: 3,27; IC 95\%: 1,77-6,02). La calidad de la evidencia fue moderada a baja por algunas limitaciones en la presencia de riesgo de sesgos e imprecisión.

Para golimumab en inducción se encontró un ensayo clínico comparado con placebo que incluyó a 732 pacientes. Este estudio no encontró diferencias significativas entre los dos grupos para el desenlace de cualquier evento adverso (OR: 1,05; IC 95\%: 0,78-1,41), reacción en el sitio de la inyección (OR: 2,52; IC 95\%: 0,9-7,02) e infección (OR: 0,96; IC 95\%: 0,61-1,51). El desenlace de eventos adversos serios tuvo un OR de 0,44 (IC 95\%: 0,21-0,92). Para la terapia de mantenimiento se encontró un ensayo clínico que incluyó a 464 pacientes. Este estudio no encontró diferencias significativas respecto a placebo para los desenlaces de cualquier evento adverso (OR: 1,42; IC 95\%: 0,932,15 ), reacción en el sitio de la inyección (OR: 1,35; IC 95\%: 0,75-2,41), infección (OR: 1,62; IC 95\%: 1,07-2,47) $y$ eventos adversos serios (OR: 1,54; IC 95\%: 0,77-3,06). La calidad de la evidencia fue moderada a baja por algunas limitaciones en la presencia de riesgo de sesgos, evidencia indirecta e imprecisión.

En cuanto a infliximab en mantenimiento se encontró un ensayo clínico comparado con placebo que incluyó a 242 
pacientes. No hubo diferencias significativas para los desenlaces de cualquier evento adverso (OR: 1,23; IC 95\%: 0,59-2,59), evento adverso serio (OR: 0,79; IC 95\%: 0,441,45), reacción en el sitio de la infección (OR: 0,91; IC 95\%: 0,4-2,1) e infección (OR: 1,23; IC 95\%: 0,73-2,05). La calidad de la evidencia fue baja por algunas limitaciones en la presencia de riesgo de sesgos e imprecisión.

Para el inhibidor de integrina $\alpha 4 \beta 7$, vedolizumab, se encontró un estudio con 374 pacientes bajo terapia de inducción. Vedolizumab no tuvo diferencias significativas respecto a placebo para los desenlaces de cualquier evento adverso (OR: 0,77; IC 95\%: 0,51-1,18), infección (OR: 0,92; IC 95\%: 0,51-1,67). Para el desenlace de eventos adversos serios, el OR fue de 0,32 (IC 95\%: 0,11-0,95). La calidad de la evidencia fue moderada a baja por algunas limitaciones en la presencia de riesgo de sesgos e imprecisión. En terapia de mantenimiento, se identificó un ensayo clínico que incluyó a 925 pacientes, donde vedolizumab frente a placebo no tuvo diferencias significativas para cualquier evento adverso (OR: 1,01; IC 95\%: 0,71-1,44), eventos adversos serios (OR: 0,91; IC 95\%: 0,6-1,69) e infección (OR: 1,15; IC 95\%: $0,87-1,54)$. La calidad de la evidencia fue baja por la presencia de riesgo de sesgos e imprecisión.

Esta misma revisión sistemática realizó comparaciones indirectas entre varios agentes biológicos para el tratamiento de los pacientes con CU moderada a grave. No hubo diferencias significativas cuando se comparó adalimumab versus golimumab en el desenlace de cualquier evento adverso, tanto en inducción como en mantenimiento (OR: 1,14; IC 95\%: 0,6-2,3; y OR: 0,94; IC 95\%: 0,94; IC 95\%: 0,29-2,95, respectivamente). Tampoco hubo diferencias significativas para eventos adversos serios (OR: 1,14; IC 95\%: 0,18-6,38 en inducción; OR: 0,73; IC 95\%: 0,27-1,3 en mantenimiento), reacción en el sitio de la inyección (OR: 0,88; IC 95\%: 0,14-6,26 en inducción; OR: 2,44; IC 95\%: 0,45-12,95 en mantenimiento) e infecciones (OR: 1,06; IC 95\%: 0,59-1,93; en inducción, OR: 0,76; IC 95\%: 0,33-1,69 en mantenimiento). Así mismo, tampoco se encontraron diferencias significativas al comparar adalimumab versus vedolizumab para los desenlaces de cualquier evento adverso (OR: 1,53; IC 95\%: 0,75-3,29 en inducción; OR: 1,30; IC 95\%: 0,43-4,14 en mantenimiento), eventos adversos serios (OR: 1,53; IC 95\%: 0,24-11,01 en inducción; OR: 1,20; IC 95\%: 0,55-2,7 en mantenimiento) e infecciones (OR: 1,13; IC 95\%: 0,56-2,2 en inducción; OR: 1,06; IC 95\%: 0,47-12,28 en mantenimiento).

Cuando se comparó adalimumab versus infliximab para terapia de mantenimiento, no se encontraron diferencias significativas para cualquier evento adverso (OR: 1,07; IC 95\%: 0,28-3,91), eventos adversos serios (OR: 1,40; IC 95\%: 0,56-3,47), reacción en el sitio de la infección (OR:
3,60; IC 95\%: 0,57-24,17) e infección (OR: 1,00; IC 95\%: $0,41-2,37)$.

Ahora bien, para la comparación entre golimumab y vedolizumab tampoco se encontraron diferencias significativas para cualquier evento adverso (OR: 1,33; IC 95\%: 0,61-2,92 en inducción; OR: 1,39; IC 95\%: 0,39-5,24 en mantenimiento), eventos adversos serios (OR: 1,37; IC 95\%: 0,17-12,69 en inducción; OR: 1,39; IC 95\%: 0,395,24 en mantenimiento), e infecciones (OR: 1,07; IC 95\%: 0,49-2,2 en inducción; OR: 1,40; IC 95\%: 0,58-3,44 en mantenimiento). Cuando se comparó golimumab versus infliximab para terapia de mantenimiento, no se encontraron diferencias significativas para cualquier evento adverso (OR: 1,16; IC 95\%: 0,27-4,75), eventos adversos serios (OR: 1,90; IC 95\%: 0,65-5,79) e infección (OR: 1,47; IC 95\%: 0,17-12.41).

Por último, cuando se comparó infliximab versus vedolizumab para mantenimiento, tampoco se obtuvieron diferencias significativas en cualquier evento adverso (OR: 1,22; IC 95\%: 0,3-5,36), eventos adversos serios (OR: 0,87; IC 95\%: 0,33-2,29) e infección (OR: 1,07; IC 95\%: $0,41-2,7)(46)$.

Todas las comparaciones indirectas tuvieron una calidad de la evidencia baja por la presencia de riesgo de sesgos, evidencia indirecta e imprecisión.

\section{Evidencia clínica: calidad de vida en el tratamiento con agentes antagonistas del FNT- $\alpha$ e inhibidor de integrina $\alpha 4 \beta 7$ en pacientes con colitis ulcerativa moderada a grave}

Se encontró una revisión sistemática y puntaje AMSTAR, de calidad moderada (47), donde se comparó el impacto de las intervenciones para CU moderada a grave sobre la calidad de vida relacionada con la salud. Los desenlaces incluyeron el cambio en los puntajes de calidad de vida y la proporción de pacientes con mejoría en la calidad de vida.

Esta revisión sistemática realizó comparaciones indirectas entre varios agentes biológicos para el tratamiento de los pacientes con CU moderada a grave. Se encontró que, comparado con placebo, infliximab (MD: 18,58; IC 95\%: 13,19-23,97) y vedolizumab (MD: 18,00; IC 95\%: 11,0824,92 ) alcanzaron una mayor mejoría en el puntaje medio del IBDQ (Inflammatory Bowel Disease Questionnaire), seguidos de golimumab (MD: 10,97; IC 95\%: 5,9416,00) y adalimumab (MD: 9,00; IC 95\%: 2,65-15,35). Comparada cada intervención entre sí, infliximab fue superior a adalimumab (MD: 9.58; IC 95\%: 1,25-17,91) y golimumab (MD: 7,61; IC 95\%: 0,24-14,99).

De igual forma, todas las intervenciones estuvieron asociadas a una mayor proporción de pacientes con un incre- 
mento clínicamente significativo en el puntaje del IBDQ de al menos 16 puntos desde la línea de base comparadas con placebo (infliximab: OR: 2,35; IC 95\%: 1,62-3,41; vedolizumab: OR: 1,98; IC 95\%: 1,34-3,16; adalimumab: OR: 1,38; IC 95\%: 1,07-1,79). No obstante, no se encontraron diferencias significativas para la comparación adalimumab versus vedolizumab (OR: 0,70; IC 95\%: 0,41$1,19)(47)$. La calidad de la evidencia fue moderada a muy baja por problemas de imprecisión, evidencia indirecta y sesgo de reporte.

\begin{tabular}{|c|c|}
\hline $\begin{array}{l}\text { Factores que } \\
\text { pueden fortalecer } \\
\text { una recomendación }\end{array}$ & Comentario \\
\hline $\begin{array}{l}\text { Calidad de la } \\
\text { evidencia }\end{array}$ & $\begin{array}{l}\text { La calidad de la evidencia fue baja por la } \\
\text { evidencia indirecta y el riesgo de sesgos. }\end{array}$ \\
\hline $\begin{array}{l}\text { Balance entre los } \\
\text { efectos deseables e } \\
\text { indeseables }\end{array}$ & $\begin{array}{l}\text { El panel consideró la seguridad de la terapia } \\
\text { biológica y el beneficio para pacientes teniendo } \\
\text { en cuenta la gravedad y la falla terapéutica. El } \\
\text { panel expresa la necesidad de monitorizar los } \\
\text { niveles de los medicamentos y de anti-FNT con } \\
\text { el fin de ajustar la terapia. }\end{array}$ \\
\hline $\begin{array}{l}\text { Valores y } \\
\text { preferencias }\end{array}$ & $\begin{array}{l}\text { El paciente invitado al panel expresó que la } \\
\text { terapia biológica fue una buena alternativa dada } \\
\text { la falla terapéutica que presentó con la primera } \\
\text { línea de tratamiento. Hasta el momento no ha } \\
\text { presentado síntomas o eventos adversos. }\end{array}$ \\
\hline $\begin{array}{l}\text { Costos (asignación } \\
\text { de recursos) }\end{array}$ & $\begin{array}{l}\text { El tratamiento con terapia biológica implica } \\
\text { altos costos para el sistema de salud. El panel } \\
\text { propone su uso como terapia de segunda línea, } \\
\text { así como el uso de biosimilares como una } \\
\text { alternativa igual de eficaz y segura. }\end{array}$ \\
\hline $\begin{array}{l}\text { Aceptabilidad y } \\
\text { viabilidad }\end{array}$ & $\begin{array}{l}\text { Esta terapia puede tener dificultades de acceso } \\
\text { debido a la falta de recursos de las áreas } \\
\text { remotas. }\end{array}$ \\
\hline
\end{tabular}

Dirección n. Resumen

Fuerte a favor

15 Se recomienda el uso de antagonistas del factor de necrosis tumoral alfa (FNT-a) (infliximab, adalimumab y golimumab), inhibidor de integrina a4ß7 (vedolizumab) e inhibidor de IL-12 e IL-23 (ustekinumab) en pacientes con colitis ulcerativa moderada a grave para la inducción y el mantenimiento de la remisión clínica y la cicatrización de la mucosa.

Calidad de evidencia baja $\oplus \oplus 00$

Punto de buena $\sqrt{ }$ En pacientes con falla previa a los anti-FNT práctica
Punto de buena $\sqrt{ }$ En caso de no respuesta inicial, pérdida práctica de respuesta o no tolerancia a un primer biológico, se sugiere utilizar un segundo biológico con diferente mecanismo de acción. Si se presenta pérdida de respuesta a un anti-FNT, se recomienda medir los niveles del medicamento (infliximab, adalimumab, golimumab) y anticuerpos anti-FNT. Si los niveles del medicamento están por debajo del rango terapéutico y no hay anticuerpos contra él, se recomienda aumentar la dosis o acortar los intervalos. Si los niveles están en el rango terapéutico, se recomienda cambiar a otro biológico con diferente mecanismo de acción.

Fuerte a favor

16 Se recomienda el uso del biosimilar del agente antagonista del FNT-a infliximab en pacientes con colitis ulcerativa moderada a grave para la inducción y el mantenimiento de la remisión clínica y la cicatrización de la mucosa. Calidad de evidencia baja $\oplus \oplus \circ \bigcirc$

Punto de buena $\sqrt{ }$ No se debe realizar intercambio entre el práctica innovador y el biosimilar en caso de falla terapéutica inicial de uno de ellos.

Punto de buena $\quad \sqrt{ }$ En caso de realizarse intercambio no médico práctica entre un biológico innovador con un biosimilar, debe informarse al médico tratante para farmacovigilancia y debe tener consentimiento por parte del paciente.

Punto de buena $\sqrt{ }$ Los pacientes mayores de 65 años en práctica tratamiento con anti-FNT tienen mayor riesgo de infección. Los pacientes con colitis ulcerativa mayores de 65 años tienen mayor riesgo de linfoma con el uso de tiopurinas.

Punto de buena $\sqrt{ }$ En pacientes masculinos menores de 35 años práctica no se recomienda el uso de terapia combinada anti-FNT con tiopurinas por el riesgo de linfoma hepatoesplénico, lo mismo en pacientes con historia de malignidad. En estos casos debe usarse monoterapia con anti-FNT.

\section{¿CUÁL ES LA EFICACIA DE LA TAMIZACIÓN Y DE LA VIGILANCIA COLONOSCÓPICA PARA LA DETECCIÓN DE CÁNCER COLORRECTAL EN PACIENTES CON COLITIS ULCERATIVA?}

Una revisión sistemática puntaje AMSTAR II, de calidad alta, evaluó la efectividad de las estrategias para la detección colonoscópica de cáncer colorrectal (CCR) en pacientes con enfermedad inflamatoria intestinal (incluidos los pacientes con $\mathrm{CU}$ ) con el fin de realizar el diagnóstico y la vigilancia de CCR y reducir la mortalidad asociada. Se identificaron 5 estudios observacionales con 7199 pacientes con enfermedad inflamatoria intestinal (EII). 
Tres estudios encontraron una tasa alta de detección de cáncer en los pacientes que se sometieron a vigilancia comparados con quienes no fueron vigilados. El CCR fue detectado en $1,83 \%$ de los pacientes no vigilados comparado con el 3,17\% de los pacientes vigilados (OR: 0,58; IC 95\%: 0,42-0,80). En términos de tasa de mortalidad asociada a CCR, el $8 \%$ de los pacientes vigilados murió de CCR y el $22 \%$ lo hizo en el grupo de pacientes no vigilados (OR: 0,36; IC 95\%: 0,19-0,69). Dos estudios reportaron una mayor tasa de detección de CCR en estadios tempranos en pacientes vigilados $(16 \%)$ que en los no vigilados (8\%) (OR: 5,40; IC 95\%: (1,51-19,30), siendo esta diferencia significativa $(p=0,009)$. Una mayor tasa de CCR en estadios avanzados fue reportada en pacientes no vigilados comparada con la de pacientes vigilados (OR: 0,46; IC 95\%: 0,08-2,51), aunque el hallazgo no es estadísticamente significativo (49). La calidad de la evidencia es muy baja por el alto riesgo de sesgo, la heterogeneidad y la inconsistencia.

Una revisión sistemática puntaje AMSTAR II, de calidad baja, evaluó la eficacia comparativa de las diferentes técnicas de detección de displasia en pacientes con CU. Se incluyeron 8 ensayos clínicos aleatorizados con 924 pacientes, donde se evaluó la vigilancia colonoscópica con endoscopia de luz blanca estándar (ELBE), endoscopia de luz blanca de alta definición (ELBAD), endoscopia de imágenes de banda estrecha (NBI) y cromoendoscopia con tinción.

Los resultados mostraron que la cromoendoscopia versus la ELBE y ELBAD, en comparaciones directas, fue más efectiva para la detección de cualquier displasia $(p<0,05)$. No se encontraron diferencias significativas entre las otras diferentes técnicas de endoscopia para la detección de displasia $(p>0,05)$. A continuación, se presentan los estimadores para cada una de las comparaciones.

\begin{tabular}{|c|c|c|}
\hline Detección de cualquier neoplasia & $\begin{array}{c}\text { Efecto de } \\
\text { comparaciones } \\
\text { directas }\end{array}$ & Estudios \\
\hline $\begin{array}{l}\text { Cromoendoscopia vs. endoscopia de } \\
\text { luz blanca estándar }\end{array}$ & $\begin{array}{c}\text { OR: } 4,37 ; \text { IC } 95 \%: \\
1,97-9,68\end{array}$ & $\begin{array}{c}1 \text { estudio } \\
(165 \\
\text { pacientes) }\end{array}$ \\
\hline $\begin{array}{l}\text { Endoscopia con NBI vs. endoscopia } \\
\text { de luz blanca estándar }\end{array}$ & $\begin{array}{l}\text { OR: } 0,68 ; \text { IC } 95 \%: \\
\quad 0,20-2,30\end{array}$ & $\begin{array}{c}1 \text { estudio } \\
\text { (42 } \\
\text { pacientes) }\end{array}$ \\
\hline $\begin{array}{l}\text { Cromoendoscopia vs. endoscopia de } \\
\text { luz blanca de alta definición }\end{array}$ & $\begin{array}{c}\text { OR: } 3,05 \text {; IC } 95 \% \text { : } \\
\quad 1,07-8,71\end{array}$ & $\begin{array}{l}1 \text { estudio } \\
\text { (103 } \\
\text { pacientes) }\end{array}$ \\
\hline $\begin{array}{l}\text { Endoscopia con NBI vs. endoscopia } \\
\text { de luz blanca de alta definición }\end{array}$ & $\begin{array}{c}\text { OR: } 1,09 ; \text { IC } 95 \% \text { : } \\
\quad 0,46-2,58\end{array}$ & $\begin{array}{l}2 \text { estudios } \\
(160 \\
\text { pacientes })\end{array}$ \\
\hline $\begin{array}{l}\text { Cromoendoscopia vs. endoscopia } \\
\text { con NBI }\end{array}$ & $\begin{array}{c}\text { OR: } 0,95 ; \text { IC } 95 \% \text { : } \\
\quad 0,56-1,63\end{array}$ & $\begin{array}{l}3 \text { estudios } \\
(454 \\
\text { pacientes })\end{array}$ \\
\hline
\end{tabular}

En cuanto a la detección de neoplasias avanzadas, ninguna de las técnicas de vigilancia endoscópica mostró superioridad sobre las otras en comparaciones directas $(p>0,05)$. Al realizar las comparaciones indirectas, ninguna de las técnicas mostró superioridad $(p>0,05)$. El uso de cromoendoscopia comparado con el uso de ELBE (OR: 1,96; IC 95\%: 0,72-5,34), NBI (OR: 1,41; IC 95\%: 0,72,84) y ELBAD (OR: 2,37; IC 95\%: 0,81-6,94) no mostró diferencias significativas en la detección de cualquier displasia (50). La calidad de la evidencia es baja por riesgo de sesgo e imprecisión.

\begin{tabular}{|c|c|}
\hline $\begin{array}{l}\text { Factores que } \\
\text { pueden fortalecer } \\
\text { una recomendación }\end{array}$ & Comentario \\
\hline $\begin{array}{l}\text { Calidad de la } \\
\text { evidencia }\end{array}$ & $\begin{array}{l}\text { La calidad de la evidencia es de baja calidad } \\
\text { por riesgo de sesgo e imprecisión. }\end{array}$ \\
\hline $\begin{array}{l}\text { Balance entre los } \\
\text { efectos deseables } \\
\text { e indeseables }\end{array}$ & $\begin{array}{l}\text { El panel consideró que los beneficios son mayores } \\
\text { a los riesgos dado que la endoscopia tiene una } \\
\text { muy baja tasa de complicaciones y la detección de } \\
\text { cáncer de colon en estadios tempranos aumentará } \\
\text { la sobrevida de los pacientes. }\end{array}$ \\
\hline $\begin{array}{l}\text { Valores y } \\
\text { preferencias }\end{array}$ & $\begin{array}{l}\text { La evidencia proveniente de revisiones } \\
\text { sistemáticas reporta que los pacientes } \\
\text { consideran que deben tener comunicación } \\
\text { constante con los clínicos y recibir respuesta } \\
\text { oportuna a las preguntas (Bewer, 2013). }\end{array}$ \\
\hline $\begin{array}{l}\text { Costos (asignación } \\
\text { de recursos) }\end{array}$ & $\begin{array}{l}\text { La endoscopia se encuentra en el plan de } \\
\text { beneficios, así como en los programas de } \\
\text { vigilancia de cáncer de colon. }\end{array}$ \\
\hline $\begin{array}{l}\text { Aceptabilidad y } \\
\text { viabilidad }\end{array}$ & $\begin{array}{l}\text { La vigilancia colonoscópica es aceptada y de } \\
\text { fácil acceso por los pacientes y el personal } \\
\text { de salud. Se requiere disponibilidad de las } \\
\text { tinciones apropiadas de acuerdo con el tipo de } \\
\text { tecnología disponible. El índigo carmín no tiene } \\
\text { indicación INVIMA para uso en medicina y la } \\
\text { endoscopia con NBI se encuentra en pocos } \\
\text { sitios en Colombia. }\end{array}$ \\
\hline
\end{tabular}
Dirección
Resumen

Fuerte a favor 17 Se recomienda la vigilancia endoscópica en pacientes diagnosticados con colitis ulcerativa (siguiendo los criterios de calidad de la colonoscopia en enfermedad inflamatoria intestinal), para la detección temprana de lesiones malignas o premalignas y para reducir la incidencia y la mortalidad por cáncer colorrectal. Calidad de evidencia baja $\oplus \oplus 00$

Fuerte a favor 18 Se recomienda que se realice preferiblemente la vigilancia endoscópica con cromoendoscopia con tinción y biopsias dirigidas en pacientes adultos diagnosticados con colitis ulcerativa. Calidad de evidencia baja $\oplus \oplus 00$ 


\begin{tabular}{|c|c|c|}
\hline $\begin{array}{l}\text { Punto de } \\
\text { buena } \\
\text { práctica }\end{array}$ & $\sqrt{ }$ & $\begin{array}{l}\text { Si se dispone de cromoendoscopia digital y se } \\
\text { cuenta con experiencia en la identificación de } \\
\text { las lesiones, esta puede ser una opción para } \\
\text { tomar biopsias dirigidas. }\end{array}$ \\
\hline $\begin{array}{l}\text { Punto de } \\
\text { buena } \\
\text { práctica }\end{array}$ & $\sqrt{ }$ & $\begin{array}{l}\text { En caso de no contar con la experiencia con } \\
\text { cromoendoscopia con tinción o endoscopias } \\
\text { con cromoendoscopia digital, se deberán tomar } \\
\text { biopsias en los } 4 \text { cuadrantes cada } 10 \mathrm{~cm} \text {, desde } \\
\text { el colon ascendente hasta el colon descendente, } \\
\text { y cada } 5 \mathrm{~cm} \text {, en el sigmoides y el recto. }\end{array}$ \\
\hline $\begin{array}{l}\text { Punto de } \\
\text { buena } \\
\text { práctica }\end{array}$ & $\sqrt{ }$ & $\begin{array}{l}\text { Debe realizarse colonoscopia después de } 8 \\
\text { años del diagnóstico de colitis ulcerativa con } \\
\text { cromoendoscopia y biopsias dirigidas de áreas } \\
\text { anormales. Es preferible que el paciente se } \\
\text { encuentre en remisión clínica. }\end{array}$ \\
\hline $\begin{array}{l}\text { Punto de } \\
\text { buena } \\
\text { práctica }\end{array}$ & $\sqrt{ }$ & $\begin{array}{l}\text { En todo paciente, independientemente de } \\
\text { la edad de inicio de la enfermedad, se debe } \\
\text { determinar el riesgo individual. En pacientes } \\
\text { de bajo riesgo, definido como colitis ulcerativa } \\
\text { sin actividad endoscópica, el seguimiento } \\
\text { endoscópico se realiza cada } 3 \text { años. }\end{array}$ \\
\hline $\begin{array}{l}\text { Punto de } \\
\text { buena } \\
\text { práctica }\end{array}$ & $\sqrt{ }$ & $\begin{array}{l}\text { En pacientes en riesgo moderado, definido } \\
\text { como colitis extensa con actividad endoscópica } \\
\text { leve o con antecedente de cáncer de colon en } \\
\text { familiar de primer grado mayor de } 50 \text { años, } \\
\text { debe realizarse seguimiento endoscópico entre } \\
1 \text { y } 3 \text { años. }\end{array}$ \\
\hline $\begin{array}{l}\text { Punto de } \\
\text { buena } \\
\text { práctica }\end{array}$ & $\sqrt{ }$ & $\begin{array}{l}\text { En pacientes de alto riesgo, definido como } \\
\text { colitis extensa, con actividad endoscópica } \\
\text { moderada o grave, o con antecedente de } \\
\text { estenosis o displasia en los } 5 \text { años previos, o } \\
\text { historia familiar de cáncer de colon en familiares } \\
\text { de primer grado menores de } 50 \text { años, o con } \\
\text { antecedente de colangitis esclerosante primaria, } \\
\text { debe realizarse anualmente. }\end{array}$ \\
\hline
\end{tabular}

\section{RESUMEN DE LAS RECOMENDACIONES}

¿Cuál es la escala más útil para establecer la actividad de colitis ulcerativa en pacientes diagnosticados?

\begin{tabular}{|c|c|c|}
\hline Dirección & n..$^{\circ}$ & Resumen \\
\hline Fuerte a favor & 1 & $\begin{array}{l}\text { Se recomienda que la actividad de colitis } \\
\text { ulcerativa se determine mediante la utilización } \\
\text { del Índice de actividad de colitis ulcerativa } \\
\text { desarrollado por el Colegio Americano de } \\
\text { Gastroenterología. } \\
\text { Calidad de evidencia muy baja } \oplus \oplus \bigcirc \bigcirc \\
\text { (opinión de expertos) }\end{array}$ \\
\hline
\end{tabular}

¿Cuál es el tratamiento más efectivo y seguro para inducir y mantener la remisión de los pacientes mayores de 16 años con colitis ulcerativa de acuerdo con su extensión y gravedad?

\section{Dirección $\quad$ n. $^{\circ} \quad$ Resumen}

Objetivos del tratamiento

Fuerte a favor 2 Se recomienda que el objetivo del tratamiento sea la remisión clínica y la cicatrización mucosa (remisión profunda y sostenida); esta última se asocia a una menor tasa de colectomía y menor riesgo de displasia y cáncer colorrectal. Calidad de evidencia muy baja $\oplus$ $\bigcirc ०$ ०

Punto de $\quad \sqrt{ } \quad$ La selección del tratamiento de colitis ulcerativa buena debe estar basada en la extensión, la gravedad práctica y de acuerdo con el pronóstico individual de cada paciente.

Punto de $\quad \sqrt{ }$ Se consideran factores de mal pronóstico en buena colitis ulcerativa, para ayudar a orientar el práctica tratamiento, los pacientes que presenten los siguientes factores de riesgo:

- edad <30 años;

- compromiso endoscópico grave;

- colitis extensa;

- hospitalización por actividad de colitis;

- PCR elevada;

- albúmina baja;

- uso de esteroides al inicio de la enfermedad;

- colangitis esclerosante asociada;

- infección por Clostridium/citomegalovirus.

Inducción de remisión

Fuerte a favor 3 Se recomienda el uso de mesalazina como primera elección para la inducción de la remisión en pacientes con colitis ulcerativa leve a moderada en dosis estándar (2 a $3 \mathrm{~g} / \mathrm{d}$ ). Calidad de evidencia moderada $\oplus \oplus \oplus \mathrm{O}$

Fuerte a favor 4 En pacientes con colitis ulcerativa leve a moderada izquierda o extensa se recomienda la combinación de mesalazina tópica y oral para la inducción de la remisión.

Calidad de evidencia muy baja $\oplus$ $\oplus$ ○०

Fuerte a favor 5 En pacientes con proctitis ulcerativa se recomienda el manejo con ASA tópico rectal. Calidad de evidencia muy baja $\oplus$ $\bigcirc 00$

Fuerte a favor 6 Se recomienda el uso de glucocorticoides como terapia de primera línea para inducir la remisión en pacientes con colitis ulcerativa activa moderada a grave de cualquier extensión. Calidad de evidencia muy baja $\oplus$ $\bigcirc$ ० 


\begin{tabular}{|c|c|c|}
\hline Fuerte a favor & 7 & $\begin{array}{l}\text { Se recomienda el uso de budesonida MMX o } \\
\text { prednisona oral para la inducción de la remisión } \\
\text { en pacientes con colitis ulcerativa con actividad } \\
\text { leve a moderada, que no respondan a las dosis } \\
\text { apropiadas de } 5 \text {-ASA oral más } 5 \text {-ASA tópico. } \\
\text { Calidad de evidencia muy baja } \oplus \text { OO० }\end{array}$ \\
\hline $\begin{array}{l}\text { Punto de } \\
\text { buena } \\
\text { práctica }\end{array}$ & $\sqrt{ }$ & $\begin{array}{l}\text { La dosis sugerida de inducción de budesonida } \\
\text { MMX es de } 9 \mathrm{mg} / \mathrm{d} \text { por } 8 \text { semanas. }\end{array}$ \\
\hline $\begin{array}{l}\text { Fuerte en } \\
\text { contra }\end{array}$ & 8 & $\begin{array}{l}\text { No se recomienda el uso de azatioprina para } \\
\text { inducir la remisión en pacientes con colitis } \\
\text { ulcerativa leve a moderada. } \\
\text { Calidad de evidencia muy baja } \oplus \text { ○০০ }\end{array}$ \\
\hline \multicolumn{3}{|c|}{ Mantenimiento de la remisión } \\
\hline Fuerte a favor & 9 & $\begin{array}{l}\text { Se recomienda el uso de inmunosupresores } \\
\text { tiopurínicos para mantener en remisión a los } \\
\text { pacientes con colitis ulcerativa dependiente de } \\
\text { esteroides. } \\
\text { Calidad de evidencia muy baja } \oplus \text { ○০০ }\end{array}$ \\
\hline Fuerte a favor & 10 & $\begin{array}{l}\text { Se recomienda el uso de 6-mercaptopurina } \\
\text { para mantener en remisión a los pacientes con } \\
\text { colitis ulcerativa que presentan intolerancia a la } \\
\text { administración de azatioprina. } \\
\text { Calidad de evidencia muy baja } \oplus \text { O०० }\end{array}$ \\
\hline $\begin{array}{l}\text { Condicional a } \\
\text { favor }\end{array}$ & 11 & $\begin{array}{l}\text { Se sugiere el uso de VSL\#3 (probiótico) para } \\
\text { inducir la remisión en los pacientes con colitis } \\
\text { ulcerativa activa leve a moderada, como terapia } \\
\text { adjunta al tratamiento con } 5 \text {-ASA y esteroides. } \\
\text { Calidad de evidencia muy baja } \oplus \text { OO० }\end{array}$ \\
\hline $\begin{array}{l}\text { Fuerte en } \\
\text { contra }\end{array}$ & 12 & $\begin{array}{l}\text { No se recomienda el uso de probióticos como } \\
\text { terapia de mantenimiento de la remisión en } \\
\text { pacientes con colitis ulcerativa. } \\
\text { Calidad de evidencia muy baja } \oplus \text { O০০ }\end{array}$ \\
\hline
\end{tabular}

¿Cuál es la efectividad y la seguridad del uso de otras alternativas terapéuticas para el tratamiento de los pacientes con colitis ulcerativa moderada a grave?

\section{Dirección $\quad$ n. $^{\circ} \quad$ Resumen}

Colitis ulcerativa moderada a severa

Condicional a 13 Se sugiere el uso de tofacitinib para inducir y favor mantener la remisión en pacientes con colitis ulcerativa moderada a grave, no respondedores $o$ intolerantes a anti-FNT.

Calidad de evidencia muy baja $\oplus$ O००

Punto de $\quad \sqrt{ }$ Los pacientes con colitis ulcerativa que usan buena tofacitinib deben tener monitorización del perfil práctica lipídico y recibir vacunación previa contra herpes zóster.

\begin{tabular}{|c|c|c|}
\hline $\begin{array}{l}\text { Punto de } \\
\text { buena } \\
\text { práctica }\end{array}$ & $\sqrt{ }$ & $\begin{array}{l}\text { Los pacientes refractarios al tratamiento o en } \\
\text { quienes no sea posible obtener remisión deben } \\
\text { ser remitidos a centros especializados en el } \\
\text { manejo de pacientes con colitis ulcerativa. }\end{array}$ \\
\hline \multirow[t]{2}{*}{$\begin{array}{l}\text { Punto de } \\
\text { buena } \\
\text { práctica }\end{array}$} & $\sqrt{ }$ & $\begin{array}{l}\text { En julio de } 2019 \text {, la FDA recomendó utilizar } \\
\text { tofacitinib con precaución en pacientes con } \\
\text { factores de riesgo de tromboembolismo } \\
\text { venoso (mayores de } 65 \text { años, antecedente } \\
\text { previo de trombosis, inmovilizados, trastornos } \\
\text { de la coagulación, malignidad, infarto de } \\
\text { miocardio, tabaquismo, hipertensión arterial, } \\
\text { diabetes mellitus, } \mathrm{HDL}<40 \mathrm{mg} / \mathrm{dL} \text {, enfermedad } \\
\text { coronaria, falla cardiaca, uso de anticonceptivos } \\
\text { o terapia de remplazo hormonal), debido a } \\
\text { que se encontró un riesgo incrementado de } \\
\text { trombosis en un estudio en artritis reumatoide } \\
\text { con la dosis de } 10 \text { mg cada } 12 \mathrm{~h} \text {. Por lo } \\
\text { anterior, en pacientes con CU, el tratamiento } \\
\text { de inducción con la dosis de } 10 \text { mg cada } 12 \\
\text { h no debe darse por más de } 16 \text { semanas, y } \\
\text { en caso de respuesta, continuar la dosis de } \\
\text { mantenimiento de } 5 \text { mg cada } 12 \mathrm{~h} \text {. En caso de } \\
\text { sospecha clínica de tromboembolismo venoso, } \\
\text { debe suspenderse inmediatamente el tofacitinib. }\end{array}$ \\
\hline & & $\begin{array}{l}\text { No existe suficiente evidencia que permita } \\
\text { recomendar o no el uso de la cúrcuma o del } \\
\text { cannabis en pacientes con colitis ulcerativa } \\
\text { activa. }\end{array}$ \\
\hline $\begin{array}{l}\text { Condicional a } \\
\text { favor }\end{array}$ & 14 & $\begin{array}{l}\text { Se sugiere el trasplante de microbiota de } \\
\text { materia fecal para el tratamiento de la colitis } \\
\text { ulcerativa moderada a grave refractaria a } \\
\text { tratamiento médico. } \\
\text { Calidad de evidencia baja } \oplus \oplus \text { O० }\end{array}$ \\
\hline $\begin{array}{l}\text { Punto de } \\
\text { buena } \\
\text { práctica }\end{array}$ & $\sqrt{ }$ & $\begin{array}{l}\text { El trasplante de materia fecal debe hacerse en } \\
\text { centros especializados con experiencia en este } \\
\text { procedimiento. }\end{array}$ \\
\hline
\end{tabular}

¿Cuál es la efectividad y la seguridad de la terapia biológica para el tratamiento de los pacientes con colitis ulcerativa moderada a grave?

\section{Dirección $\quad n^{0} \quad$ Resumen}

Fuerte a favor 15 Se recomienda el uso de antagonistas del factor de necrosis tumoral alfa (FNT-a) (infliximab, adalimumab y golimumab), inhibidor de integrina a4 $\beta 7$ (vedolizumab) e inhibidor de IL-12 e IL-23 (ustekinumab) en pacientes con colitis ulcerativa moderada a grave para la inducción y el mantenimiento de la remisión clínica y la cicatrización de la mucosa. Calidad de evidencia baja $\oplus \oplus \circ \bigcirc$ 


\begin{tabular}{|c|c|c|}
\hline $\begin{array}{l}\text { Punto de } \\
\text { buena } \\
\text { práctica }\end{array}$ & $\sqrt{ }$ & $\begin{array}{l}\text { En pacientes con falla previa a los anti-FNT } \\
\text { se sugiere utilizar ustekinumab o tofacitinib. } \\
\text { Vedolizumab tiene el riesgo más bajo de } \\
\text { infección entre los biológicos. }\end{array}$ \\
\hline $\begin{array}{l}\text { Punto de } \\
\text { buena } \\
\text { práctica }\end{array}$ & $\sqrt{ }$ & $\begin{array}{l}\text { En caso de no respuesta inicial, pérdida } \\
\text { de respuesta o no tolerancia a un primer } \\
\text { biológico, se sugiere utilizar un segundo } \\
\text { biológico con diferente mecanismo de acción. } \\
\text { Si se presenta pérdida de respuesta a un } \\
\text { anti-TNF, se recomienda medir los niveles } \\
\text { del medicamento (infliximab, adalimumab, } \\
\text { golimumab) y anticuerpos anti-TNF. Si los } \\
\text { niveles del medicamento están por debajo del } \\
\text { rango terapéutico y no hay anticuerpos contra } \\
\text { él, se recomienda aumentar la dosis o acortar } \\
\text { los intervalos. Si los niveles están en el rango } \\
\text { terapéutico, se recomienda cambiar a otro } \\
\text { biológico con diferente mecanismo de acción. }\end{array}$ \\
\hline Fuerte a favor & 16 & $\begin{array}{l}\text { Se recomienda el uso del biosimilar del agente } \\
\text { antagonista del FNT-a infliximab en pacientes } \\
\text { con colitis ulcerativa moderada a grave para } \\
\text { la inducción y el mantenimiento de la remisión } \\
\text { clínica y la cicatrización de la mucosa. } \\
\text { Calidad de evidencia baja } \oplus \oplus \bigcirc \bigcirc\end{array}$ \\
\hline $\begin{array}{l}\text { Punto de } \\
\text { buena } \\
\text { práctica }\end{array}$ & $\sqrt{ }$ & $\begin{array}{l}\text { No se debe realizar el intercambio entre el } \\
\text { innovador y el biosimilar en caso de falla } \\
\text { terapéutica inicial de uno de ellos. }\end{array}$ \\
\hline $\begin{array}{l}\text { Punto de } \\
\text { buena } \\
\text { práctica }\end{array}$ & $\sqrt{ }$ & $\begin{array}{l}\text { En caso de realizarse intercambio no médico } \\
\text { entre un biológico innovador con un biosimilar, } \\
\text { debe informarse al médico tratante para } \\
\text { farmacovigilancia y debe tener consentimiento } \\
\text { por parte del paciente. }\end{array}$ \\
\hline $\begin{array}{l}\text { Punto de } \\
\text { buena } \\
\text { práctica }\end{array}$ & $\sqrt{ }$ & $\begin{array}{l}\text { Los pacientes mayores de } 65 \text { años en } \\
\text { tratamiento con anti-FNT tienen mayor riesgo } \\
\text { de infección. Los pacientes con colitis ulcerativa } \\
\text { mayores de } 65 \text { años tienen mayor riesgo de } \\
\text { linfoma con el uso de tiopurinas. }\end{array}$ \\
\hline $\begin{array}{l}\text { Punto de } \\
\text { buena } \\
\text { práctica }\end{array}$ & $\sqrt{ }$ & $\begin{array}{l}\text { En pacientes masculinos menores de } 35 \text { años } \\
\text { no se recomienda el uso de terapia combinada } \\
\text { anti-FNT con tiopurinas por el riesgo de linfoma } \\
\text { hepatoesplénico, lo mismo en pacientes con } \\
\text { historia de malignidad. En estos casos debe } \\
\text { usarse monoterapia con anti-FNT. }\end{array}$ \\
\hline
\end{tabular}

\section{¿Cuál es la eficacia de la tamización y la vigilancia colonoscópica para la detección de cáncer colorrectal en pacientes con colitis ulcerativa?}

\section{Dirección $\quad n^{\circ} \quad$ Resumen}

Fuerte a favor 17 Se recomienda la vigilancia endoscópica en pacientes diagnosticados con colitis ulcerativa (siguiendo los criterios de calidad de la colonoscopia en enfermedad inflamatoria intestinal) para la detección temprana de lesiones malignas o premalignas y para reducir la incidencia y la mortalidad por cáncer colorrectal. Calidad de evidencia baja $\oplus \oplus \circ \mathrm{O}$

Fuerte a favor 18 Se recomienda que se realice preferiblemente la vigilancia endoscópica con cromoendoscopia con tinción y biopsias dirigidas en pacientes adultos diagnosticados con colitis ulcerativa. Calidad de evidencia baja $\oplus \oplus 00$

\begin{tabular}{|c|c|c|}
\hline $\begin{array}{l}\text { Punto de } \\
\text { buena } \\
\text { práctica }\end{array}$ & $\sqrt{ }$ & $\begin{array}{l}\text { Si se dispone de cromoendoscopia digital y se } \\
\text { cuenta con experiencia en la identificación de } \\
\text { las lesiones, esta puede ser una opción para } \\
\text { tomar biopsias dirigidas. }\end{array}$ \\
\hline $\begin{array}{l}\text { Punto de } \\
\text { buena } \\
\text { práctica }\end{array}$ & $\sqrt{ }$ & $\begin{array}{l}\text { En caso de no contar con la experiencia con } \\
\text { cromoendoscopia con tinción o endoscopias } \\
\text { con cromoendoscopia digital, se deberán tomar } \\
\text { biopsias en los } 4 \text { cuadrantes cada } 10 \mathrm{~cm} \text {, desde } \\
\text { el colon ascendente hasta el colon descendente, } \\
\text { y cada } 5 \mathrm{~cm} \text {, en el sigmoide y recto. }\end{array}$ \\
\hline $\begin{array}{l}\text { Punto de } \\
\text { buena } \\
\text { práctica }\end{array}$ & $\sqrt{ }$ & $\begin{array}{l}\text { Debe realizarse colonoscopia después de } 8 \\
\text { años del diagnóstico de colitis ulcerativa con } \\
\text { cromoendoscopia y biopsias dirigidas de áreas } \\
\text { anormales. Es preferible que el paciente se } \\
\text { encuentre en remisión clínica. }\end{array}$ \\
\hline $\begin{array}{l}\text { Punto de } \\
\text { buena } \\
\text { práctica }\end{array}$ & $\sqrt{ }$ & $\begin{array}{l}\text { En todo paciente, independientemente de } \\
\text { la edad de inicio de la enfermedad, se debe } \\
\text { determinar el riesgo individual. En pacientes } \\
\text { de bajo riesgo, definido como colitis ulcerativa } \\
\text { sin actividad endoscópica, el seguimiento } \\
\text { endoscópico se realiza cada } 3 \text { años. }\end{array}$ \\
\hline $\begin{array}{l}\text { Punto de } \\
\text { buena } \\
\text { práctica }\end{array}$ & $\sqrt{ }$ & $\begin{array}{l}\text { En pacientes en riesgo moderado, definido como } \\
\text { colitis extensa con actividad endoscópica leve o } \\
\text { con antecedente de cáncer de colon en familiar de } \\
\text { primer grado mayor de } 50 \text { años, debe realizarse } \\
\text { seguimiento endoscópico entre } 1 \text { y } 3 \text { años. }\end{array}$ \\
\hline $\begin{array}{l}\text { Punto de } \\
\text { buena } \\
\text { práctica }\end{array}$ & $\sqrt{ }$ & $\begin{array}{l}\text { En pacientes de alto riesgo, definido como } \\
\text { colitis extensa, con actividad endoscópica } \\
\text { moderada o grave, o con antecedente de } \\
\text { estenosis o displasia en los } 5 \text { años previos, o } \\
\text { historia familiar de cáncer de colon en familiares } \\
\text { de primer grado menores de } 50 \text { años, o con } \\
\text { antecedente de colangitis esclerosante primaria, } \\
\text { debe realizarse anualmente. }\end{array}$ \\
\hline
\end{tabular}




\section{ALGORITMOS}

\section{ALGORITMO 1}

\section{Proctitis ulcerativa activa leve}

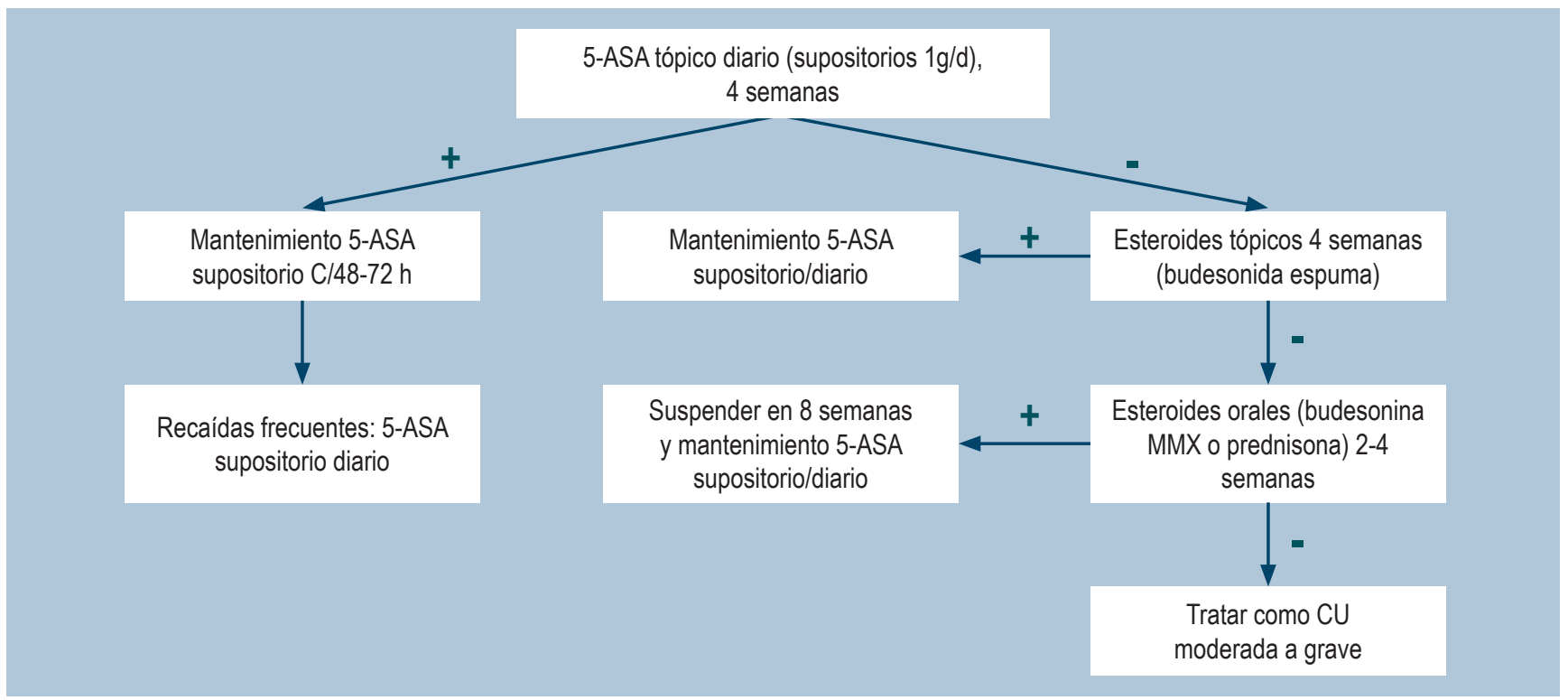

\section{ALGORITMO 2}

\section{Colitis ulcerativa izquierda 0 extensa activa leve}

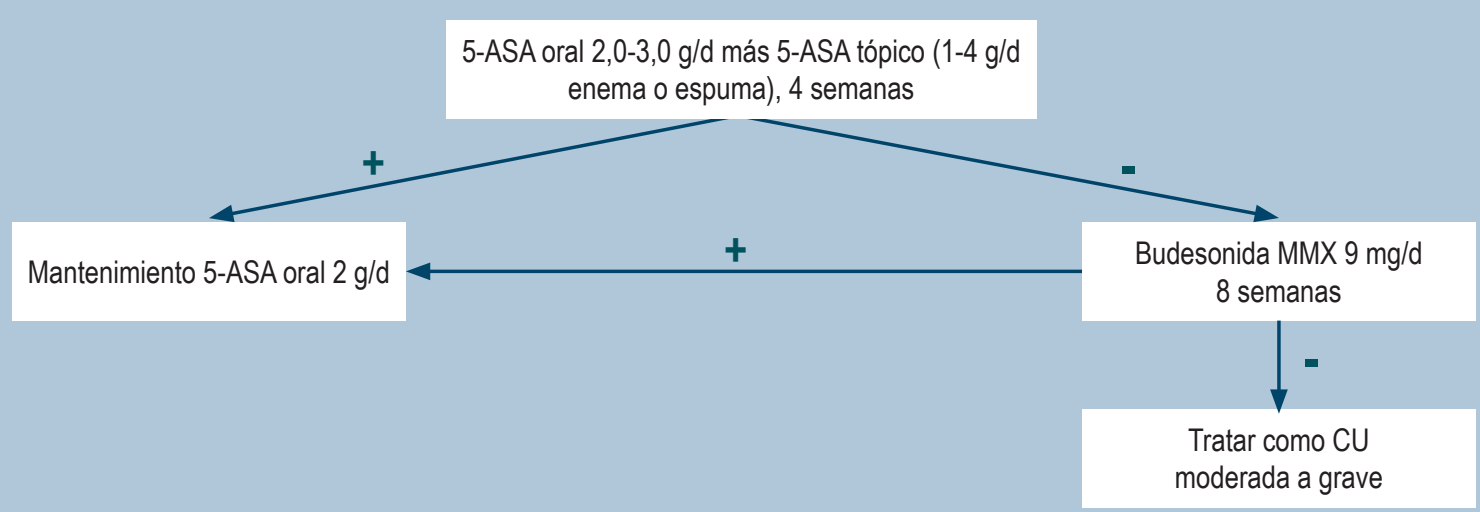




\section{ALGORITMO 3}

\section{Colitis ulcerativa izquierda o extensa activa moderada-grave}

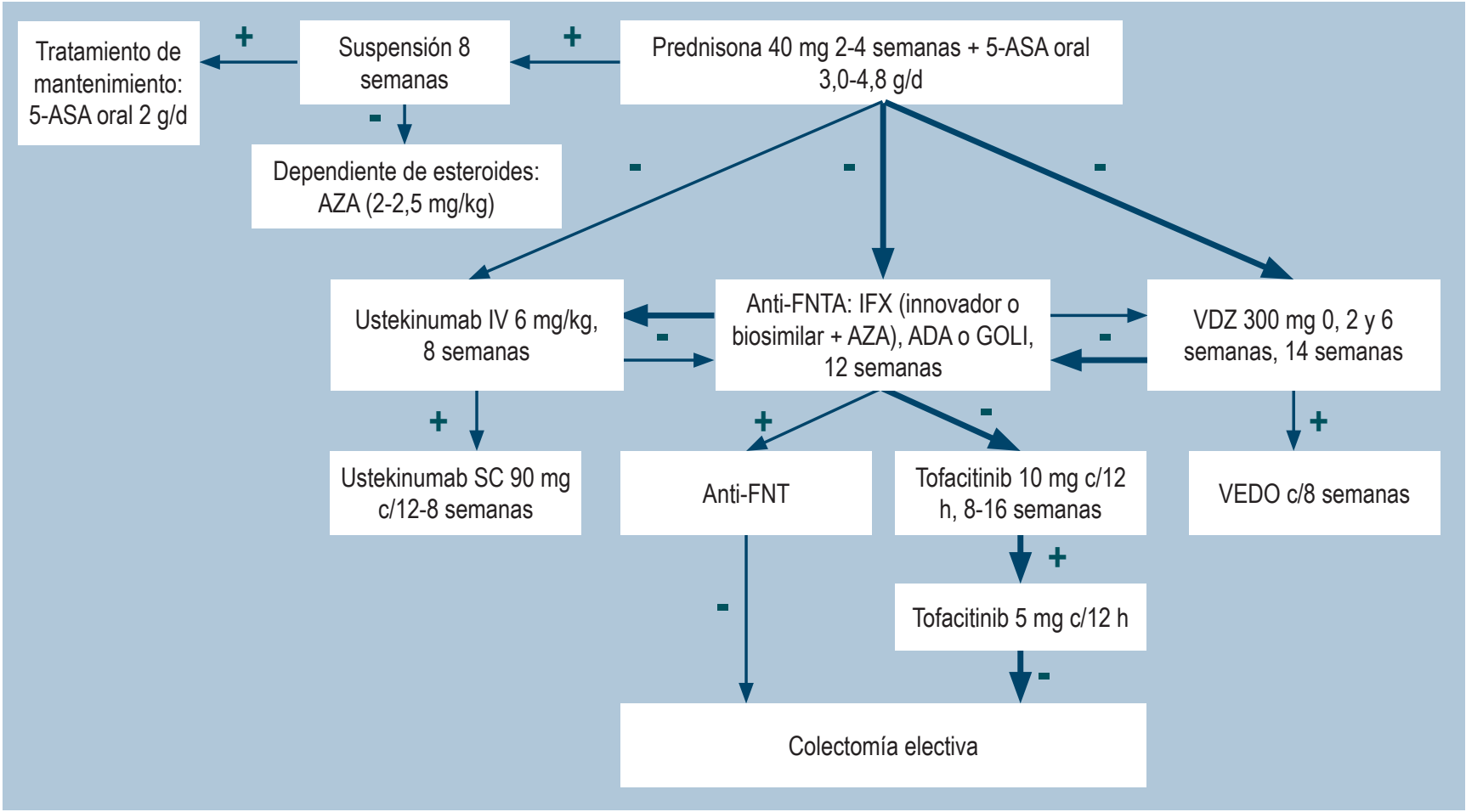

\section{ALGORITMO 4}

\section{Colitis ulcerativa aguda grave}

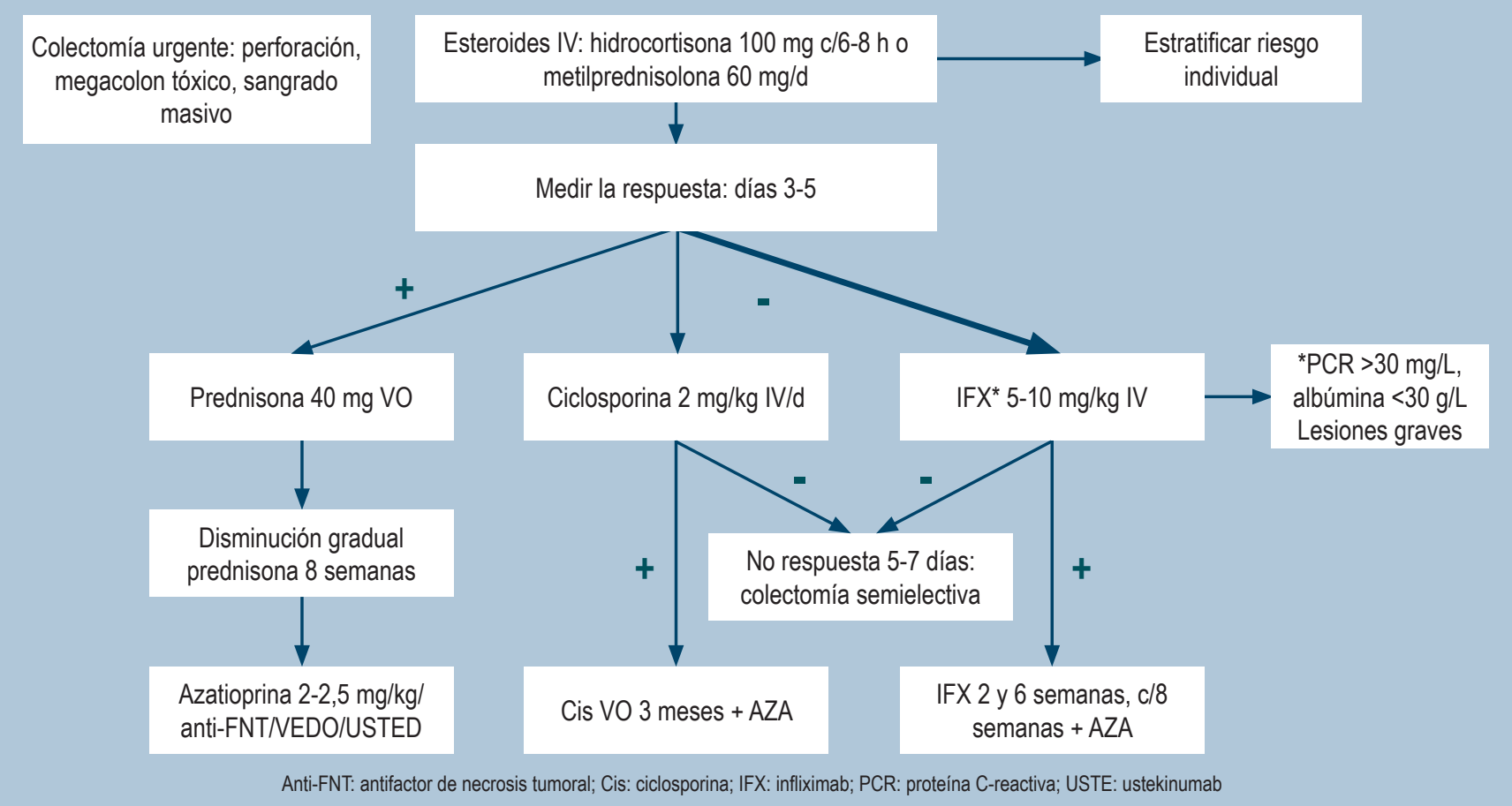




\section{ANEXO 1}

\section{Análisis de conflictos de interés}

\begin{tabular}{|c|c|c|c|}
\hline Experto & Declaración & Tipo de conflicto & Decisión \\
\hline Fabián Juliao & $\begin{array}{l}\text { Conferencista e invitado de Janssen, Takeda, Abbvie y RB } \\
\text { Pharmaceutical. Terapia biológica: infliximab, adalimumab y vedolizumab }\end{array}$ & Económico directo & $\begin{array}{l}\text { Exclusión de la pregunta } \\
\text { de terapia biológica }\end{array}$ \\
\hline Alejandro Concha & No declarado & Sin conflicto & Participación completa \\
\hline María Teresa Galiano & $\begin{array}{l}\text { Ponente y asesor para Abbvie, Janssen y Takeda. Terapia biológica para } \\
\text { colitis ulcerativa }\end{array}$ & Económico directo & $\begin{array}{l}\text { Exclusión de la pregunta } \\
\text { de terapia biológica }\end{array}$ \\
\hline Juan Márquez & $\begin{array}{l}\text { Parte del centro de investigaciones: Instituto de Coloproctología ICO } \\
\text { S.A.S, que realiza ensayos clínicos. Ponente de Abbvie. Protocolo } \\
\text { Abbvie PI-ABS-1146: estudio de unas moléculas nuevas (biológicos) para } \\
\text { determinar la eficacia en la colitis ulcerativa }\end{array}$ & Económico directo & $\begin{array}{l}\text { Exclusión de la pregunta } \\
\text { de terapia biológica }\end{array}$ \\
\hline William Otero & Invitado de Abbvie a una conferencia no relacionada con colitis ulcerativa & Económico no directo & Participación completa \\
\hline Fabio Gil & Invitado de Abbvie a una conferencia no relacionada con colitis ulcerativa & Económico no directo & Participación completa \\
\hline
\end{tabular}

\section{ANEXO 2}

\section{Preguntas pico}

\section{¿Cuál es la eficacia y la seguridad de las intervenciones terapéuticas para inducir} y mantener la remisión en pacientes adultos con colitis ulcerativa?

Población Intervención/comparador
Desenlaces

$\begin{array}{lll}\text { Población mayor de 16 } & \text { - Mesalazina/mesalamina (5-ASA) oral, tópica } & \text { - Tasa de respuesta } \\ \text { años con diagnóstico } & \text { - Mesalazina de liberación prolongada } & \text { - Tasa de remisión } \\ \text { confirmado de CU activo } & \text { - Esteroides IV } & \text { - Tasa de remisión libre de esteroides } \\ \text { o en remisión } & \text { - Esteroides orales (prednisolona, prednisona, budesonida) } & \text { - Tasa de recaída } \\ & \text { - Inmunomoduladores (azatioprina/6-mercaptopurina, } & \text { - Tasa de cicatrización mucosa } \\ & \text { metotrexato) } & \text { - Tasa de hospitalización } \\ & \text { - Tofacitinib } & \text { - Tasa de colectomía } \\ & \text { - Cúrcuma } & \text { - Tasa de eventos adversos (infecciones, cáncer y otros) } \\ & \text { - Probióticos } & \text { - Adherencia al tratamiento } \\ & \text { - Cannabis } & \text { - Calidad de vida } \\ & \text { - Cicatrización de la mucosa como objetivo terapéutico }\end{array}$

\section{¿Cuál es la efectividad y la seguridad de la terapia biológica para el tratamiento} de los pacientes con colitis ulcerativa moderada a grave?

\section{Población}

Intervención/comparador

Población mayor de 16 años con diagnóstico confirmado de colitis ulcerativa activa o en remisión
- Infliximab

- Adalimumab

- Golimumab

- Vedolizumab

- Certolizumab pegol

- Ustekinumab

Biosimilares anti-FNT:

- Infliximab

- Adalimumab

\section{Desenlaces}

- Tasa de respuesta

- Tasa de remisión

- Tasa de remisión libre de esteroides

- Tasa de recaída

- Tasa de cicatrización mucosa

- Tasa de hospitalización

- Tasa de colectomía

- Tasa de eventos adversos (infecciones, cáncer y otros)

- Adherencia al tratamiento

- Calidad de vida

- Cicatrización de la mucosa como objetivo terapéutico 


\section{ANEXO 3}

\section{Estrategias de búsqueda}

\section{Reporte de búsqueda electrónica \#1}

\begin{tabular}{|c|c|c|}
\hline Tipo de búsqueda & Actualización & \\
\hline Bases de datos & $\begin{array}{l}\text { - MEDLINE } \\
\text { MEDLINE In-Process \& Other Non-Indexed Citations } \\
\text { MEDLINE Daily Update }\end{array}$ & \\
\hline Plataforma & Ovid & \\
\hline Fecha de búsqueda & 02/02/2019 & \\
\hline Rango de fecha de búsqueda & 2015 a 2019 & \\
\hline Restricciones de lenguaje & Ninguna & \\
\hline Otros límites & Filtro: revisiones sistemáticas & \\
\hline $\begin{array}{l}\text { Estrategia de búsqueda } \\
\text { (resultados) }\end{array}$ & $\begin{array}{l}\text { 1. exp Colitis, Ulcerative/ (32555) } \\
\text { 2. (ulcer\$ adj5 colitis).tw. (32777) } \\
\text { 3. } 1 \text { or } 2 \text { (41312) } \\
\text { 4. exp Child/ (1808600) } \\
\text { 5. child\$.tw. (1170547) } \\
\text { 6. } 4 \text { or } 5 \text { (2137708) } \\
\text { 7. } 3 \text { not } 6 \text { (36390) } \\
\text { 8. exp Mesalamine/ (3286) } \\
\text { 9. mesalazine.tw. (1231) } \\
\text { 10. mesalamine.tw. (807) } \\
\text { 11. (aminosalicylic adj5 acid).tw. (2809) } \\
\text { 12. aminosalicylate.tw. (510) } \\
\text { 13. exp Hydrocortisone/ (70871) } \\
\text { 14. hydrocortisone.tw. (15080) } \\
\text { 15. exp Budesonide/ (4246) } \\
\text { 16. budesonide.tw. (4498) } \\
\text { 17. exp Prednisone/ (38215) } \\
\text { 18. prednisone.tw. (23879) } \\
\text { 19. exp Prednisolone/ (49318) } \\
\text { 20. prednisolone.tw. (22535) } \\
\text { 21. exp Methylprednisolone/ (18659) } \\
\text { 22. methylprednisolone.tw. (13616) } \\
\text { 23. exp Glucocorticoids/ (184416) } \\
\text { 24. glucocorticoid\$.tw. (59562) } \\
\text { 25. exp Azathioprine/ (14255) } \\
\text { 26. 'azathioprine.tw. (13507) } \\
\text { 27. exp 6-Mercaptopurine/ (19150) } \\
\text { 28. mercaptopurin\$.tw. (4086) } \\
\text { 29. (thiopurine adj5 derivative).tw. (6) }\end{array}$ & 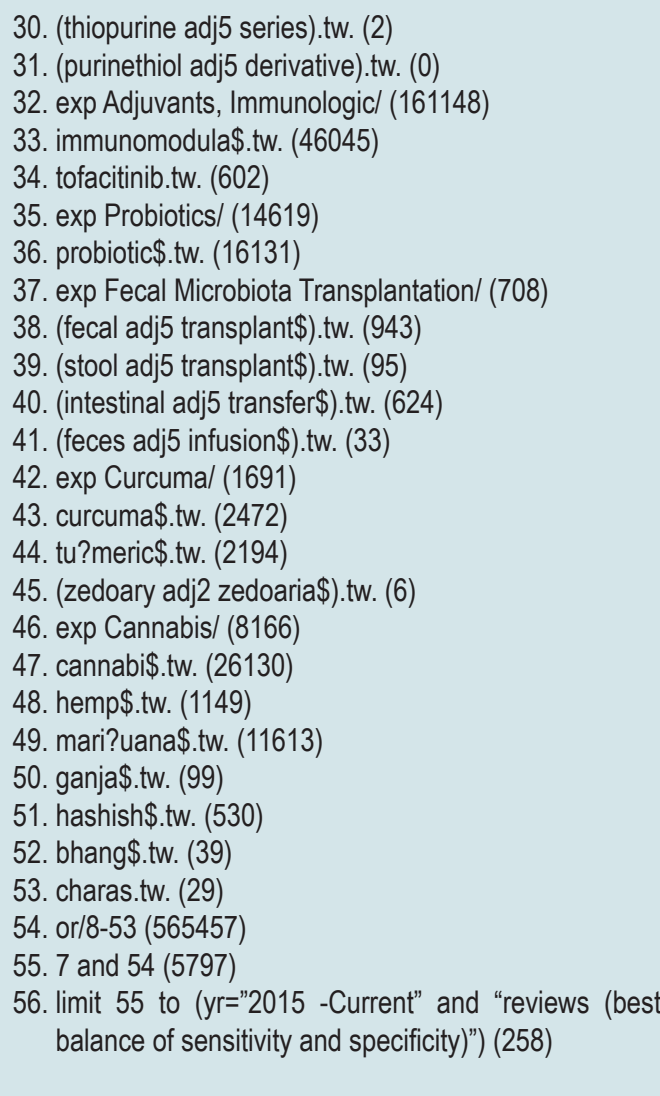 \\
\hline \# de referencias identificadas & 258 & \\
\hline $\begin{array}{l}\text { \# de referencias sin } \\
\text { duplicados }\end{array}$ & 247 & \\
\hline
\end{tabular}


Reporte de búsqueda electrónica \#2

\begin{tabular}{|c|c|c|}
\hline Tipo de búsqueda & Actualización & \\
\hline Base de datos & EMBASE & \\
\hline Plataforma & EMBASE.com & \\
\hline Fecha de búsqueda & 02/02/2019 & \\
\hline Rango de fecha de búsqueda & 2015 a 2019 & \\
\hline Restricciones de lenguaje & Ninguna & \\
\hline Otros límites & Revisiones sistemáticas & \\
\hline $\begin{array}{l}\text { Estrategia de búsqueda } \\
\text { (resultados) }\end{array}$ & $\begin{array}{l}\text { 1. 'ulcerative colitis'/exp (69934) } \\
\text { 2. (ulcer* NEAR/5 colitis):ab,ti (57591) } \\
\text { 3. \#1 OR \#2 (76181) } \\
\text { 4. 'child'/exp (2681753) } \\
\text { 5. child':ab,ti (1666883) } \\
\text { 6. \#4 OR \#5 (3150722) } \\
\text { 7. \#3 NOT \#6 (68532) } \\
\text { 8. 'mesalazine'/exp (16653) } \\
\text { 9. mesalazine:ab,ti (2445) } \\
\text { 10. mesalamine:ab,ti (1952) } \\
\text { 11. (aminosalicylic NEAR/5 acid):ab,ti (3694) } \\
\text { 12. (5 NEAR/5 asa):ab,ti (4821) } \\
\text { 13. aminosalicylate:ab,ti (762) } \\
\text { 14. 'hydrocortisone'/exp (128502) } \\
\text { 15. hydrocortisone:ab,ti (20802) } \\
\text { 16. 'budesonide'lexp (19397) } \\
\text { 17. budesonide:ab,ti (7716) } \\
\text { 18. 'prednisone'lexp (166138) } \\
\text { 19. prednisone:ab,ti (43781) } \\
\text { 20. 'prednisolone'lexp (122304) } \\
\text { 21. prednisolone:ab,ti (36472) } \\
\text { 22. 'methylprednisolone'lexp (88449) } \\
\text { 23. methylprednisolone:ab,ti (23111) } \\
\text { 24. 'glucocorticoid'lexp (707105) } \\
\text { 25. glucocorticoid*:ab,ti (82222) } \\
\text { 26. 'azathioprine'lexp ( } 89585) \\
\text { 27. 'azathioprine':ab,ti (24216) } \\
\text { 28. 'mercaptopurine'/exp (26270) } \\
\text { 29. mercaptopurin*:ab,ti (6272) } \\
\text { 30. '6 mercaptopurine derivative'/exp (979) } \\
\text { 31. (mercaptopurine NEAR/5 derivative):ab,ti (27) } \\
\text { 32. (thiopurine NEAR/5 derivative):ab,ti (7) } \\
\text { 33. (thiopurine NEAR/5 series):ab,ti (6) } \\
\text { 34. (purinethiol NEAR/5 derivative):ab,ti } \\
\text { 35. 'immunomodulating agent'/exp (1160071) }\end{array}$ & 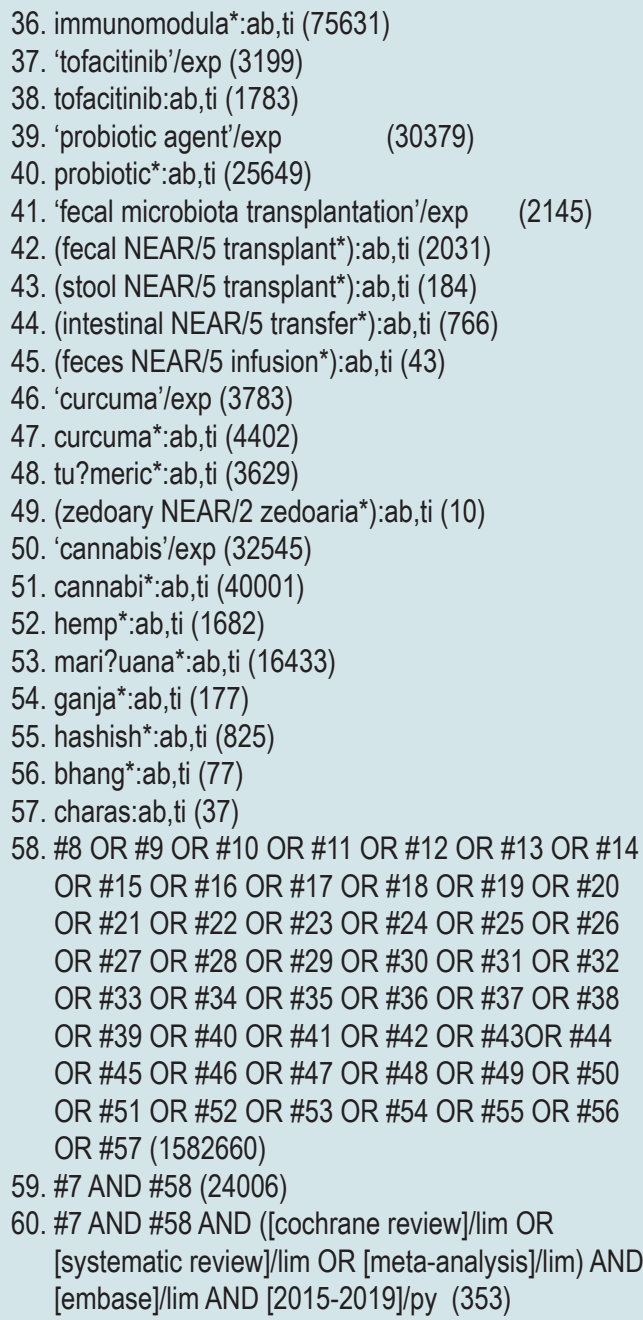 \\
\hline \# de referencias identificadas & 353 & \\
\hline $\begin{array}{l}\text { \# de referencias sin } \\
\text { duplicados }\end{array}$ & 318 & \\
\hline
\end{tabular}


Reporte de búsqueda electrónica \#3

\begin{tabular}{|c|c|c|}
\hline Tipo de búsqueda & \multicolumn{2}{|l|}{ Nueva } \\
\hline Base de datos & \multicolumn{2}{|l|}{$\begin{array}{l}\text { Cochrane Library } \\
\text { http://onlinelibrary.wiley.com/cochranelibrary/search/quick }\end{array}$} \\
\hline Plataforma & \multicolumn{2}{|l|}{ Wiley } \\
\hline Fecha de búsqueda & \multicolumn{2}{|l|}{ 05/02/2019 } \\
\hline Rango de fecha de búsqueda & \multicolumn{2}{|l|}{2015 a 2019} \\
\hline Restricciones de lenguaje & \multicolumn{2}{|l|}{ Ninguna } \\
\hline Otros límites & \multicolumn{2}{|l|}{ Revisiones sistemáticas } \\
\hline $\begin{array}{l}\text { Estrategia de búsqueda } \\
\text { (resultados) }\end{array}$ & $\begin{array}{l}\text { 1. MeSH descriptor: [Colitis, Ulcerative] explode all trees } \\
\text { (1331) } \\
\text { 2. (ulcer* NEAR/5 colitis):ab,ti (2875) } \\
\text { 3. \#1 or \# (23028) } \\
\text { 4. MeSH descriptor: [Child] explode all trees (1111) } \\
\text { 5. child*:ab,ti (86882) } \\
\text { 6. \#4 or \#5 (86978) } \\
\text { 7. \#3 not \#6 (2906) } \\
\text { 8. MeSH descriptor: [Mesalamine] explode all trees } \\
\text { 504 } \\
\text { 9. mesalazine:ab,ti (406) } \\
\text { 10. mesalamine:ab,ti (300) } \\
\text { 11. (aminosalicylic NEAR/5 acid):ab,ti (326) } \\
\text { 12. (5 NEAR/5 asa):ab,ti (521) } \\
\text { 13. (aminosalicylate):ab,ti (34) } \\
\text { 14. MeSH descriptor: [Hydrocortisone] explode all trees } \\
\text { (5628) } \\
\text { 15. hydrocortisone:ab,ti (1779) } \\
\text { 16. MeSH descriptor: [Budesonide] explode all trees } \\
\text { (1655) } \\
\text { 17. budesonide:ab,ti (3382) } \\
\text { 18. MeSH descriptor: [Prednisone] explode all trees } \\
\text { (3614) } \\
\text { 19. prednisone:ab,ti (5287) } \\
\text { 20. MeSH descriptor: [Prednisolone] explode all trees } \\
\text { (4417) } \\
\text { 21. prednisolone:ab,ti ( } 3585) \\
\text { 22. MeSH descriptor: [Methylprednisolone] explode all } \\
\text { trees (2361) } \\
\text { 23. methylprednisolone:ab,ti (2513) } \\
\text { 24. MeSH descriptor: [Glucocorticoids] explode all trees } \\
\text { (4206) } \\
\text { 25. glucocorticoid*:ab,ti ( } 3237) \\
\text { 26. MeSH descriptor: [Azathioprine] explode all trees } \\
\text { (1159) } \\
\text { 27. azathioprine:ab,ti (1810) } \\
\text { 28. MeSH descriptor: [Mercaptopurine] explode all trees } \\
\text { (338) }\end{array}$ & 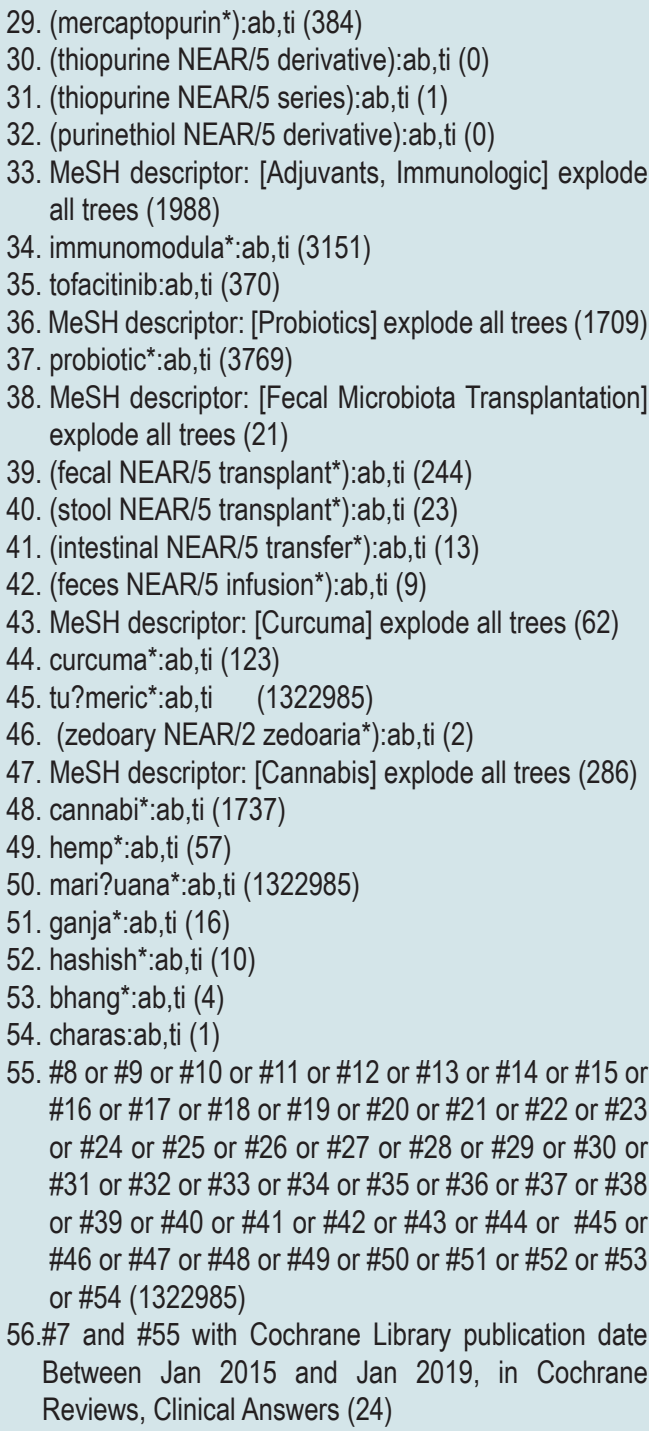 \\
\hline \# de referencias identificadas & 24 & \\
\hline $\begin{array}{l}\text { \# de referencias sin } \\
\text { duplicados }\end{array}$ & 21 & \\
\hline
\end{tabular}


Reporte de búsqueda electrónica \#1

\begin{tabular}{|c|c|c|}
\hline Tipo de búsqueda & Actualización & \\
\hline Bases de datos & $\begin{array}{ll}\text { - } & \text { MEDLINE } \\
\text { - } & \text { MEDLINE In-Process \& Other Non-Indexed Citations } \\
\text { - } & \text { MEDLINE Daily Update }\end{array}$ & \\
\hline Plataforma & Ovid & \\
\hline Fecha de búsqueda & $06 / 02 / 2019$ & \\
\hline Rango de fecha de búsqueda & 2015 a 2019 & \\
\hline Restricciones de lenguaje & Ninguna & \\
\hline Otros límites & Filtro: revisiones sistemáticas & \\
\hline $\begin{array}{l}\text { Estrategia de búsqueda } \\
\text { (resultados) }\end{array}$ & $\begin{array}{l}\text { 1. exp Colitis, Ulcerative/ (32561) } \\
\text { 2. (ulcer\$ adj5 colitis).tw. (32782) } \\
\text { 3. } 1 \text { or } 2 \text { ( } 41319) \\
\text { 4. exp Child/ (1808941) } \\
\text { 5. child\$.tw. (1170778) } \\
\text { 6. } 4 \text { or } 5 \text { ( } 2138082) \\
\text { 7. } 3 \text { not } 6 \text { (36397) } \\
\text { 8. exp Colonoscopy/ (28005) } \\
\text { 9. colonoscop\$.tw. (23758) } \\
\text { 10. colo?scopy.tw. (502) } \\
\text { 11. exp Endoscopy/ (328156) } \\
\text { 12. exp Endoscopy, Gastrointestinal/ (83710) } \\
\text { 13. endoscop\$.tw. (167309) } \\
\text { 14. or/8-13 (398624) } \\
\text { 15. neoplas\$.mp. (2695462) } \\
\text { 16. tumor\$.mp. (1654976) }\end{array}$ & 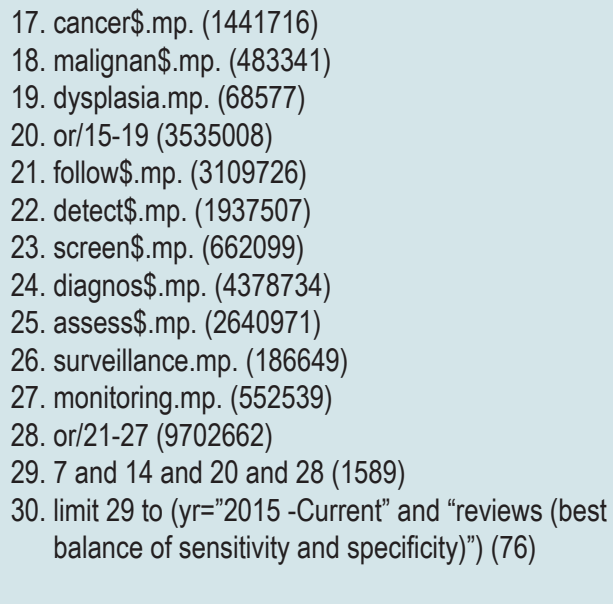 \\
\hline \# de referencias identificadas & 76 & \\
\hline $\begin{array}{l}\text { \# de referencias sin } \\
\text { duplicados }\end{array}$ & 76 & \\
\hline
\end{tabular}

\section{Reporte de búsqueda electrónica \#2}

\begin{tabular}{|ll}
\hline Tipo de búsqueda & Actualización \\
\hline Base de datos & EMBASE \\
\hline Plataforma & EMBASE.com \\
\hline Fecha de búsqueda & $06 / 02 / 2019$ \\
\hline Rango de fecha de búsqueda & 2015 a 2019 \\
\hline Restricciones de lenguaje & Ninguna \\
\hline Otros límites & Revisiones sistemáticas \\
\hline
\end{tabular}




\begin{tabular}{|c|c|c|}
\hline $\begin{array}{l}\text { Estrategia de búsqueda } \\
\text { (resultados) }\end{array}$ & $\begin{array}{l}\text { 1. 'ulcerative colitis'/exp (69948) } \\
\text { 2. (ulcer* NEAR/5 colitis):ab,ti (57599) } \\
\text { 3. \#1 OR \#2 (76196) } \\
\text { 4. 'child'/exp (2682129) } \\
\text { 5. child*:ab,ti (1667138) } \\
\text { 6. \#4 OR \#5 (3151161) } \\
\text { 7. \#3 NOT \#6 (68546) } \\
\text { 8. 'colonoscopy'lexp (70459) } \\
\text { 9. colonoscop*:ab,ti (51668) } \\
\text { 10. colo?scopy:ab,ti (384) } \\
\text { 11. 'endoscopy'lexp (582171) } \\
\text { 12. 'digestive tract endoscopy'/exp (196094) } \\
\text { 13. endoscop*:ab,ti (293362) } \\
\text { 14. \#8 OR \#9 OR \#10 OR \#11 OR \#12 OR \#13 } \\
\text { (709544) } \\
\text { 15. neoplas* (1143514) } \\
\text { 16. tumor* (2979663) }\end{array}$ & $\begin{array}{l}\text { 17. cancer* }(3838559) \\
\text { 18. malignan* }(916353) \\
\text { 19. dysplasia (124748) } \\
\text { 20. \#15 OR \#16 OR \#17 OR \#18 OR \#19 (5468935) } \\
\text { 21. follow* }(4736989) \\
\text { 22. detect* }(2802512) \\
\text { 23. screen* }(1209211) \\
\text { 24. diagnos* }(6280598) \\
\text { 25. assess* }(4626986) \\
\text { 26. surveillance (277377) } \\
\text { 27. monitoring (894998) } \\
\text { 28. \#21 OR \#22 OR \#23 OR \#24 OR \#25 OR \#26 OR } \\
\text { \#27 (14596755) } \\
\text { 29. \#7 AND \#14 AND \#20 AND \#28 (4742) } \\
\text { 30. \#7 AND \#14 AND \#20 AND \#28 AND [embase]/lim } \\
\text { AND [2015-2015]/py AND ([cochrane review]/lim OR } \\
\text { [systematic review]/lim OR [meta analysis]/lim) (12) }\end{array}$ \\
\hline \# de referencias identificadas & 12 & \\
\hline he reteremicias sim uupic & 11 & \\
\hline
\end{tabular}

Reporte de búsqueda electrónica \#3

\begin{tabular}{|c|c|c|}
\hline Tipo de búsqueda & \multicolumn{2}{|l|}{ Actualización } \\
\hline Base de datos & \multicolumn{2}{|l|}{$\begin{array}{l}\text { Cochrane Library } \\
\text { http://onlinelibrary.wiley.com/cochranelibrary/search/quick }\end{array}$} \\
\hline Plataforma & \multicolumn{2}{|l|}{ Wiley } \\
\hline Fecha de búsqueda & \multicolumn{2}{|l|}{ 06/02/2019 } \\
\hline Rango de fecha de búsqueda & \multicolumn{2}{|l|}{2015 a 2019} \\
\hline Restricciones de lenguaje & \multicolumn{2}{|l|}{ Ninguna } \\
\hline Otros límites & \multicolumn{2}{|l|}{ Revisiones sistemáticas } \\
\hline $\begin{array}{l}\text { Estrategia de búsqueda } \\
\text { (resultados) }\end{array}$ & $\begin{array}{l}\text { 1. MeSH descriptor: [Colitis, Ulcerative] explode all } \\
\text { trees (1331) } \\
\text { 2. (ulcer* NEAR/5 colitis):ab,ti (2875) } \\
\text { 3. \#1 or \#2 (3028) } \\
\text { 4. MeSH descriptor: [Child] explode all trees (1111) } \\
\text { 5. child*:ab,ti ( } 86882) \\
\text { 6. \#4 or \#5 (86978) } \\
\text { 7. \#3 not \#6 (2906) } \\
\text { 8. MeSH descriptor: [Colonoscopy] explode all trees } \\
\text { (1840) } \\
\text { 9. colonoscop*:ab,ti ( } 3808) \\
\text { 10. colo?scopy:ab,ti ( } 51) \\
\text { 11. MeSH descriptor: [Endoscopy] explode all trees } \\
\text { (15946) } \\
\text { 12. MeSH descriptor: [Endoscopy, Gastrointestinal] } \\
\text { explode all trees ( } 4230) \\
\text { 13. endoscop*:ab,ti (16702) } \\
\text { 14. \#8 or \#9 or \#10 or \#11 or \#12 or \#13 ( } 29169)\end{array}$ & $\begin{array}{l}\text { 15. neoplas* }(67126) \\
\text { 16. tumor* }(46462) \\
\text { 17. cancer* }(133419) \\
\text { 18. malignan* }(16482) \\
\text { 19. dysplasia (2997) } \\
\text { 20. \#15 or \#16 or \#17 or \#18 or \#19 (162961) } \\
\text { 21. follow* }(349603) \\
\text { 22. detect* }(68762) \\
\text { 23. screen* ( } 47105) \\
\text { 24. diagnos* }(167854) \\
\text { 25. assess* (352547) } \\
\text { 26. surveillance }(6678) \\
\text { 27. monitoring (46728) } \\
\text { 28. \#21 or \#22 or \#23 or \#24 or \#25 or \#26 or \#27 } \\
\text { (664738) } \\
\text { 29. \#7 and \#14 and \#20 and \#28 with Cochrane Library } \\
\text { publication date Between Jan } 2015 \text { and Jan } 2019 \text {, in } \\
\text { Cochrane Reviews, Clinical Answers ( } 7 \text { ) }\end{array}$ \\
\hline \# de referencias identificadas & 7 & \\
\hline \# de referencias sin duplicados & 5 & \\
\hline
\end{tabular}




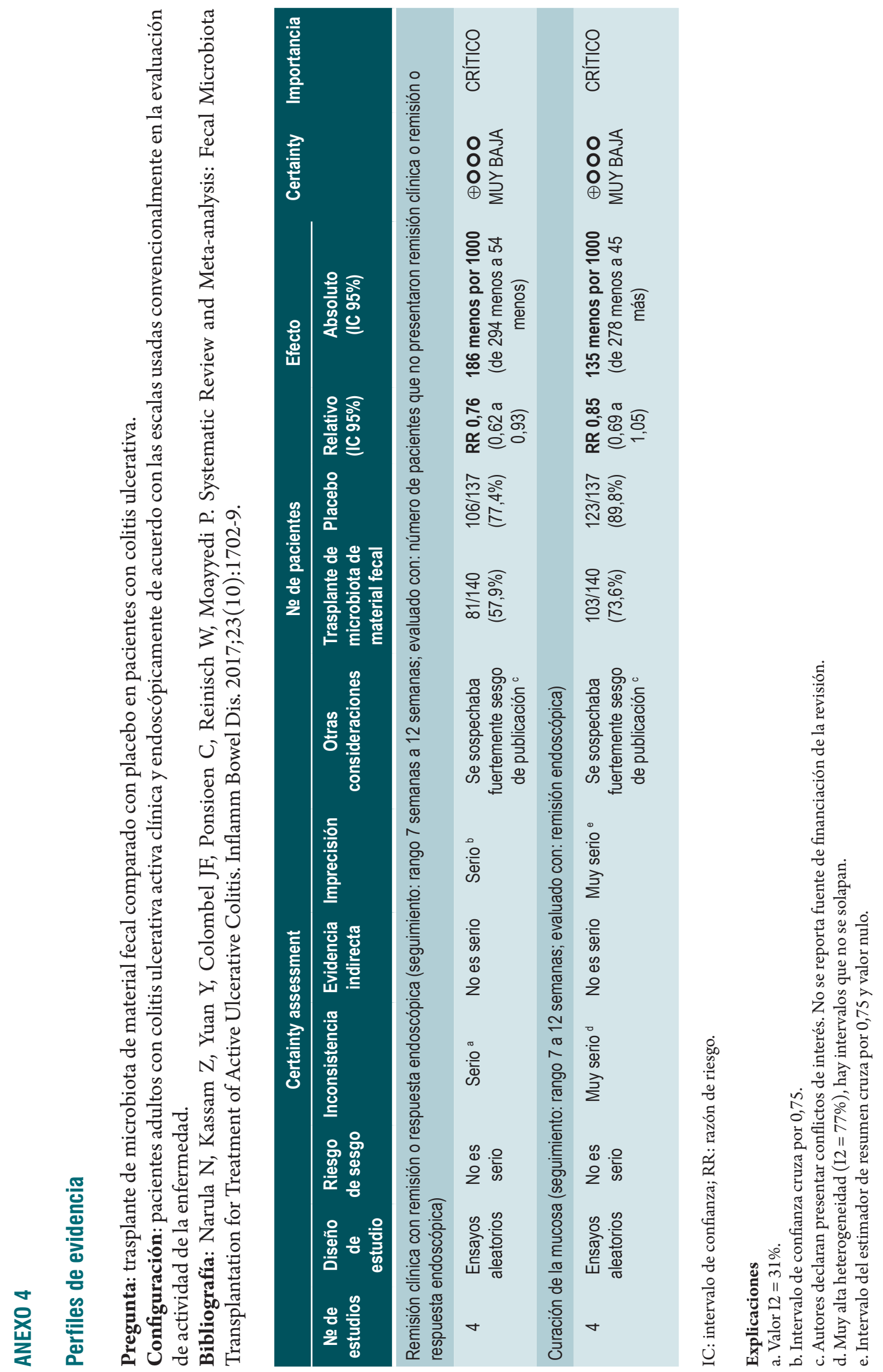




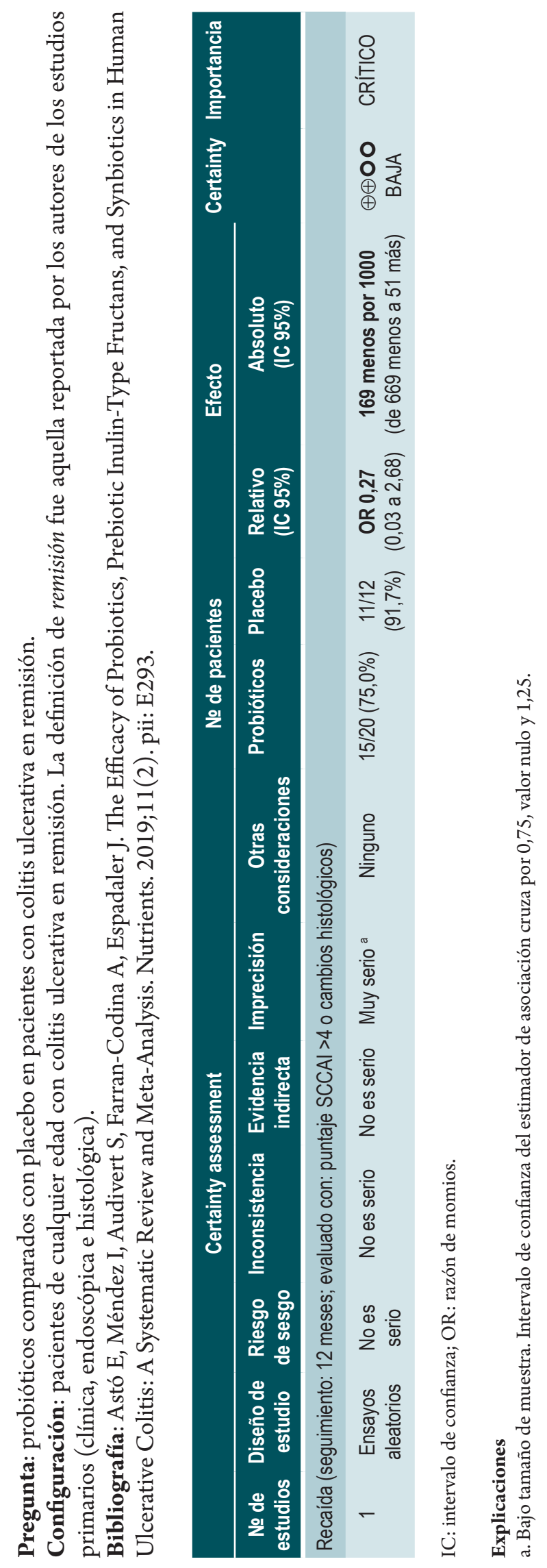




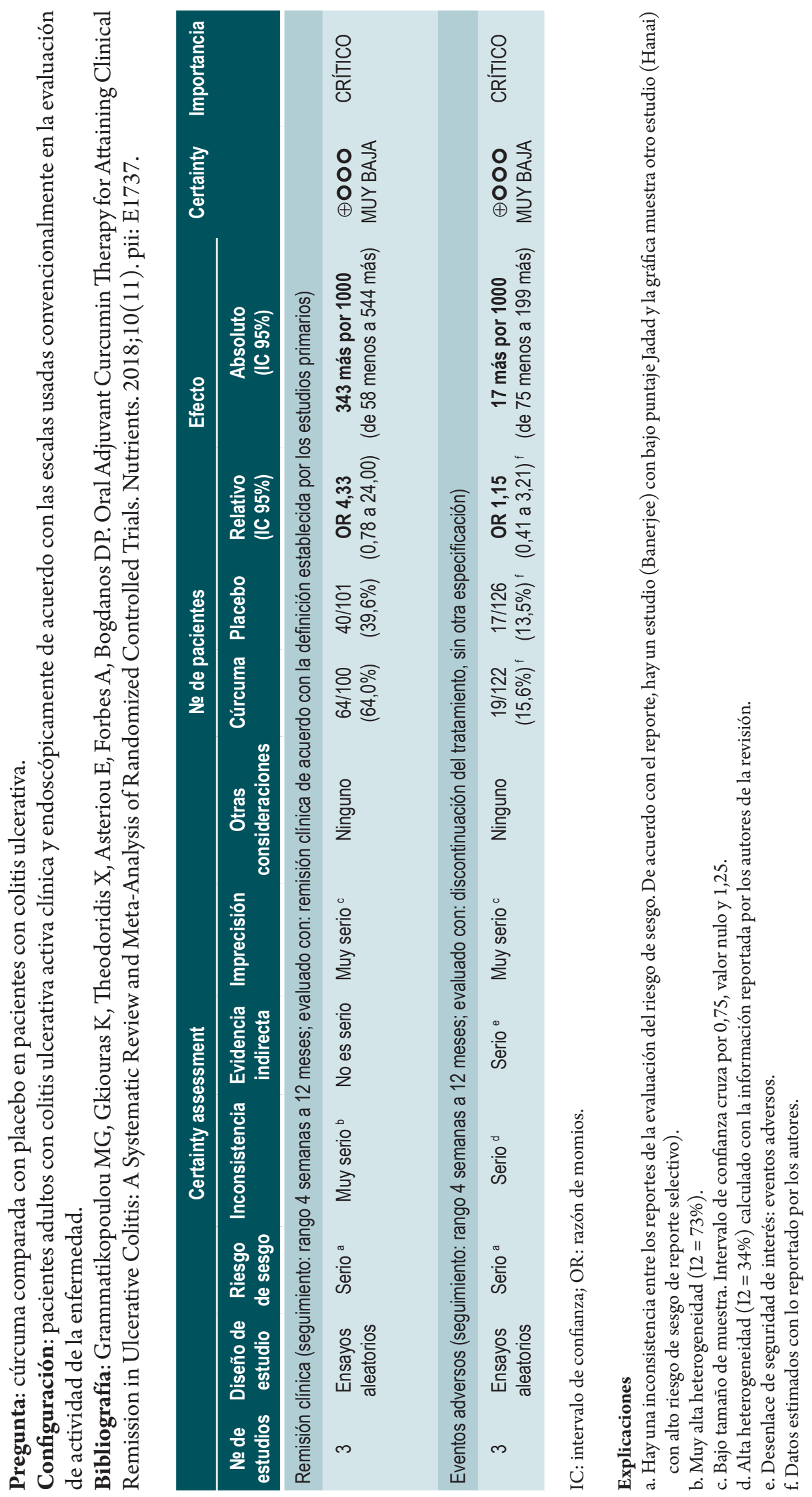




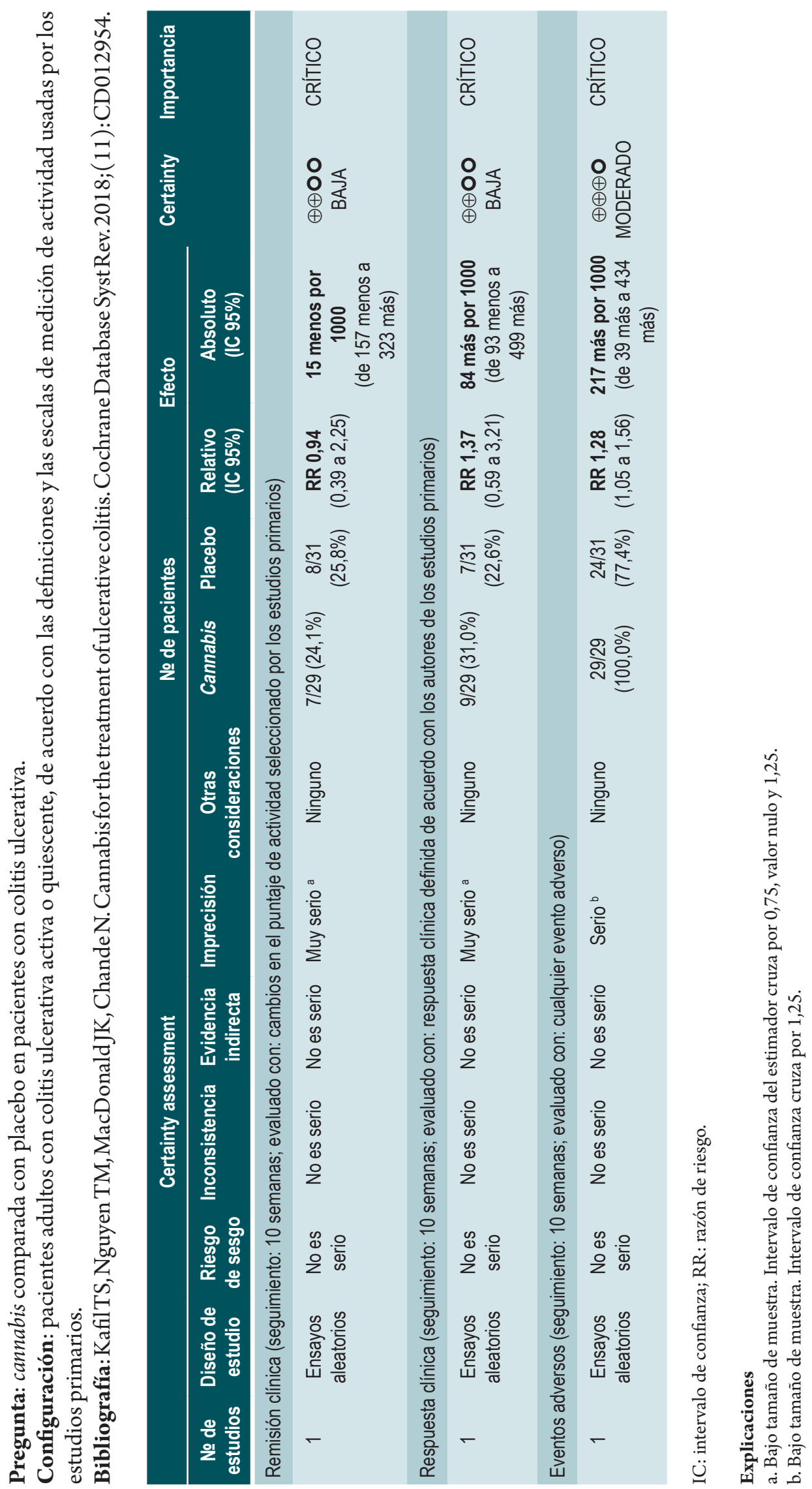




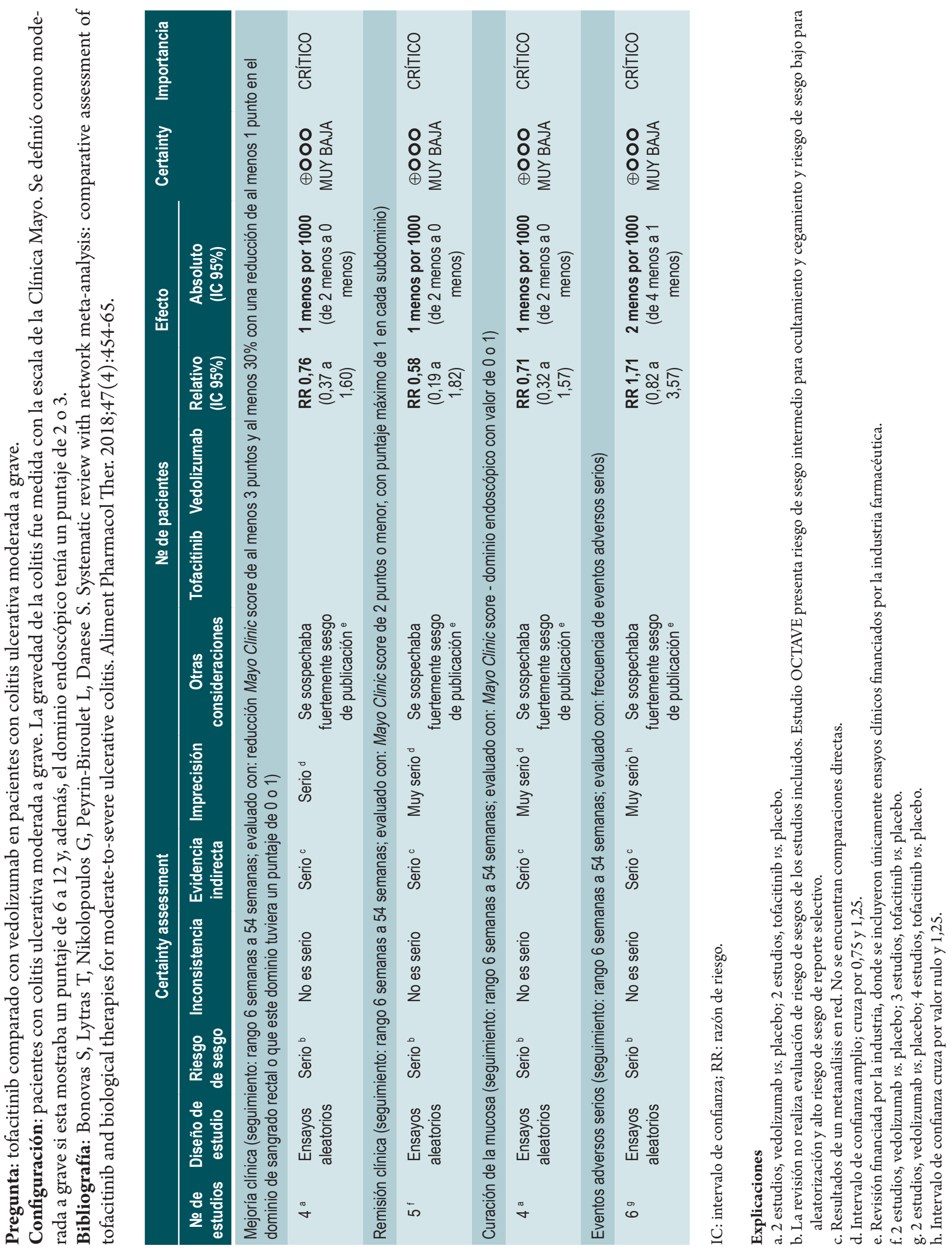




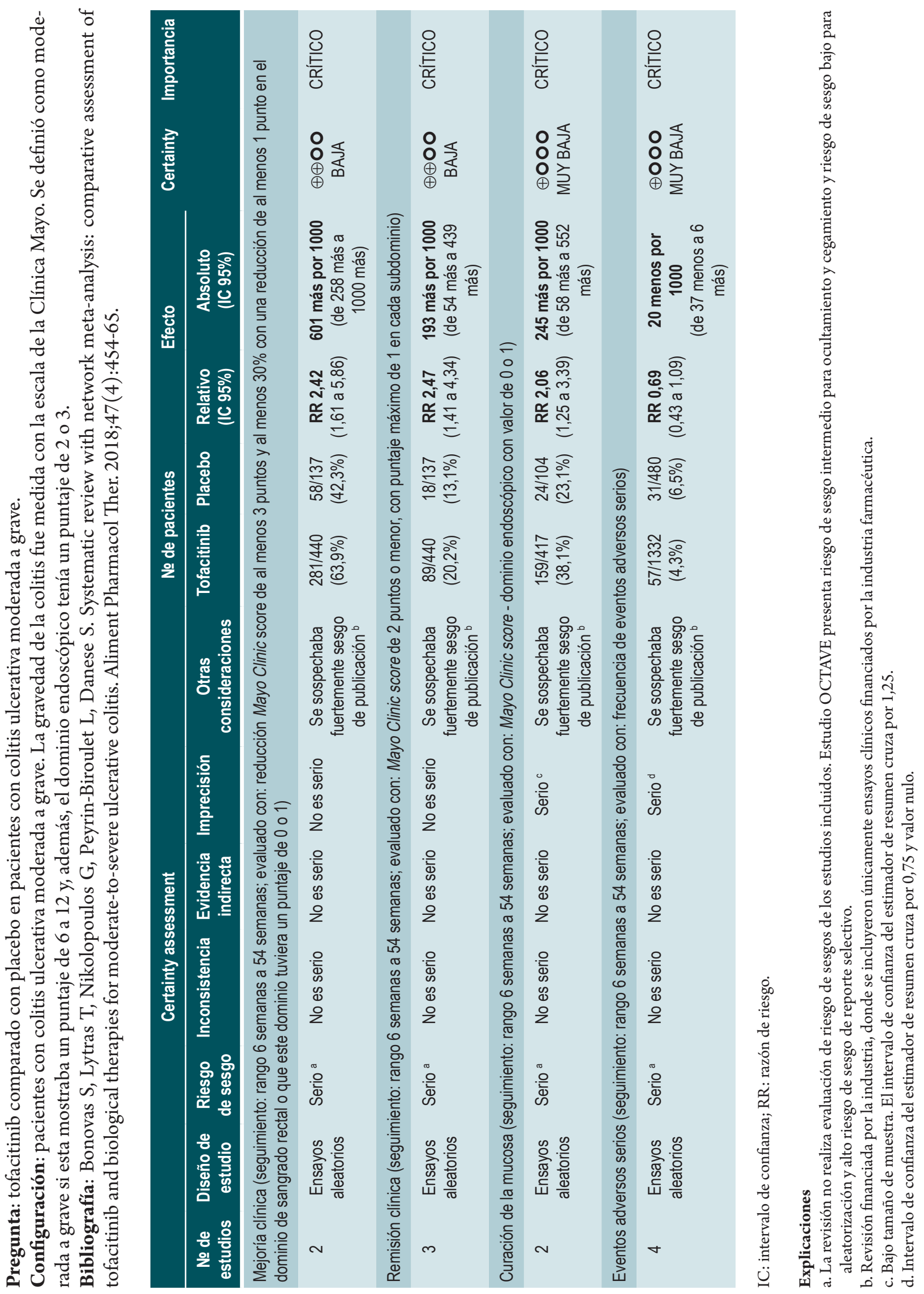




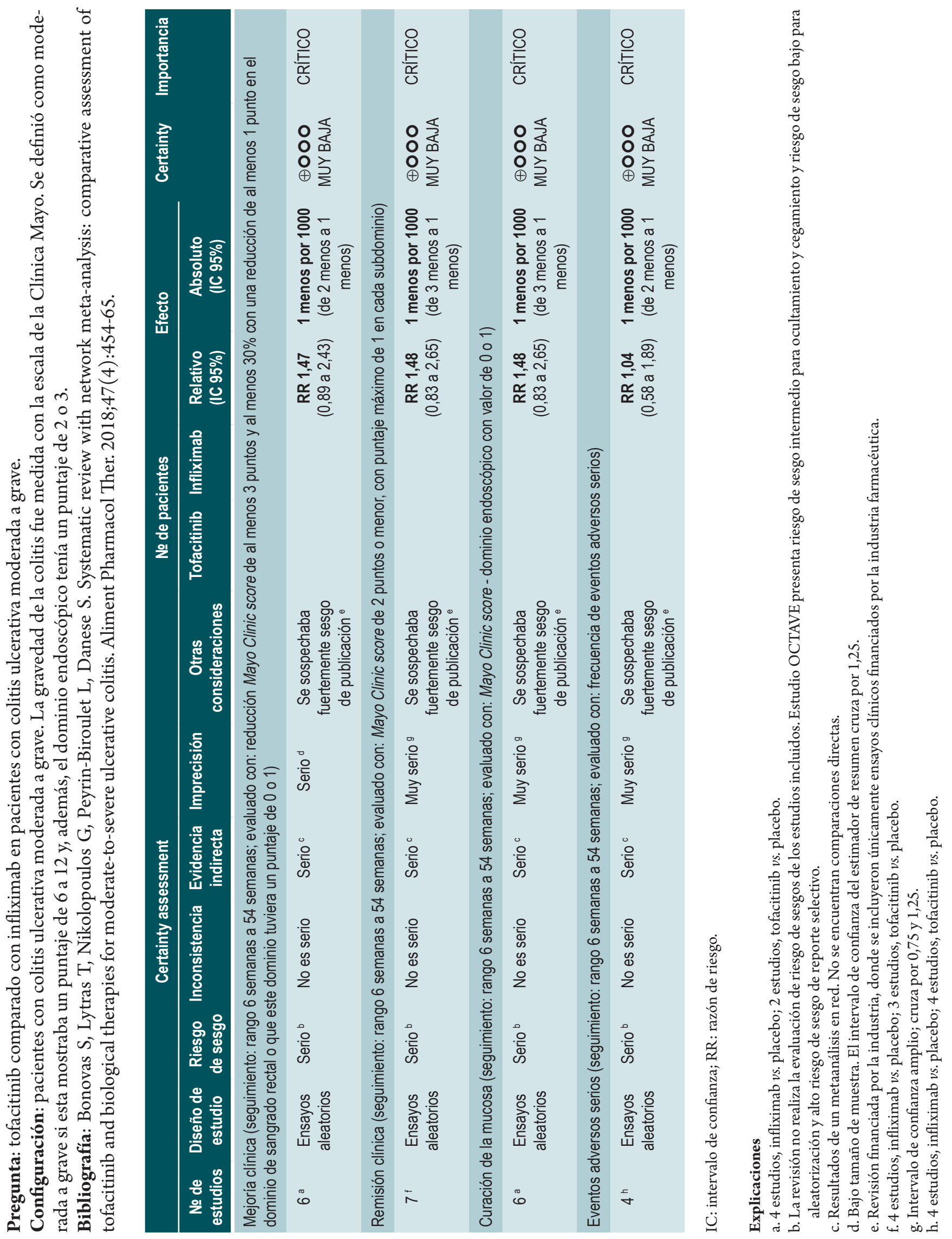




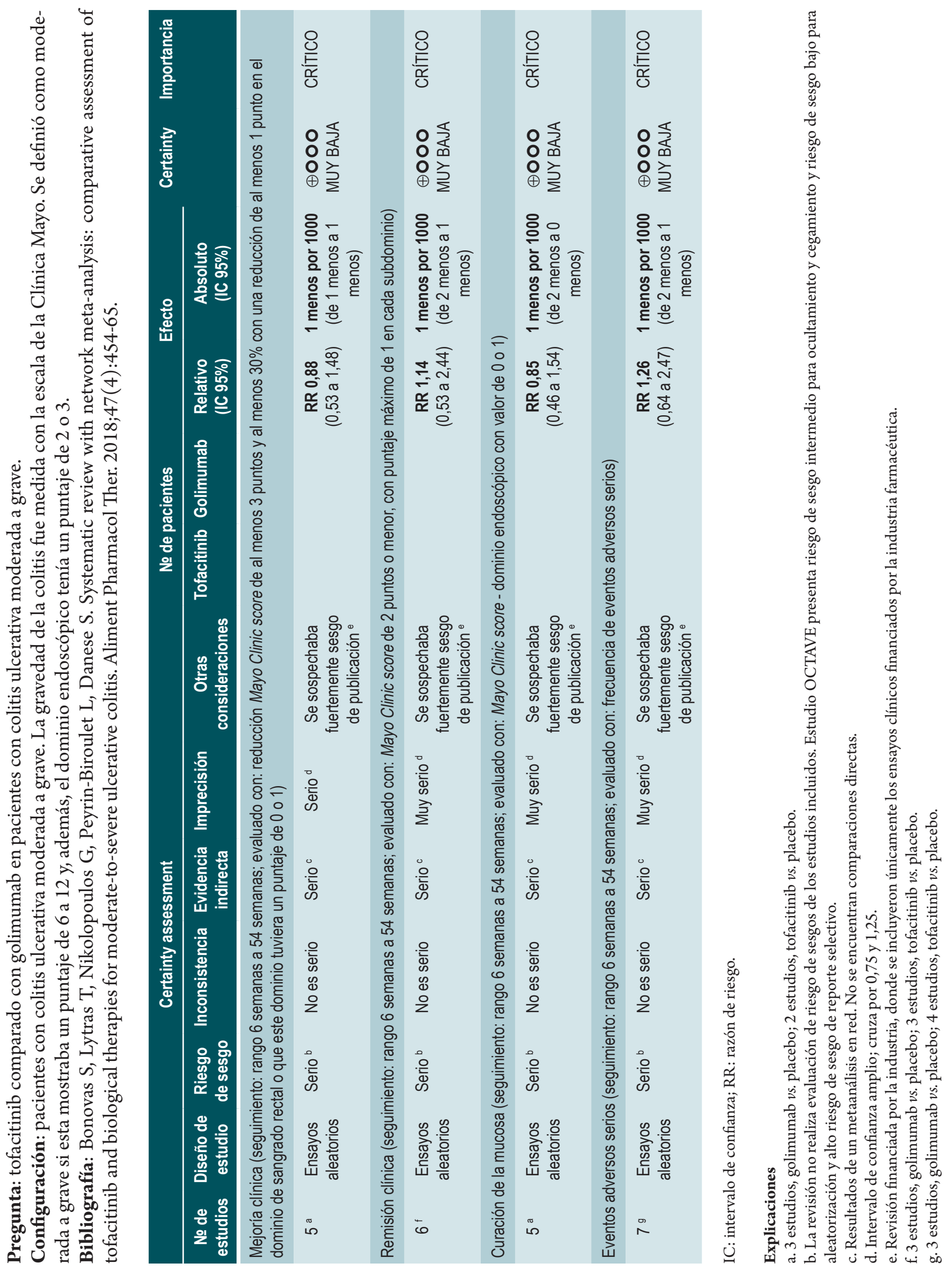




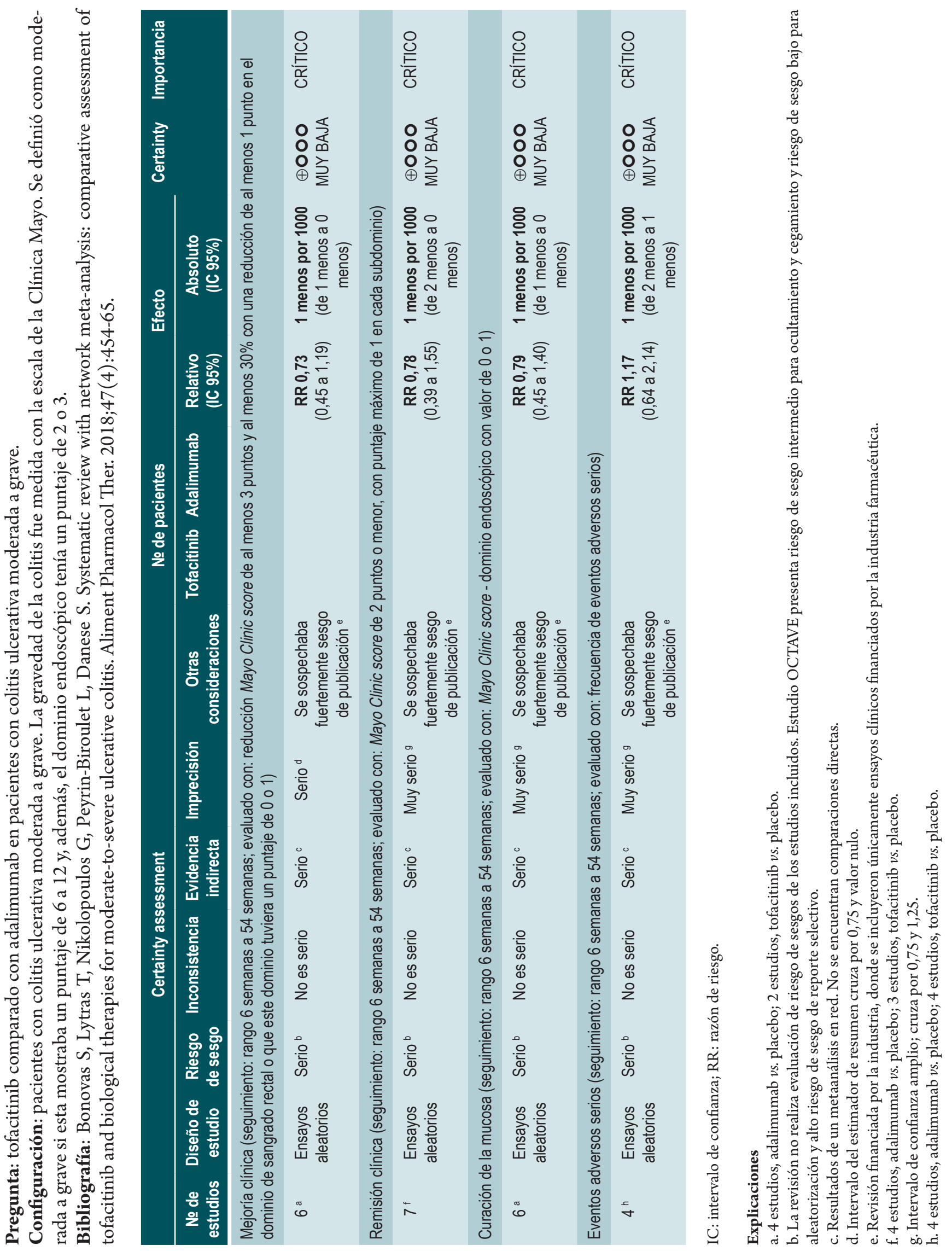




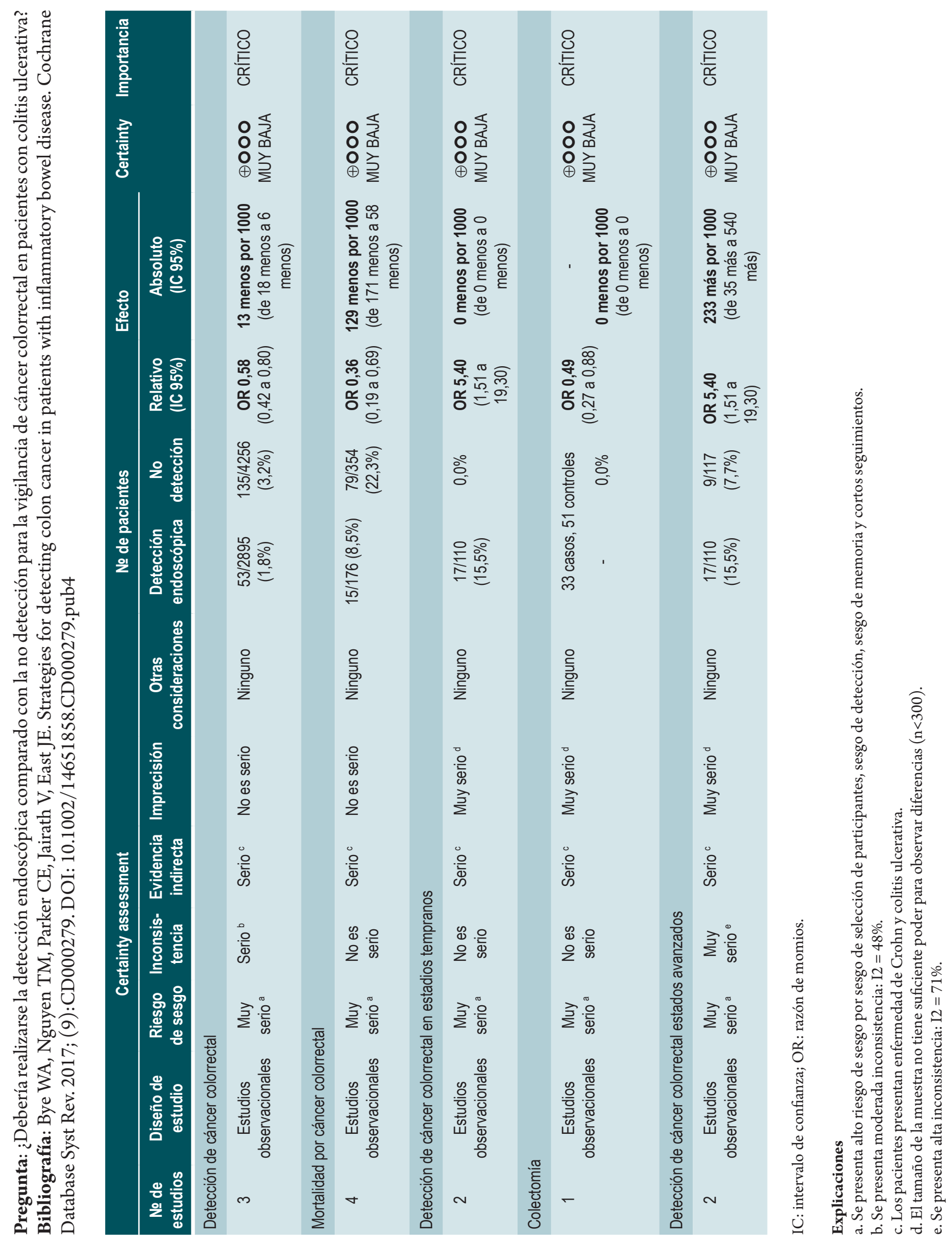




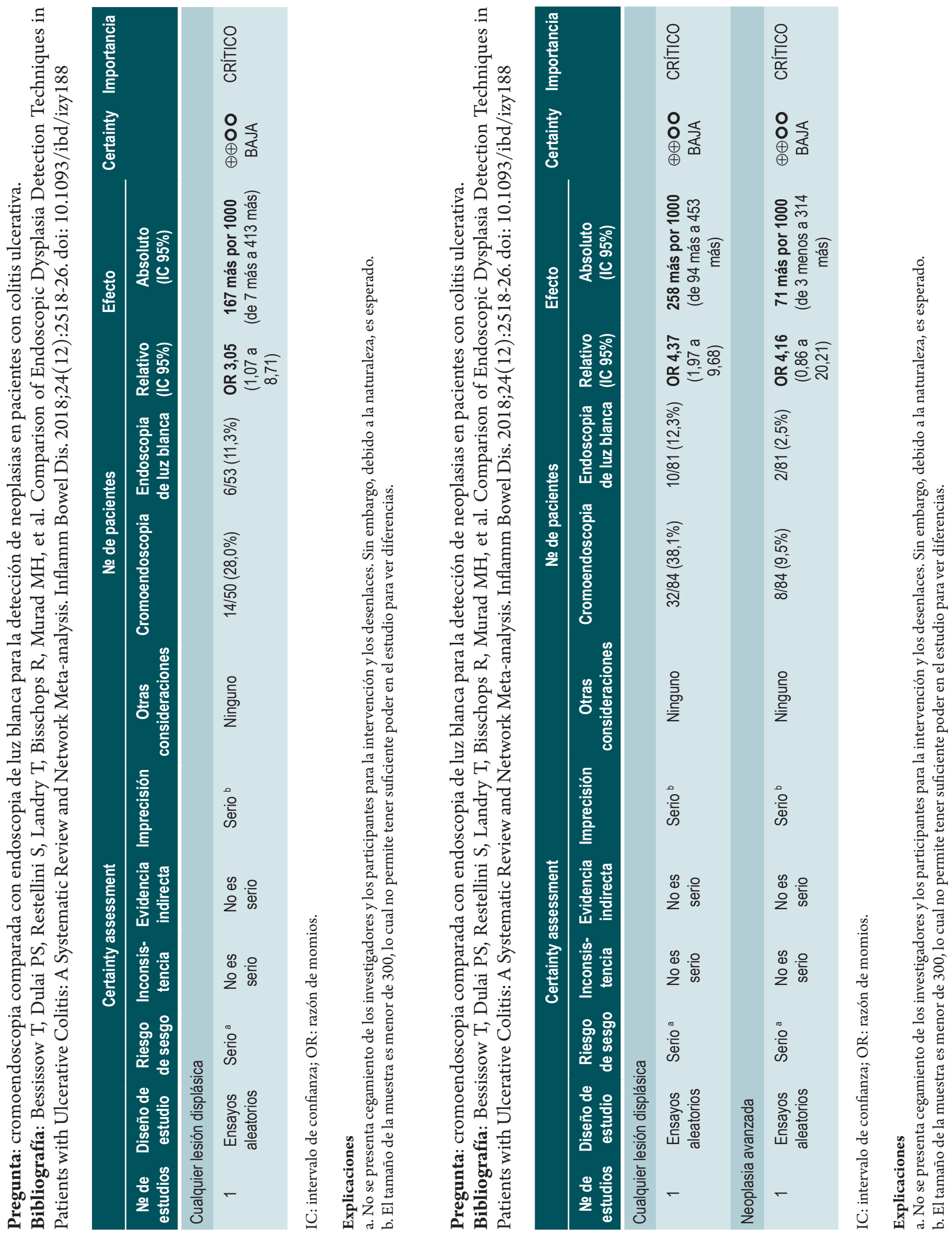



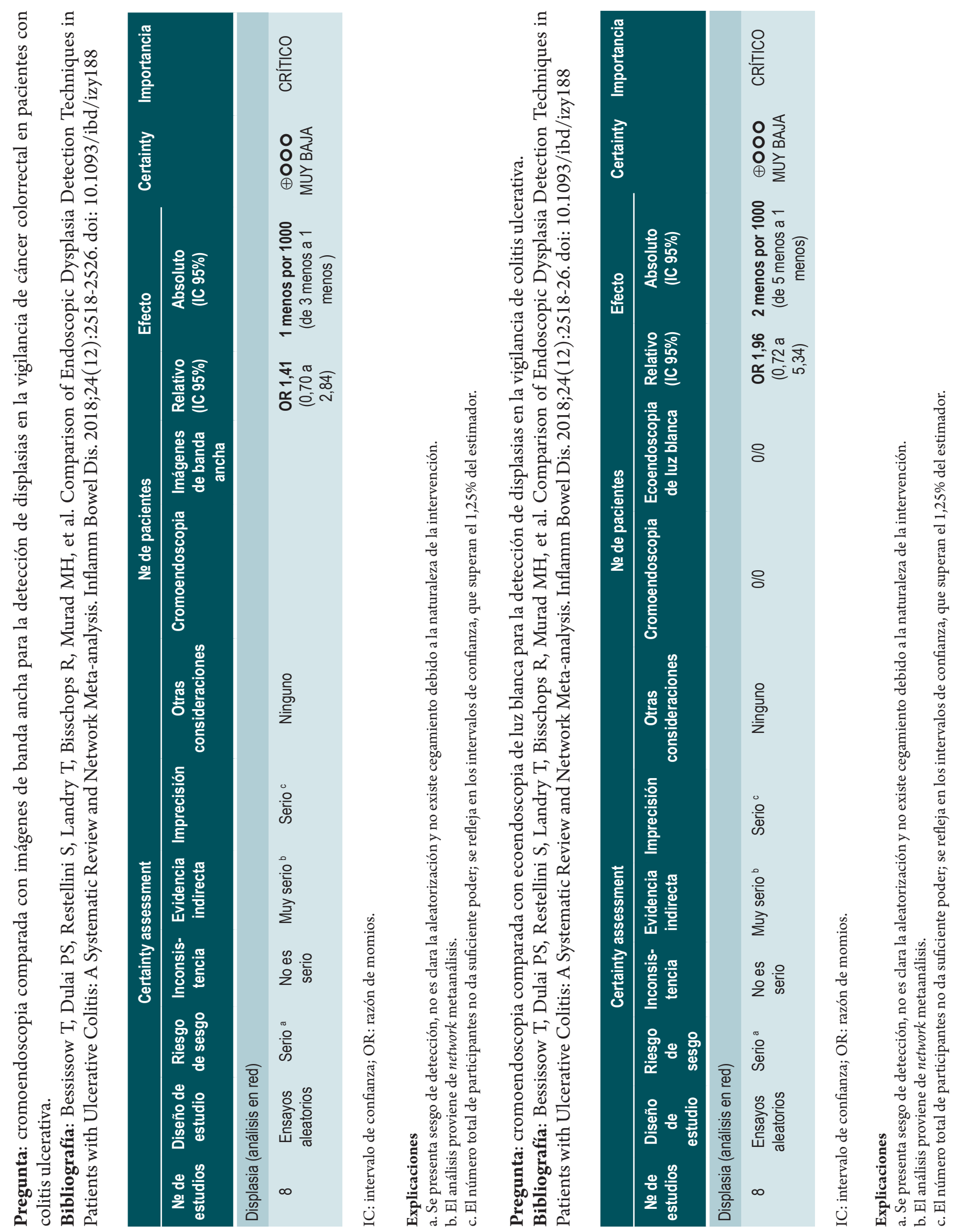


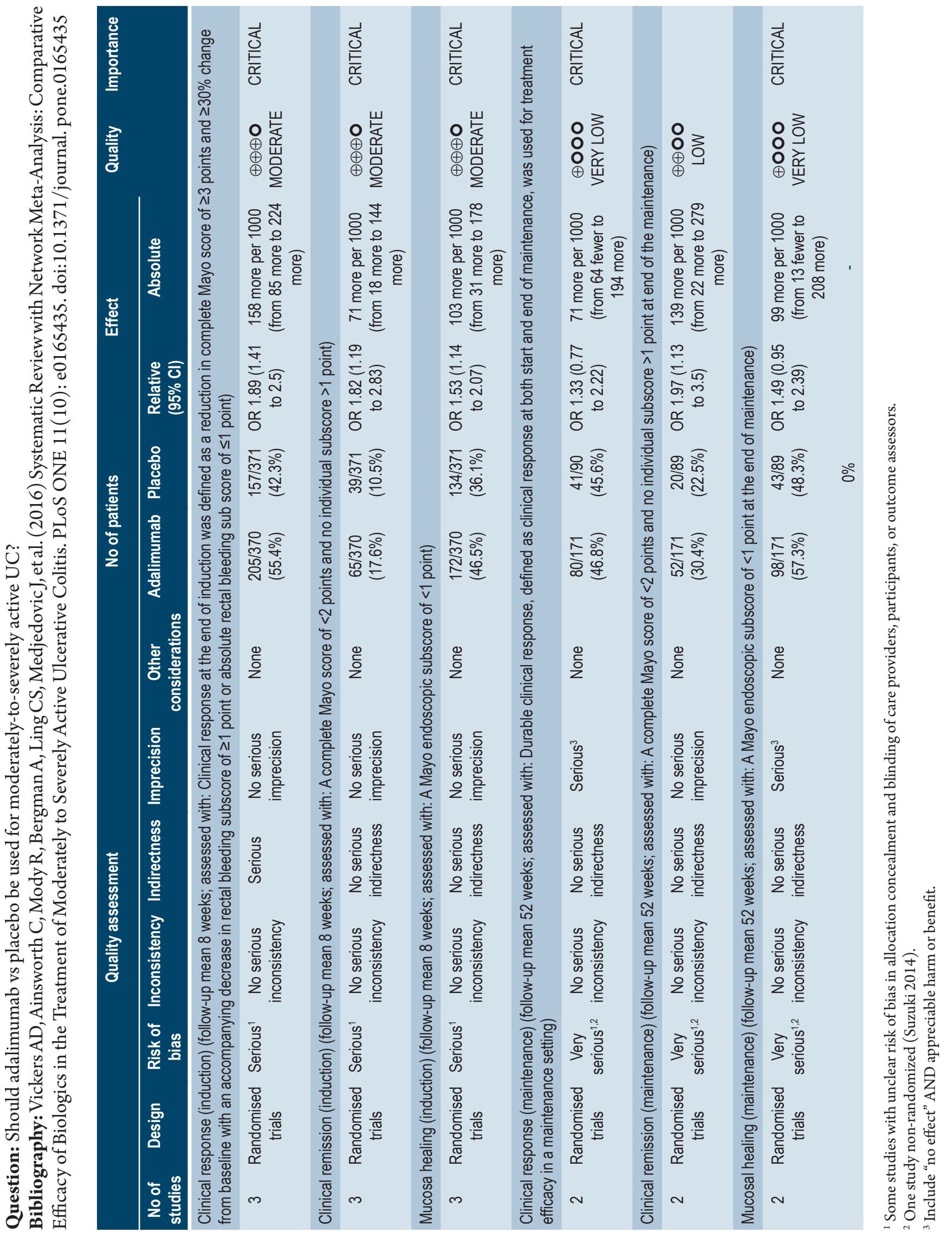




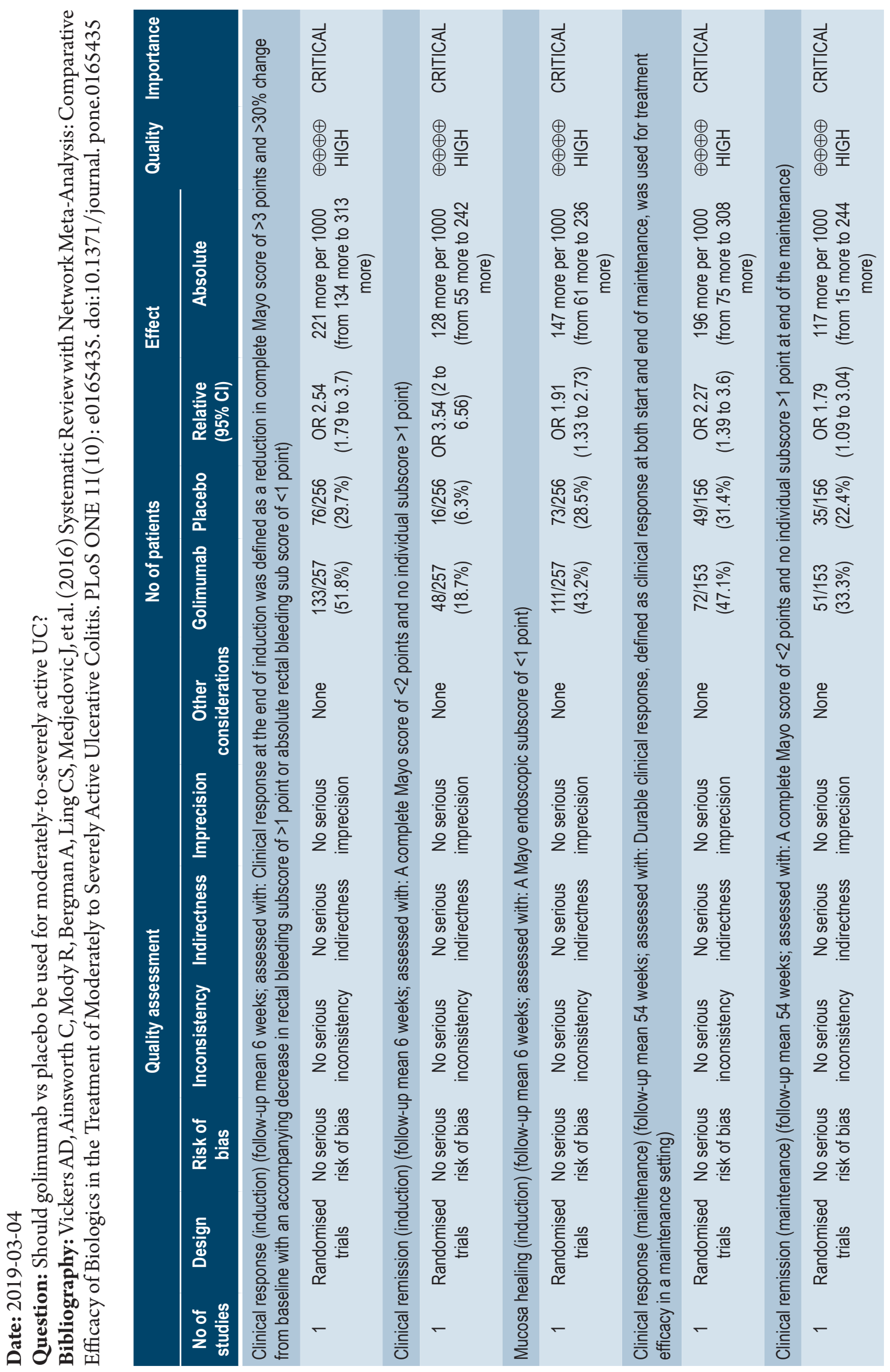




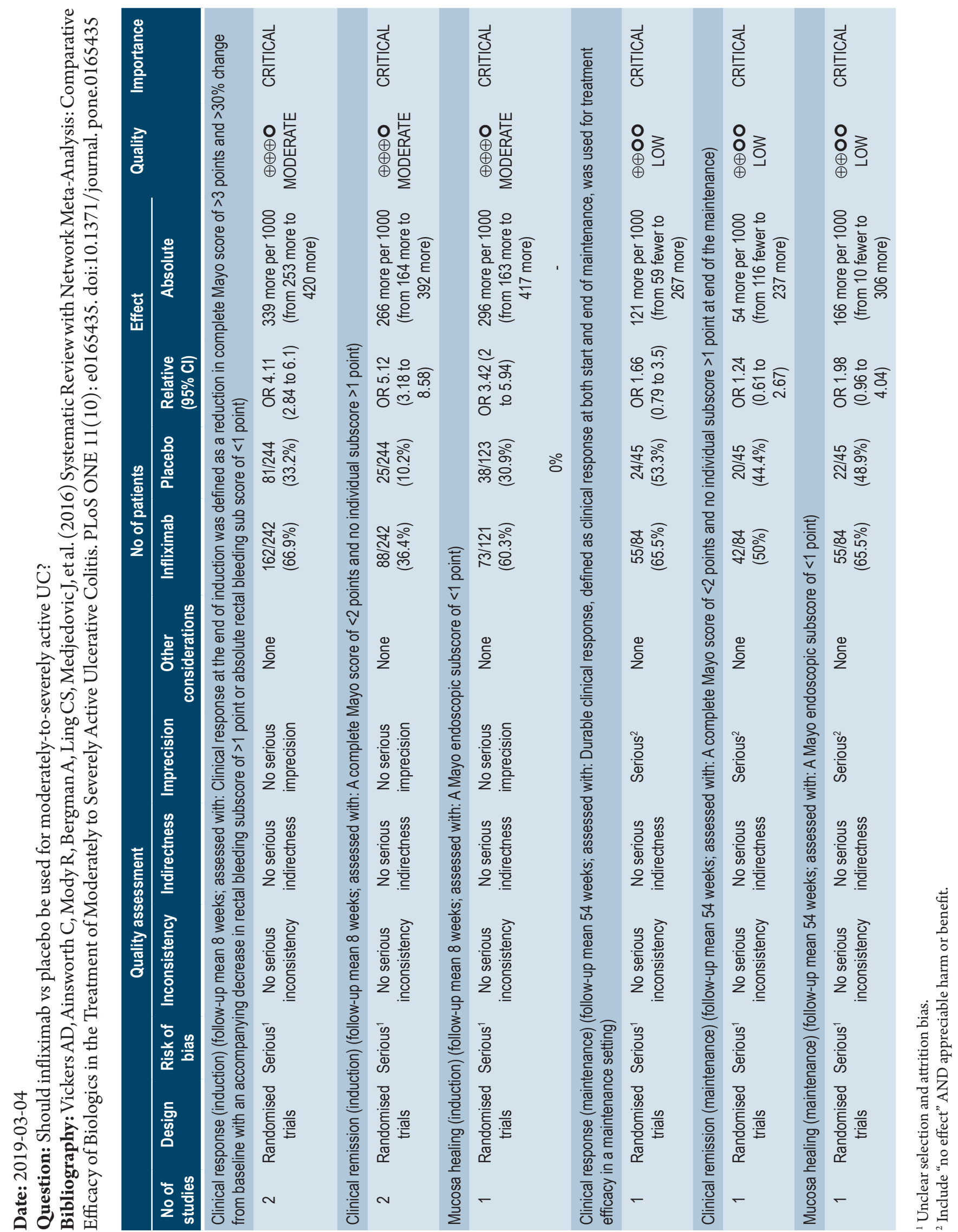




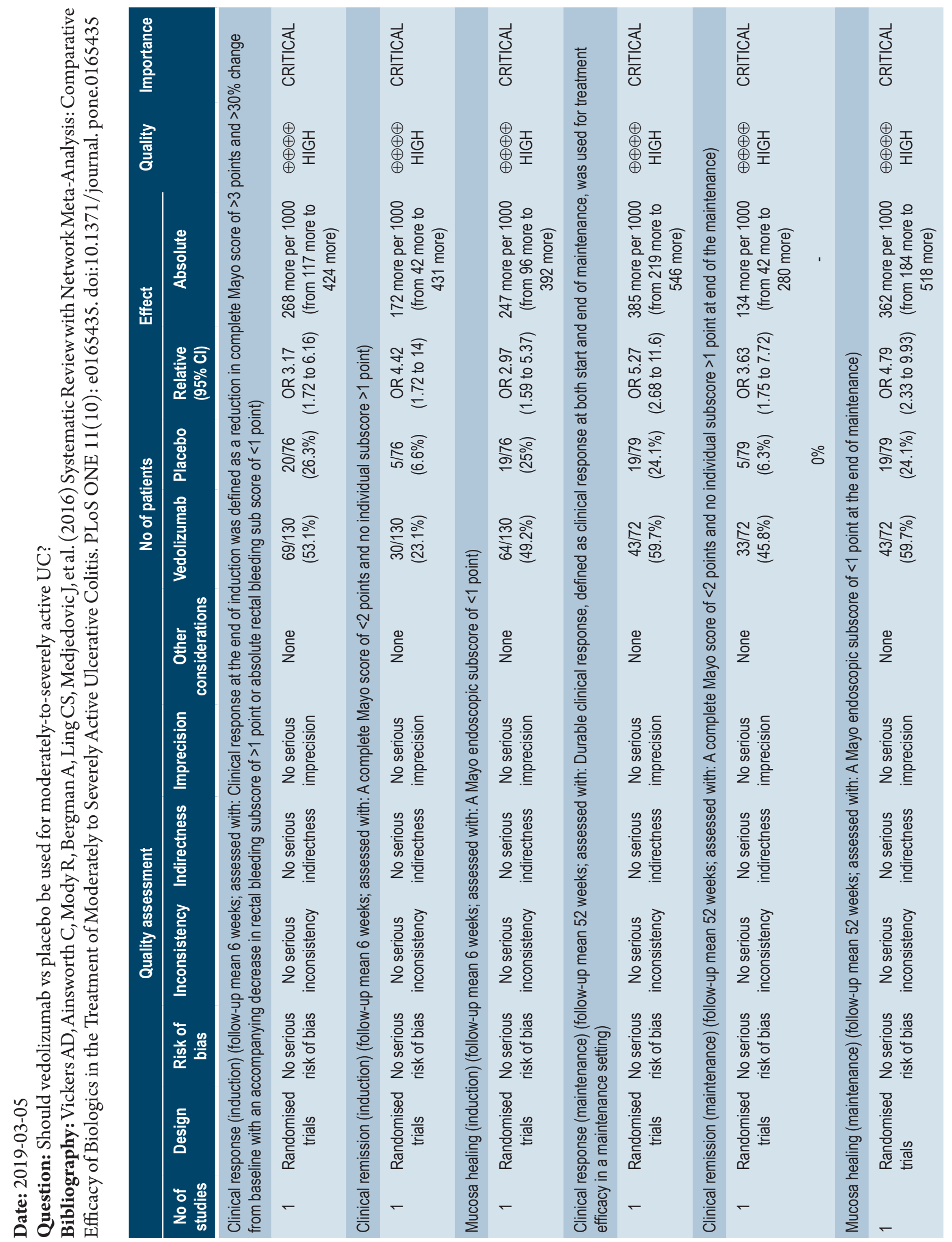




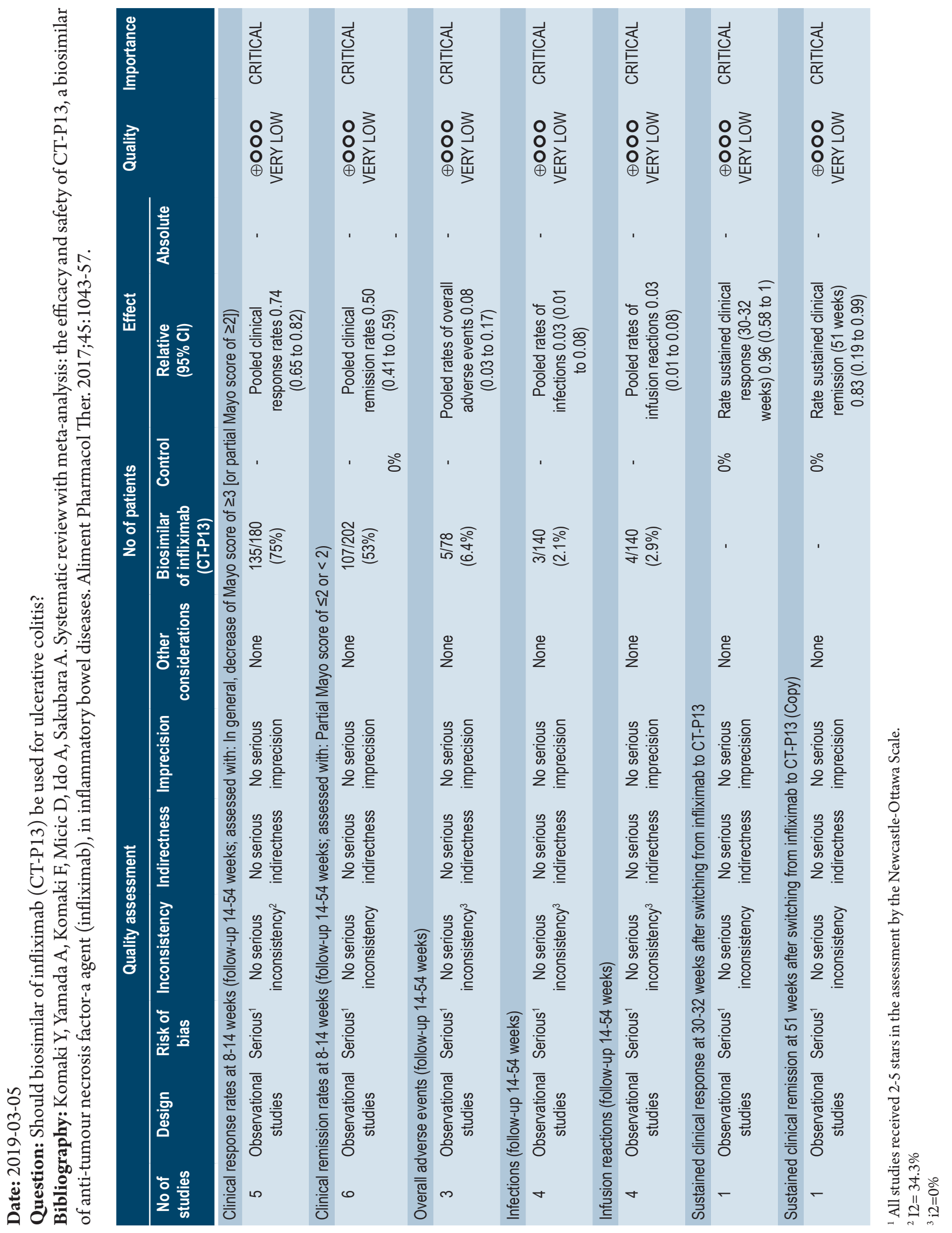




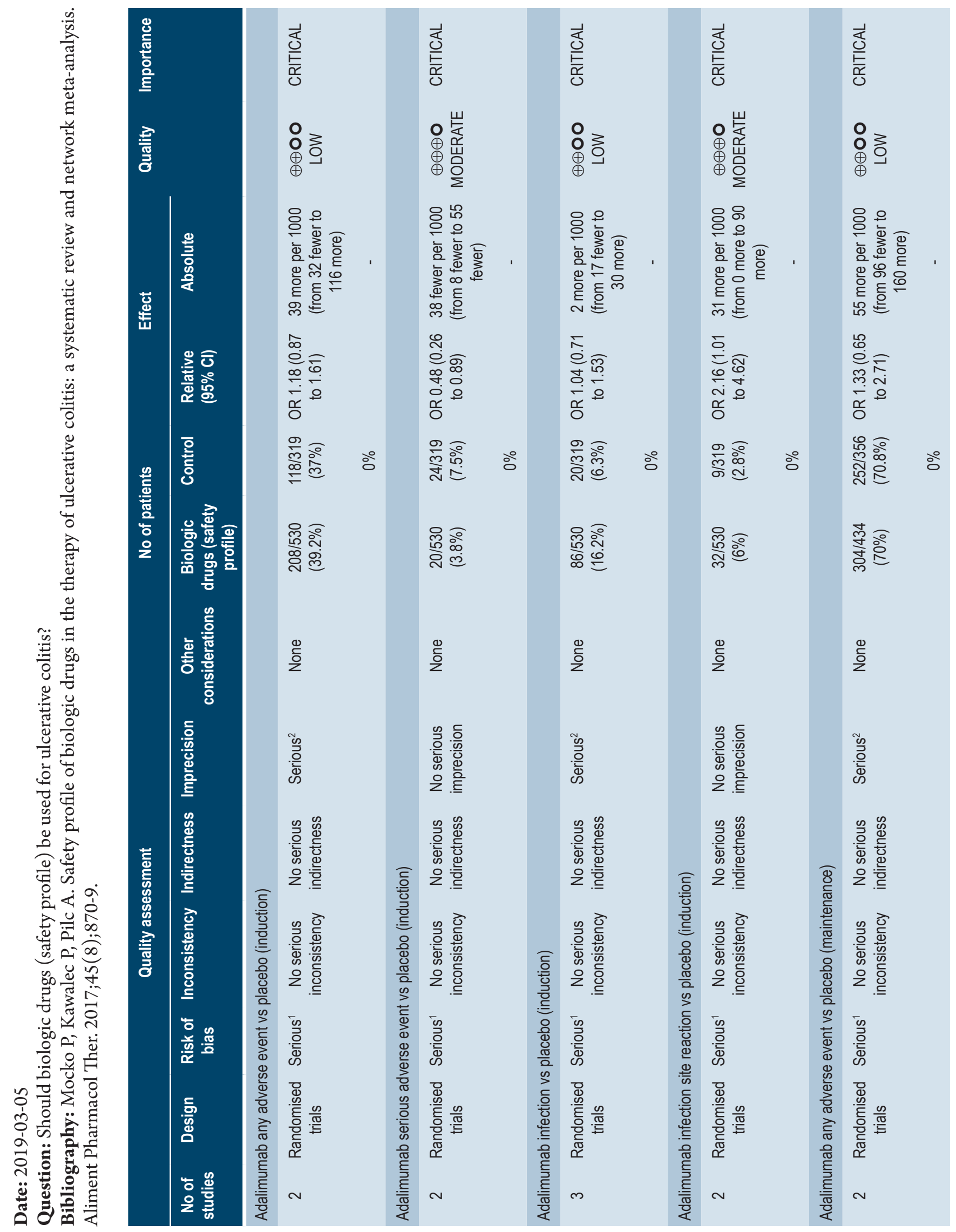




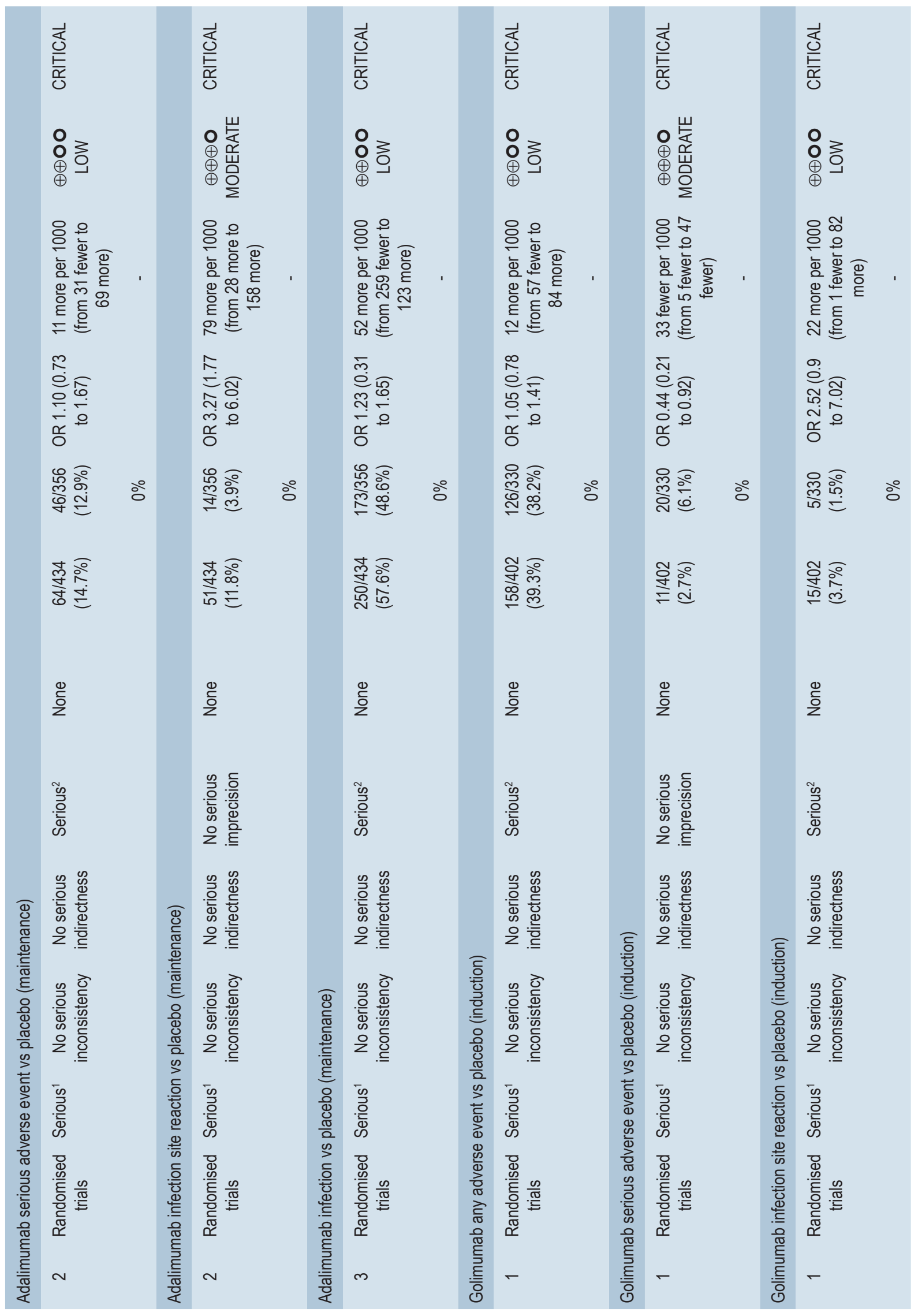




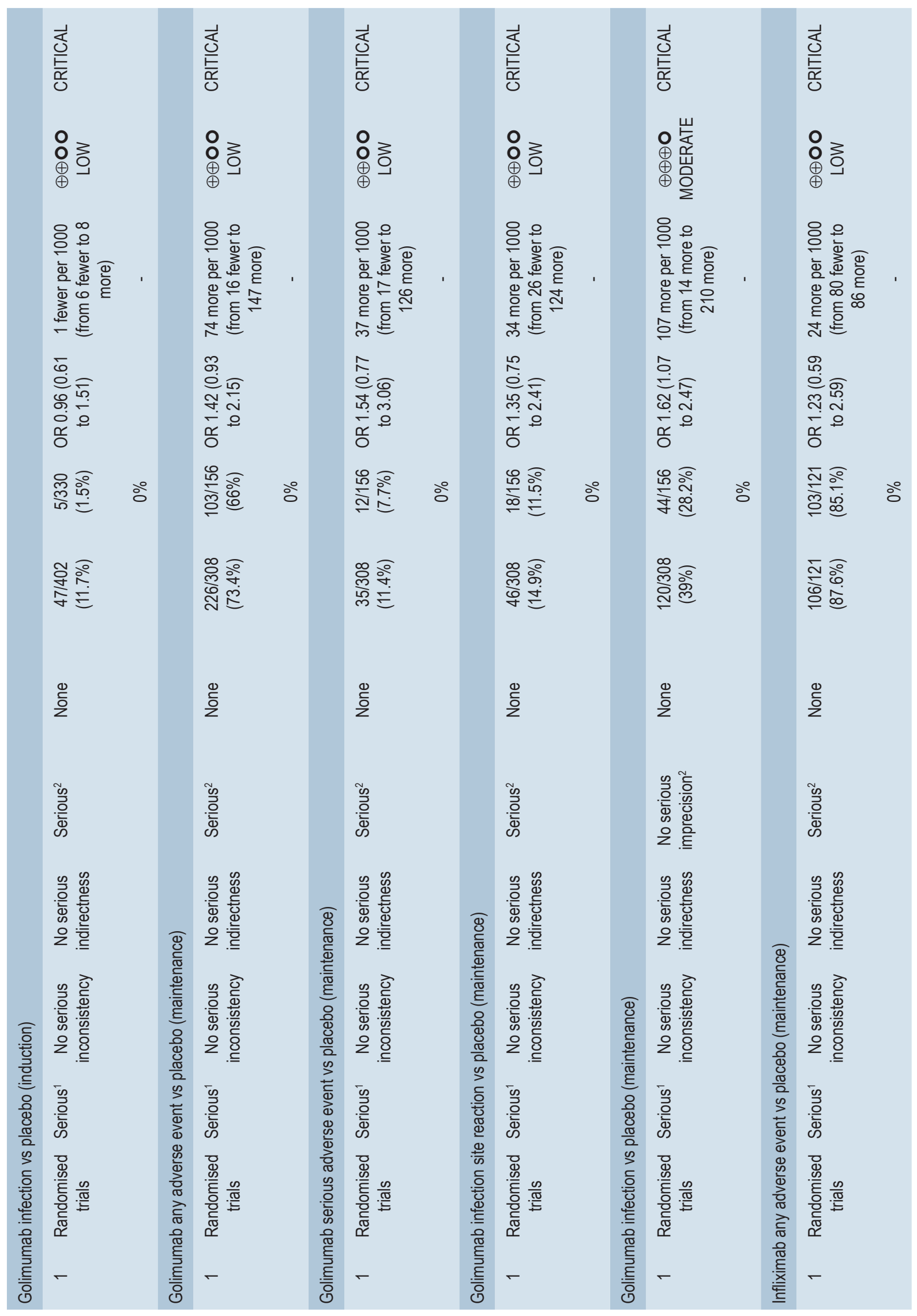




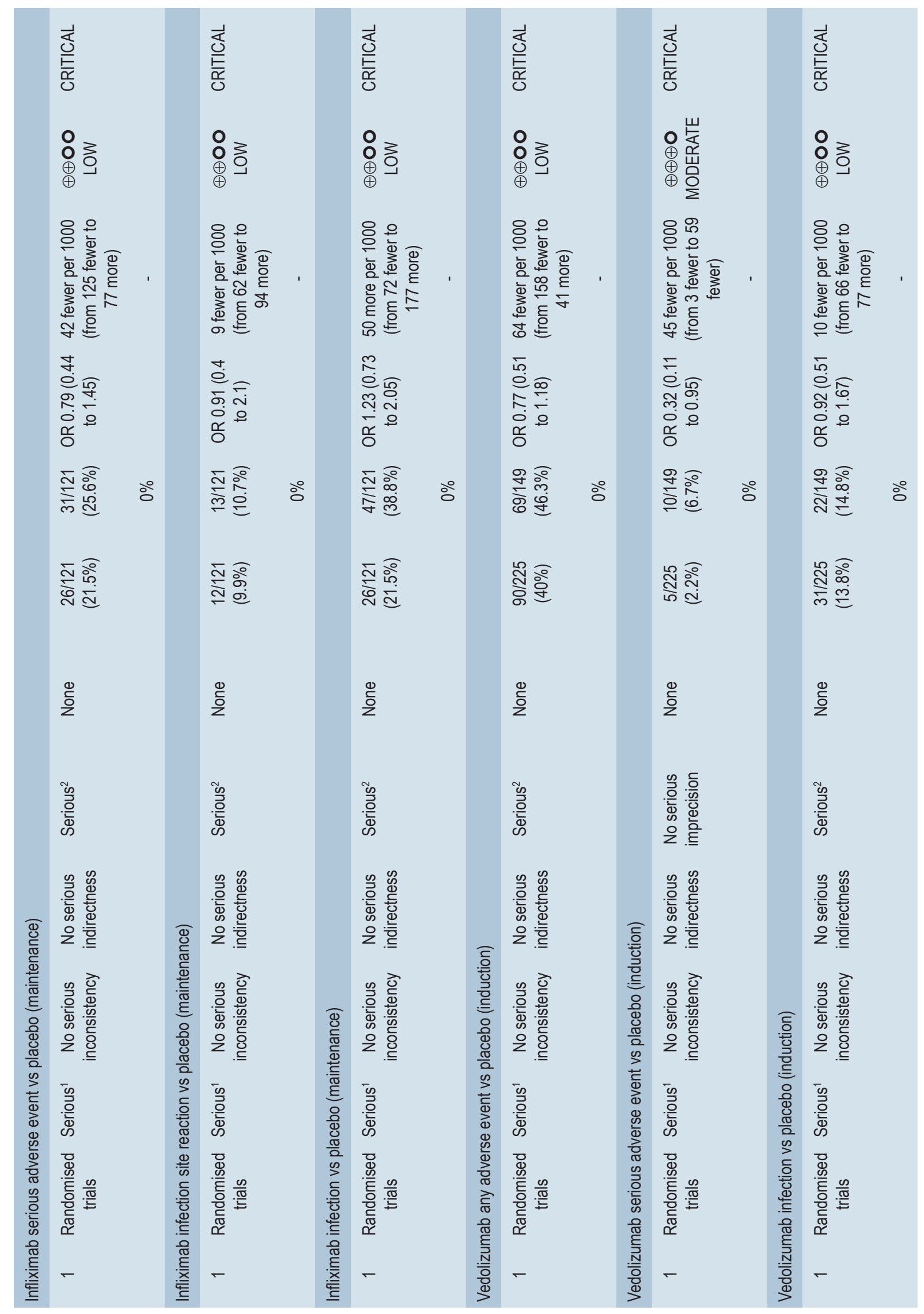




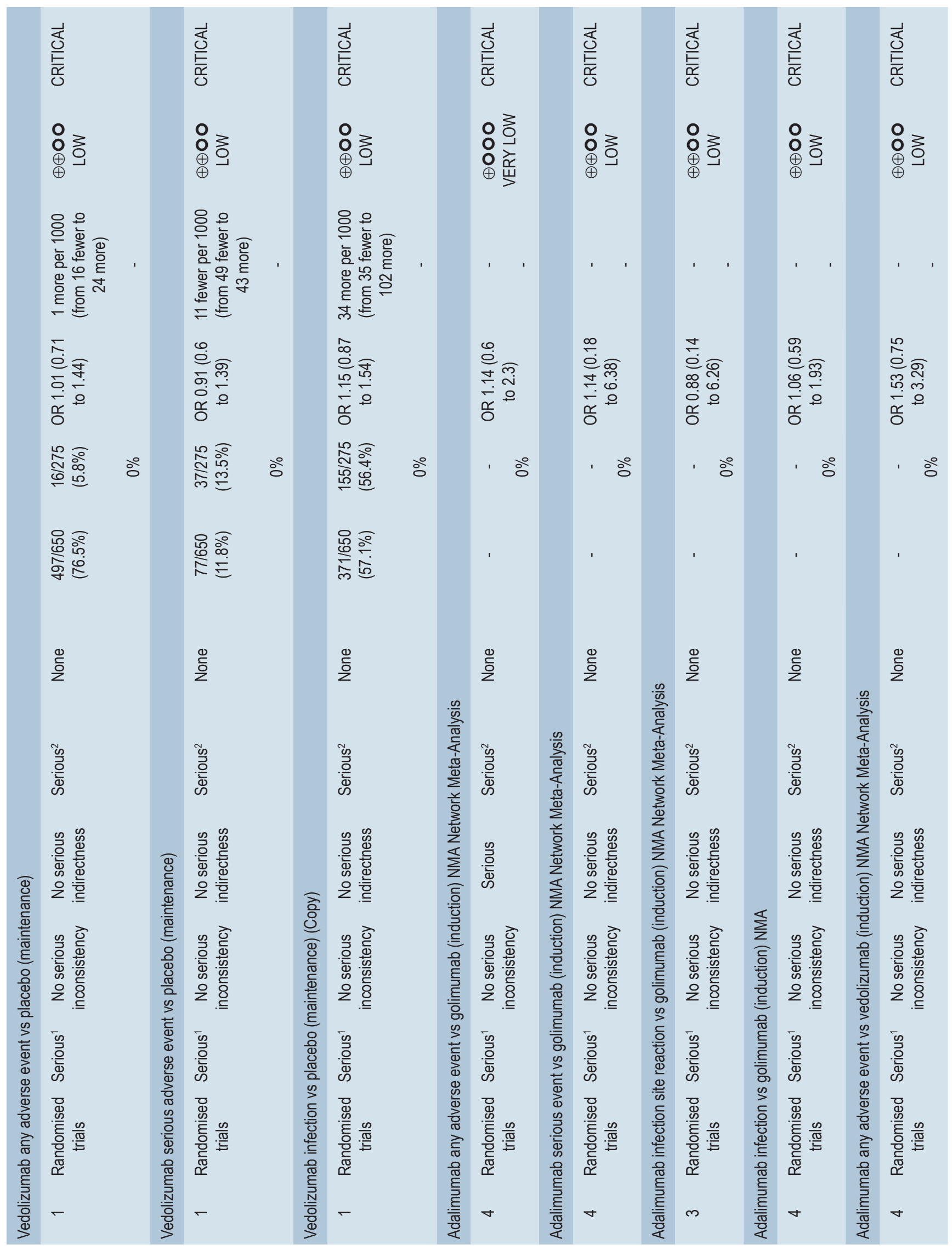




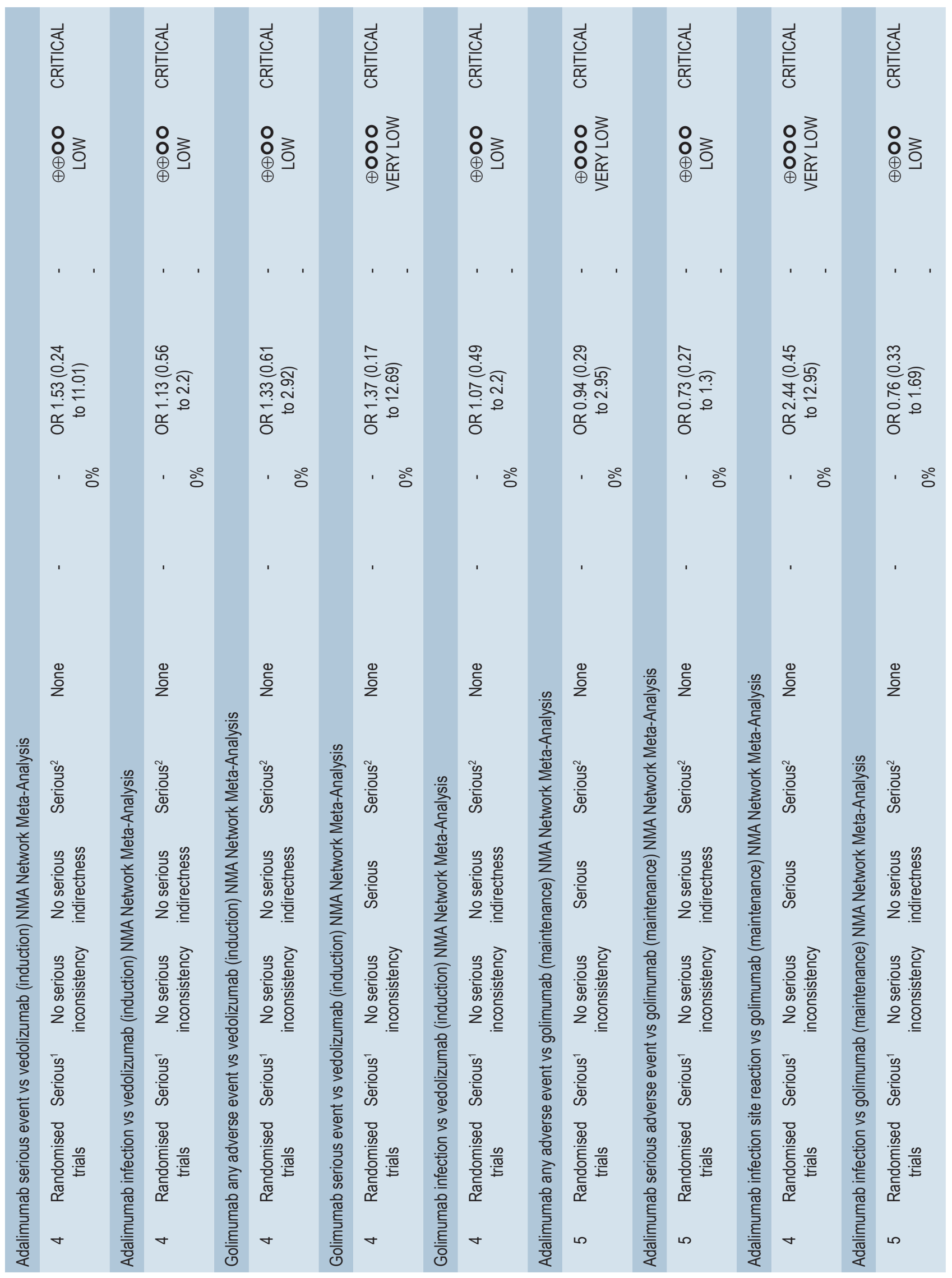




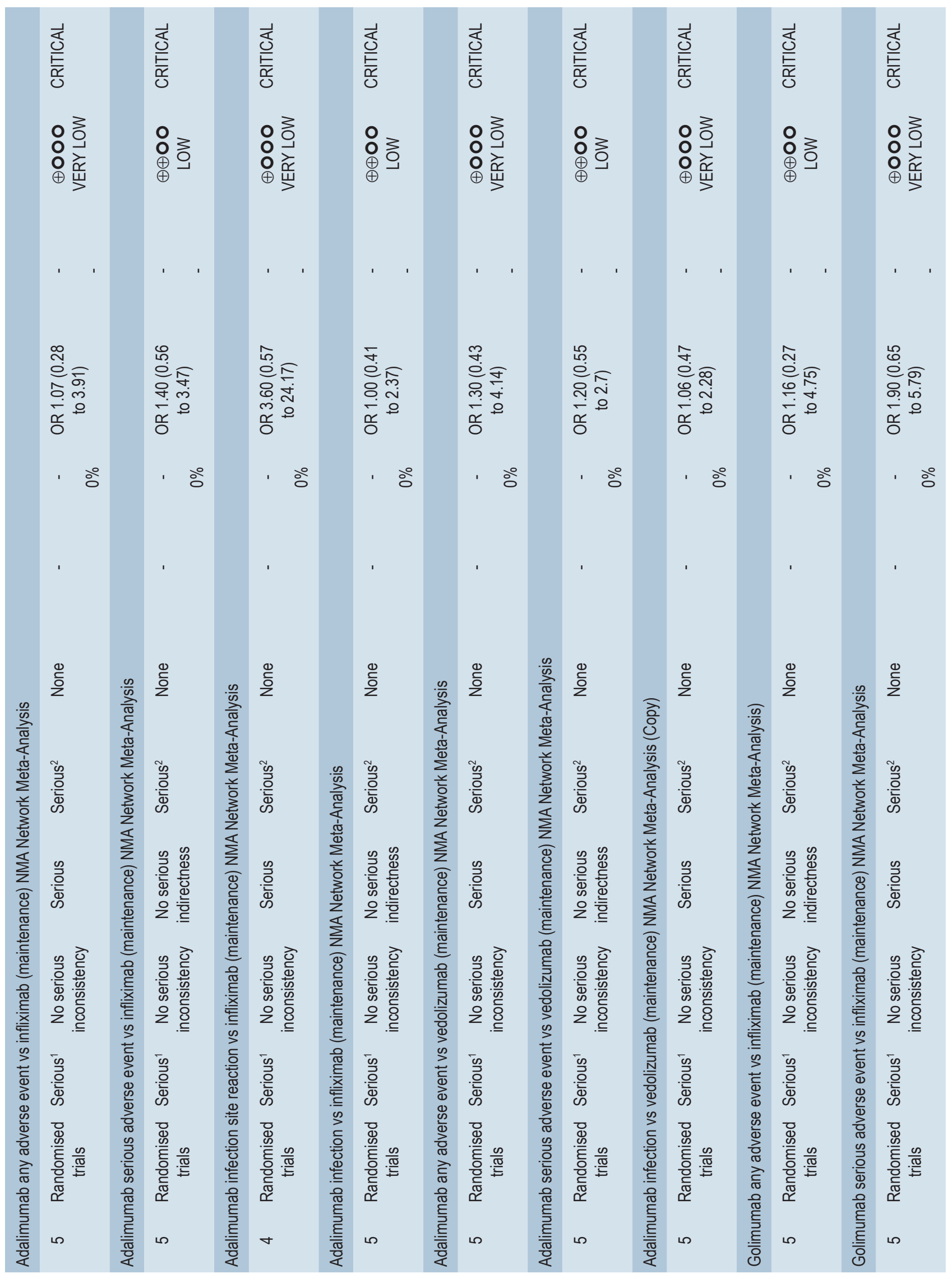




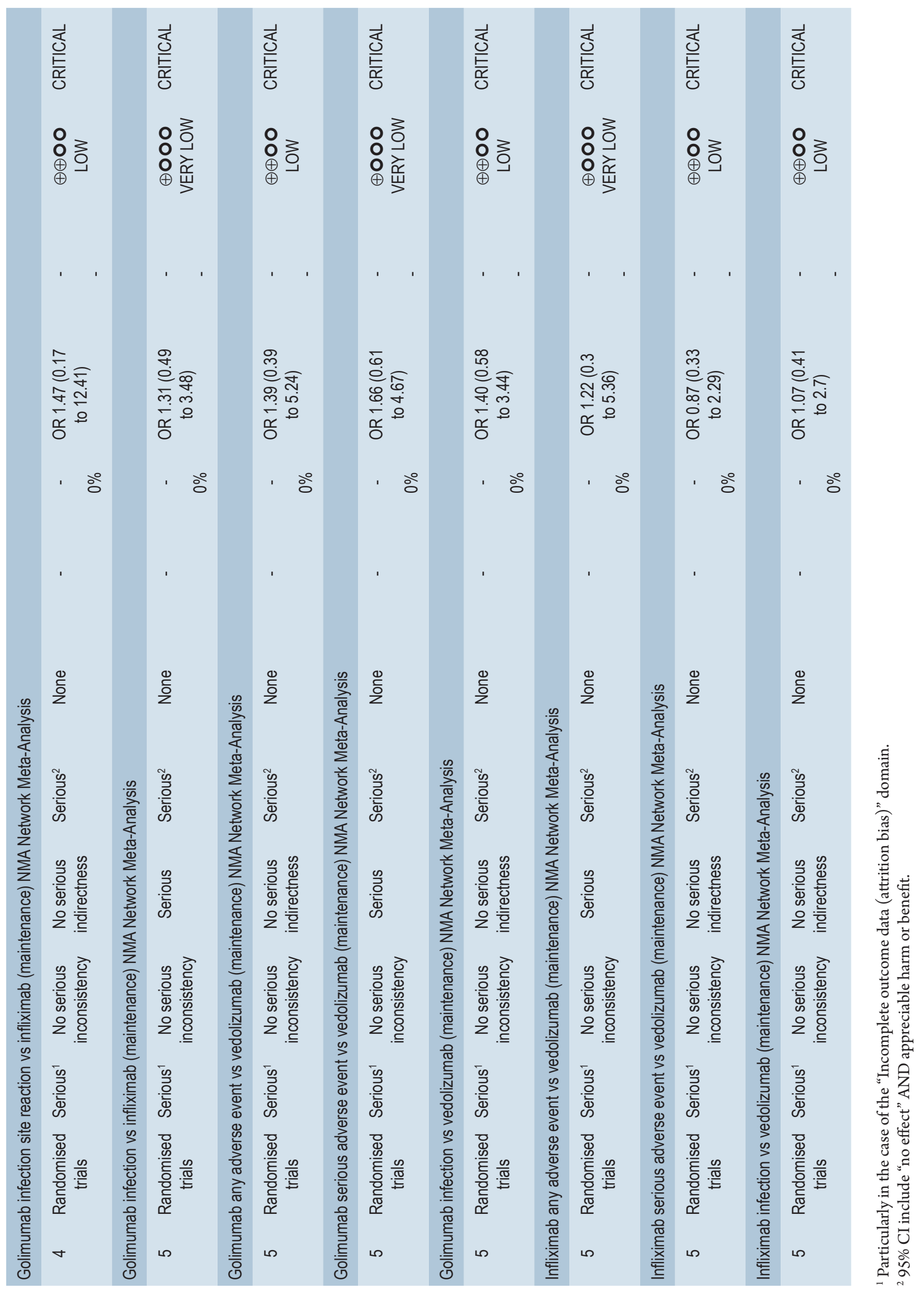




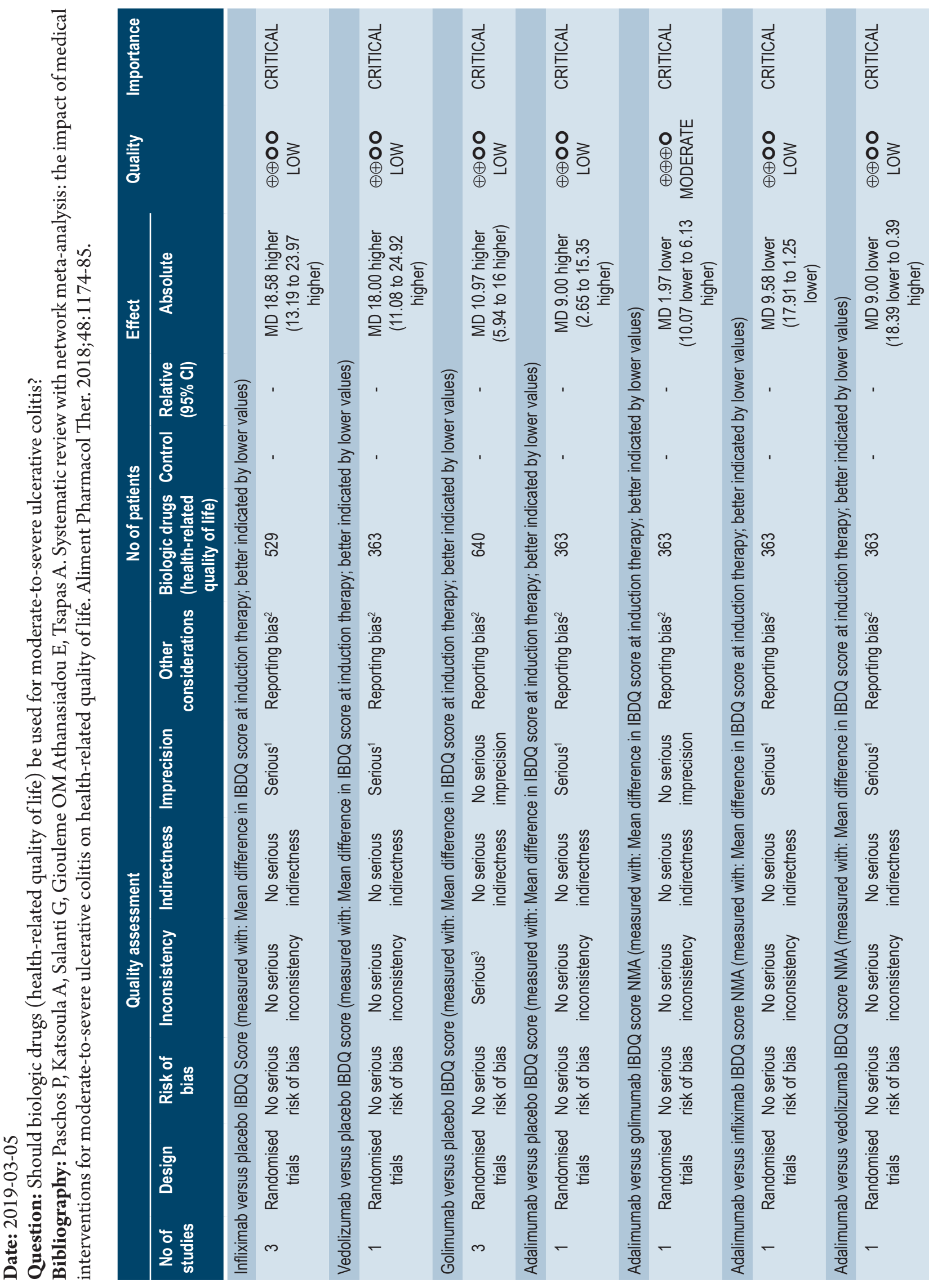




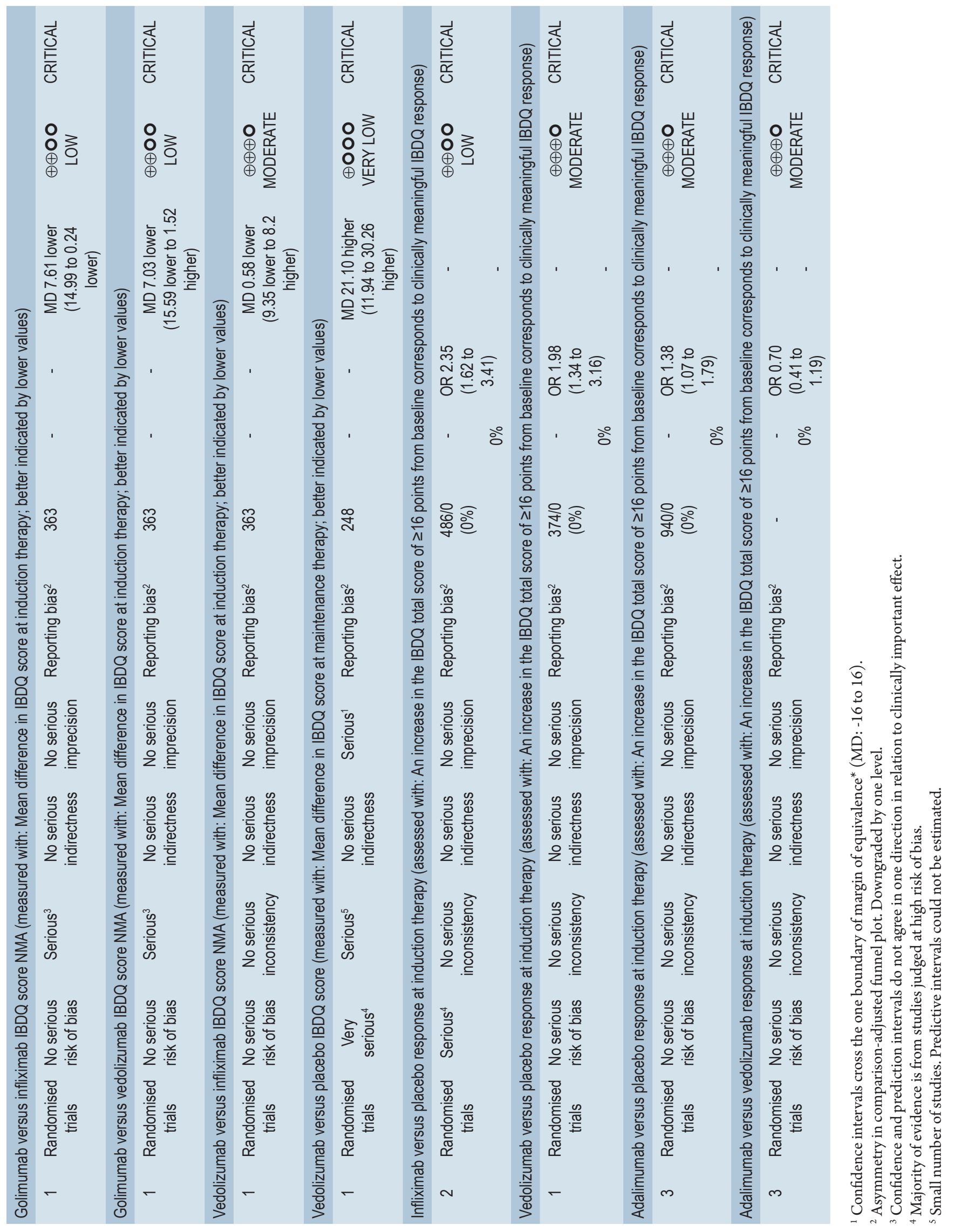



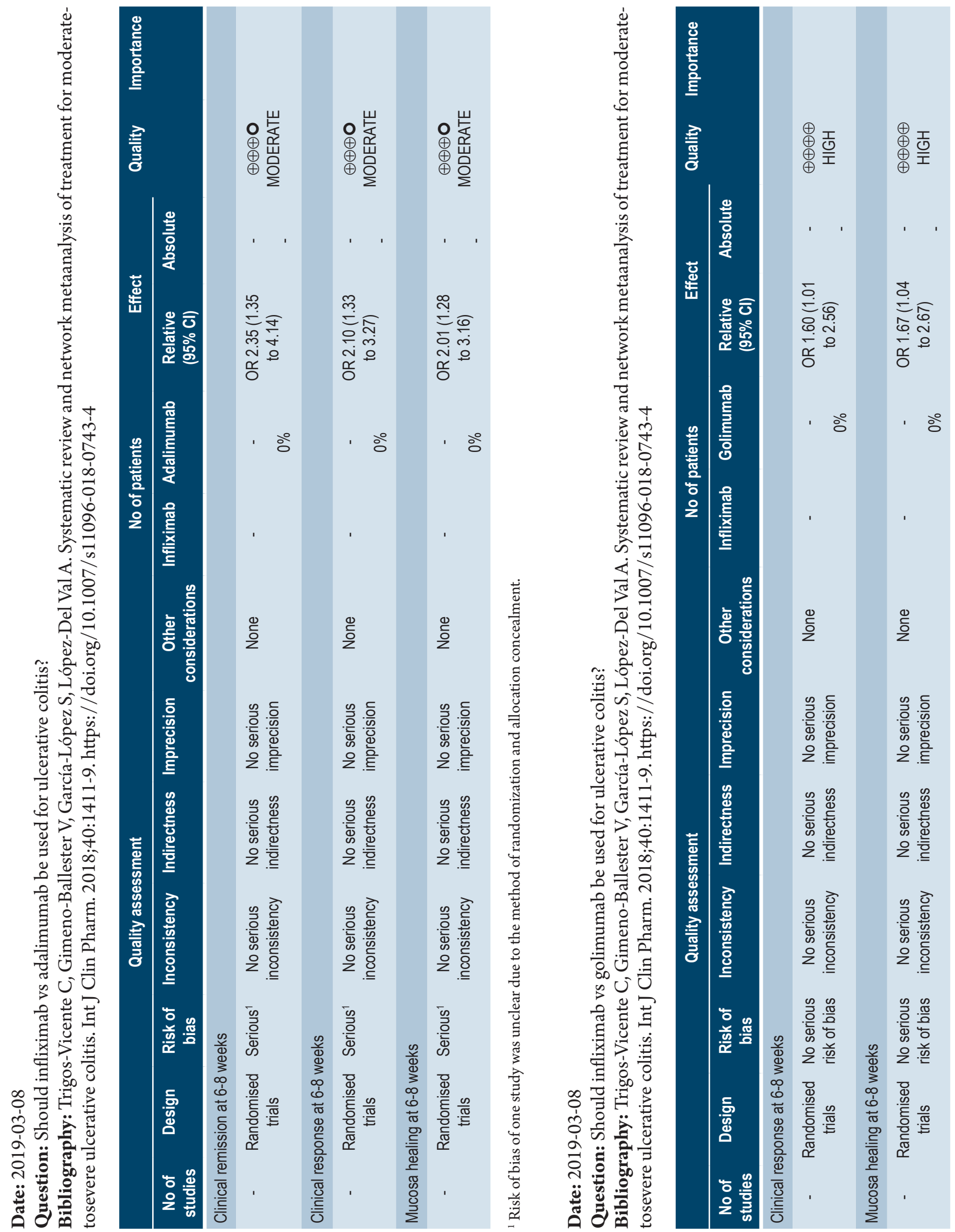
1. Ungaro R, Mehandru S, Allen PB, Peyrin L, Colombel JF. Ulcerative colitis. Lancet. 2017;389(10080):1756-1770. https://doi.org/10.1016/S0140-6736(16)32126-2

2. Magro F, Gionchetti P, Eliakim R, Ardizzone S, Armuzzi A, Barreriro M, et al. Third European Evidence-based Consensus on Diagnosis and Management of Ulcerative Colitis. Part 1: Definitions, Diagnosis, Extra-intestinal Manifestations, Pregnancy, Cancer Surveillance, Surgery, and Ileo-anal Pouch Disorders. J Crohns Colitis. 2017;11(6):649-70. https://doi.org/10.1093/ecco-jcc/ jjx008

3. Kaplan GG, Ng SC. Understanding and preventing the global increase of inflammatory bowel disease. Gastroenterology. 2017;152(2):313-21. https://doi. org/10.1053/j.gastro.2016.10.020

4. Loftus Jr EV, Sandborn WJ. Epidemiology of inflammatory bowel disease. Gastroenterol Clin N Am. 2002;31(1):1-20. https://doi.org/10.1016/S0889-8553(01)00002-4

5. Ng SC, Shi HY, Hamidi N, Underwood F, Tang W, Benchimol E, et al. Worldwide incidence and prevalence of inflammatory bowel disease in the 21 st century: a systematic review of population-based studies. Lancet. 2017;390(10114):2769-78. https://doi.org/10.1016/ S0140-6736(17)32448-0

6. Juliao-Baños F, Damas OM, Arrubla M, Calixto O, Camargo J, Cruz L, et al. The Prevalence of Inflammatory Bowel Disease in Colombia is Increasing: Report on the National Prevalence of IBD and Description of IBD Phenotype. Gastroenterology. 2019;156(6):S-405. https://doi.org/10.1016/S0016-5085(19)37865-5

7. Ordás I, Eckmann L, Talamini M, Baumgart D, Sandborn WJ. Ulcerative colitis. Lancet. 2012;380(9853):1606-19. https://doi.org/10.1016/S0140-6736(12)60150-0

8. Beaugerie L, Massot N, Carbonnel F, Cattan S, Gendre JP, Cosnes J. Impact of cessation of smoking on the course of ulcerative colitis. Am J Gastroenterol. 2001;96(7):2113-16. https://doi.org/10.1111/j.1572-0241.2001.03944.x

9. Koutroubakis IE, Vlachonikolis IG. Appendectomy and the development of ulcerative colitis: Results of a metaanalysis of published case-control studies. Am J Gastroenterol. 2000;95(1):171-6. https://doi.org/10.1111/j.15720241.2000.01680.x

10. Sonnenberg A, Genta RM. Low prevalence of Helicobacter pylori infection among patients with inflammatory bowel disease. Aliment Pharmacol Ther. 2012;35:469-76. https:// doi.org/10.1111/j.1365-2036.2011.04969.x

11. Lönnfors S, Vermeire S, Avenado L. IBD and health-related quality of life -- Discovering the true impact. J Crohn Colitis. 2014;8(10):1281-6. https://doi.org/10.1016/j. crohns.2014.03.005

12. Juliao F, Ruiz M, Flórez JF, Donado J, Marín J, Monsalve $\mathrm{C}$, et al. Fenotipo e historia natural de la enfermedad inflamatoria intestinal en un centro de referencia en MedellínColombia. Rev Col Gastro. 2010;23(3):240-51.
13. Maaser C, Sturm A, Vavricka SR, Kucharzik T, Fiorino G, Annese V, et al. ECCO-ESGAR Guideline for Diagnostic Assessment in IBD Part 1: Initial diagnosis, monitoring of known IBD, detection of complications. J Crohns Colitis. 2019;13(2):144-64. https://doi.org/10.1093/ecco-jcc/jjy113

14. Silverberg MS, Satsangi J, Ahmad T, Arnott ID, Bernstein $\mathrm{CN}$, Brant SR, et al. Toward an integrated clinical, molecular and serological classification of inflammatory bowel disease: report of a working party of the 2005 Montreal World Congress of Gastroenterology. Can J Gastroenterol. 2005;19(Suppl A):5-36. https://doi. org/10.1155/2005/269076

15. Truelove SC, Witts LJ. Cortisone in ulcerative colitis: final report on a therapeutic trial. Br Med J. 1955;2:1041-8. https://doi.org/10.1136/bmj.2.4947.1041

16. Rubin DT, Ananthakrishnan AN, Siegel CA, Sauer BG, Long MD. ACG Clinical Guideline: Ulcerative Colitis in Adults. Am J Gastroenterol. 2019;114(3):384-413. https://doi.org/10.14309/ajg.0000000000000152

17. Rioux K. What is the prognosis of ulcerative colitis? Inflamm Bowel disease. 2008; 14(Suppl 2):S52-3. https:// doi.org/10.1002/ibd.20574

18. Roda G, Narula N, Pinotti R, Skamnelos A, Katsanos K, Ungaro R, et al. Systematic review with meta-analysis: proximal disease extension in limited ulcerative colitis. Aliment Pharmacol Ther. 2017;45:1481-92. https://doi. org/10.1111/apt.14063

19. Frolkis AD, Dykeman J, Negrón ME, Ghosh S, Wiebe S, Kaplan G. Risk of Surgery for Inflammatory Bowel Diseases Has Decreased Over Time: A Systematic Review and Metaanalysis of Population-Based Studies. Gastroenterology. 2013;145(5):996-1006. https://doi.org/10.1053/j.gastro.2013.07.041

20. Singh S, Feuerstein JD, Binion DG, Tremaine WJ. AGA Technical Review on the Management of Mildto-Moderate Ulcerative Colitis. Gastroenterology. 2019;156(3):769-808. https://doi.org/10.1053/j.gastro.2018.12.008

21. Singh S, Allegretti JR, Siddique SM, Terdiman JP. AGA Technical Review on the Management of Moderate to Severe Ulcerative Colitis. Gastroenterology. 2020;158(5):1465-96. https://doi.org/10.1053/j.gastro.2020.01.007

22. Directriz para el fortalecimiento de los programas nacionales de guías informadas por la evidencia. Una herramienta para la adaptación e implementación de guías en las américas. Washington, D.C.: Organización Panamericana de la Salud; 2018. Disponible en: http://iris.paho.org/xmlui/ handle/123456789/49145

23. Guyatt G, Oxman AD, Akl EA, Kunz R, Vist G, Brozek $\mathrm{J}$, et al. GRADE guidelines: 1. Introduction-GRADE evidence profiles and summary of findings tables. J Clin Epidemiol. 2011;64(4):383-94. https://doi.org/10.1016/j. jclinepi.2010.04.026 
24. Shea BJ, Reeves BC, Wells G, Thuku M, Hamel C, Moran J, et al. AMSTAR 2: a critical appraisal tool for systematic reviews that include randomised or non-randomised studies of healthcare interventions, or both. BMJ. 2017;358:j4008. https://doi.org/10.1136/bmj.j4008

25. Higgins JPT, Deeks JJ, Davenport C, Clarke MJ (editores). Cochrane Handbook for Systematic Reviews of Interventions. Version 5.2.0 (actualizada en febrero de 2017), Cochrane, 2017.

26. Bewtra M, Johnsson R. Assessing Patient Preferences for Treatment Options and Process of Care in Inflammatory Bowel Disease: A Critical Review of Quantitative Data. Patient. 2013;6(4):241-55. https://doi.org/10.1007/ s40271-013-0031-2

27. Shah SC, Colombel JF, Sands BE, Narula N. Mucosal Healing Is Associated with Improved Long-term Outcomes of Patients with Ulcerative Colitis: A Systematic Review and Meta-analysis. Clin Gastroenterol Hepatol. 2016;14(9):1245-55. https://doi.org/10.1016/j. cgh.2016.01.015

28. National Clinical Guideline Centre (UK). Ulcerative Colitis: Management in Adults, Children and Young People [Internet]. Londres: Royal College of Physicians; 2013. Disponible en: http://www.ncbi.nlm.nih.gov/books/ NBK247597/PubMed

29. Marshall JK, Thabane M, Steinhart AH, Newman JR, Anand A, Irvine EJ. Rectal 5-aminosalicylic acid for induction of remission in ulcerative colitis. Cochrane Database Syst Rev. 2010;(1):CD004115. https://doi. org/10.1002/14651858

30. Ford AC, Khan KJ, Achkar JP, Moayyedi P. Efficacy of Oral vs. Topical, or Combined Oral and Topical 5-Aminosalicylates, in Ulcerative Colitis: Systematic Review and Meta-Analysis. Am J Gastroenterol. 2012;107(2):167-76. https://doi.org/10.1038/ ajg.2011.410

31. Wang Y, Parker CE, Bhanji T, Feagan BG, MacDonald JK. Oral 5-aminosalicylic acid for induction of remission in ulcerative colitis. Cochrane Database Syst Rev. 2016;4:CD000543. https://doi.org/10.1002/14651858. CD000543.pub4

32. Ford A, Bernstein C, Khan K, Abreu M, Marshall J, Talley $\mathrm{N}$, et al. Glucocorticosteroid Therapy in Inflammatory Bowel Disease: Systematic Review and Meta-Analysis. Am J Gastroenterol. 2011;106(4):590-9; quiz 600. https://doi. org/10.1038/ajg.2011.70

33. Sherlock ME, MacDonald JK, Griffiths AM, Steinhart $\mathrm{AH}$, Seow $\mathrm{CH}$. Oral budesonide for induction of remission in ulcerative colitis. Cochrane Database Syst Rev. 2015; (10):CD007698. https://doi. org/10.1002/14651858.CD007698.pub3

34. Timmer A, Patton PH, Chande N, McDonald JW, MacDonald JK. Azathioprine and 6-mercaptopurine for maintenance of remission in ulcerative colitis. Cochrane Database Syst Rev. 2016;(5):CD000478. https://doi. org/10.1002/14651858.CD000478.pub4
35. Astó E, Méndez I, Audivert S, Farran-Codina A, Espadaler J. The Efficacy of Probiotics, Prebiotic Inulin-Type Fructans, and Synbiotics in Human Ulcerative Colitis: A Systematic Review and Meta-Analysis. Nutrients. 2019;11(2).pii:E293. https://doi.org/10.3390/ nu11020293

36. Bonovas S, Lytras T, Nikolopoulos G, Peyrin-Biroulet L, Danese S. Systematic review with network meta-analysis: comparative assessment of tofacitinib and biological therapies for moderate-to-severe ulcerative colitis. Aliment Pharmacol Ther. 2018;47(4):454-65. https://doi. org/10.1111/apt.14449

37. Paschos P, Katsoula A, Giouleme O, Sarigianni M, Liakos A, Athanasiadou E, et al. Tofacitinib for induction of remission in ulcerative colitis: systematic review and metaanalysis. Ann Gastroenterol. 2018;31(5):572-82. https:// doi.org/10.20524/aog.2018.0276

38. Grammatikopoulou MG, Gkiouras K, Theodoridis X, Asteriou E, Forbes A, Bogdanos DP. Oral Adjuvant Curcumin Therapy for Attaining Clinical Remission in Ulcerative Colitis: A Systematic Review and Meta-Analysis of Randomized Controlled Trials. Nutrients. 2018;10(11). pii: E1737. https://doi.org/10.3390/nu10111737

39. Kafil TS, Nguyen TM, MacDonald JK, Chande N. Cannabis for the treatment of ulcerative colitis. Cochrane Database Syst Rev. 2018;(11):CD012954. https://doi. org/10.1002/14651858.CD012954

40. Narula N, Kassam Z, Yuan Y, Colombel JF, Ponsioen C, Reinisch W, et al. Systematic Review and Meta-analysis: Fecal Microbiota Transplantation for Treatment of Active Ulcerative Colitis. Inflamm Bowel Dis. 2017;23(10):17029. https://doi.org/10.1097/MIB.0000000000001228

41. Vickers AD, Ainsworth C, Mody R, Bergman A, Ling C, Medjedovic J, et al. Systematic Review with Network Meta-Analysis: Comparative Efficacy of Biologics in the Treatment of Moderately to Severely Active Ulcerative Colitis. PLoS ONE. 2016;11(10):e0165435. https://doi. org/10.1371/journal.pone.0165435

42. Trigos-Vicente C, Gimeno-Ballester V, García-López S, López-Del Val A. Systematic review and network metaanalysis of treatment for moderatetosevere ulcerative colitis. Int J Clin Pharm. 2018;40:1411-9. https://doi. org/10.1007/s11096-018-0743-4

43. Sands BE, Peyrin-Biroulet L, Loftus EV Jr, Danese S, Colombel JF, Törüneret $M$, et al. Vedolizumab versus Adalimumab for Moderate-to-Severe Ulcerative Colitis. N Engl J Med. 2019;381(13):1215-26. https://doi. org/10.1056/NEJMoa1905725

44. Komaki Y, Yamada A, Komaki F, Micic D, Ido A, Sakubara A. Systematic review with meta-analysis: the efficacy and safety of CT-P13, a biosimilar of anti-tumor necrosis factor-a agent (infliximab), in inflammatory bowel diseases. Aliment Pharmacol Ther. 2017;45:1043-57. https://doi. org/10.1111/apt.13990

45. Sands BE, Sandborn WJ, Panaccione R, O’Brien Ch, Zhang H, Johanns J, et al. Ustekinumab as Induction and 
Maintenance Therapy for Ulcerative Colitis. N Engl J

Med. 2019;381(13):1201-14. https://doi.org/10.1056/

NEJMoa 1900750

46. Mocko P, Kawalec P, Pilc A. Safety profile of biologic drugs in the therapy of ulcerative colitis: a systematic review and network meta-analysis. Aliment Pharmacol Ther. 2017;45(8):870-9. https://doi.org/10.1002/phar.1785

47. Paschos P, Katsoula A, Salanti G, Giouleme OM Athanasiadou E, Tsapas A. Systematic review with network meta-analysis: the impact of medical interventions for moderate-to-severe ulcerative colitis on health-related quality of life. Aliment Pharmacol Ther. 2018;48:1174-85. https://doi.org/10.1111/apt.15005

48. Singh S, Murad MH, Fumery M, Dulai PS, Sandborn WJ. First- and Second-Line Pharmacotherapies for Patients with Moderate to Severely Active Ulcerative Colitis: An Updated Network Meta-Analysis. Clin Gastroenterol Hepatol. 2020;18(10):P2179-2191.E6. https://doi. org/10.1016/j.cgh.2020.01.008

49. Bye WA, Nguyen TM, Parker CE, Jairath V, East JE. Strategies for detecting colon cancer in patients with inflammatory bowel disease. Cochrane Database Syst Rev. 2017; (9):CD000279. https://doi.org/10.1002/14651858. CD000279.pub4

50. Bessissow T, Dulai PS, Restellini S, Landry T, Bisschops $\mathrm{R}$, Murad MH, et al. Comparison of Endoscopic Dysplasia Detection Techniques in Patients with Ulcerative Colitis: A Systematic Review and Network Meta-analysis. Inflamm Bowel Dis. 2018;24(12):2518-26. https://doi. org/10.1093/ibd/izy188 